NBSIR 82-2401

\title{
Heating Values of Natural Gas and Its Components
}

U.S. DEPARTMENT OF COMMERCE Nationa! Bureau of Standards

Center for Chemical Physics

Chemical Thermodynamics Division

Washington, DC 20234

May 1982

Technical Report

Issued August 1982

ored by

pe International des Importateurs

Gaz natural Liquifie (GIIGNAL)

.456

ú2-2401

1932 

U.S. DEPARTMENT OF COMMERCE

National Bureau of Standards

Center for Chemical Physics

Chemical Thermodynamics Division

Washington, DC 20234

May 1982

Technical Report

Issued August 1982

\section{Sponsored by}

Groupe International des Importateurs

de Gaz Natural Liquifie (GIIGNAL)

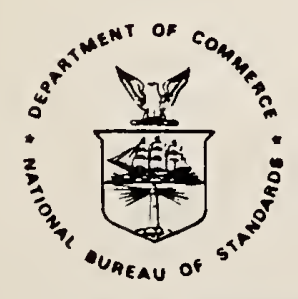

U.S. DEPARTMENT OF COMMERCE, Malcolm Baldrige, Secretary NATIONAL BUREAU OF STANDARDS, Ernest Ambler, Director 



\section{Preface}

The Office of Standard Reference Data of the Nationai Bureau of Standards is responsible for a broad-based program to provide reliable physical and chemical reference data to the U.S. technical comminity. Under this program a number of data evaluation centers both at NBS and at universities and other private institutions are supported and coordinated; these activities are collectively known as the National Standard Reference Data System (NSRDS). Important areas of the physical sciences are covered systematically by NSRDS data centers, and data bases with broad utility are prepared and disseminated. These centers can also take on specia? cumpilations of data addressing specific applications. The existence of an ongoing program permits the collection of data for these speciai compilations to be carried out in an efficient and timely manner.

This Report on the Heating Values of Natural Gas and Its Components was prepared with the assistance of the Chemical Thermodynamics Data Center of the National Bureau of Standards. We hope that it will provide a useful source of reference data and computational methods for all those concerned with the heating value of natural gas.

David R. Lide, Jr. Chief

Office of Standard Reference Data 
Dr. George Thompson Armstrong, the senior author, died on March 9, 1982. At that time an almost complete, well written draft was at hand and had been reviewed by several of his colleagues, including myself. It has been my privilege to help prepare the final version. The original organization and wording have been retained wherever possible. Several sections have been completed, based on indications in the text. New atomic masses and heat capacities have been selected and a discussion of the enthalpy of combustion of methane (in Appendix 7) has been written. All of these were influenced by notes and letters, but, at times, go beyond them. I hope that the spirit and quality of the criginal has been maintained.

There is one section missing: acknowledgements. Neither Mr. Jobe nor I can reconstruct a record of the many persons who were consulted, who advised or who sent in material. We thank all who have helped and hope that this report will both be useful to them and meet with their approval.

David Garvin

Chemical Thermodynamics Data Center 
Abstract

This document gives the basic data needed, recommended procedures and illustrative calculations for computing heating values of natural gas mixtures from the composition of the mixtures and the properties of the components at commonly used reference conditions for gas measurement. Much of the data is given in the form of tables, and sufficient information is given for calculating properties at conditions other than those for which tables are given. Symbols and terns used are defined, units of measurement are defined and conversion factors and physical constants are given.

The standard enthalpies of combustion and heat capacities of the pure hydrocarbon gases $C_{1}$ to $C_{6}$ are selected from prior initial evaluations of experimental measurements. The enthalpies of combustion of the ideal gases at the reference temperatures $273.15 \mathrm{~K}\left(0{ }^{\circ} \mathrm{C}\right), 288.15 \mathrm{~K}\left(15{ }^{\circ} \mathrm{C}\right)$, $288.71 \mathrm{~K}\left(60^{\circ} \mathrm{F}\right)$, and $298.15 \mathrm{~K}\left(25^{\circ} \mathrm{C}\right)$ on a molar basis, and a volumetric basis are given. Tables are for the dry gases, and information is given to calculate the enthalpy of combustion of the ideal water-saturated gas on a volumetric basis. The calculation of enthalpies or combustion of ideal gas mixtures on a molar, mass, or volumetric basis is described.

Second virial coefficients as functions of temperature for the pure substances and for binary interactions with methane as one component are presented as selected from recent compilations based on experimental measurements.

Tables are given for molar volumes, ethalpic effects $\left(H-H^{\circ}\right)$, and the heating values of the dry reai-gas hydrocarbons on a molar basis, a mass basis, and a volumetric basis at two reference conditions, $288.15 \mathrm{~K}$ 
$\left(15^{\circ} \mathrm{C}\right), 101325 \mathrm{~Pa}$; and $288.71\left(60^{\circ} \mathrm{F}\right), 101560 \mathrm{~Pa}(14.73 \mathrm{psia})$. The procedure used in calculating these tables is described and information is provided for making similar calculations for other reference conditions. An analysis of the uncertainties of the data is presented, together with procedures for calculating the propagation of errors and the effects of these errors on calculated heating values. Supporting data, sources of the data, and discussions of the relationships involved are presented in a series of appendixes.

KEYWORDS: Calorific value, enthalpy of combustion; fuel gas mixtures; heat capacities; heating value; hydrocarbons; liquefied natural gas; natural gas; propagation of errors; reference conditions. 
1. Introduction 1

2. Symbols 4

3. Definitions of terms 5

4. Units of measurement 6

5. Physical constants 7

6. Reference conditions of measurement 10

7. Thermodynamic data for auxiliary substances 12

8. Thermodynamic quantities for hydrocarbons - ideal gas, molar basis $\quad 15$

9. Standard-state volumetric properties of hydrocarbons 18

10. Properties of the real gases 24

11. Voiumetric enthaipy of combustion of the real gas 32

12. Calculating the heating values of gas mixtures 37

13. Uncertainties 48

General 1ist of references $\quad 55$

$\begin{array}{ll}\text { Figures } 1 \text { and } 2 & 58,59\end{array}$

Appendix 1. Proposed composition limits 60

Appendix 2. Symbols 61

Appendix 3. Definitions of terms used in this document 64

Appendix 4. Unit.s of measurement and conversion factors 72

Appendix 5. Discussion of physicai constants 74

Appendix 6. Discussion of reference conditions 92

Appendix 7. Thermodynamic data: their sources and 
Appendix 8. Relationships between thermodynamic quantities in Tables 3 and 4

Appendix 9. Non-ideality effects and the virial equation of state

Appendix 10. Propagation of uncertainties 
Table 1. Physical constants

a. Relative atomic and molecular masses used in this document

b. Other physical constants used in this document 9

Table 2. Reference conditions of measurement used in this document 11

Table 3. Thermodynamic data for selected (auxiliary) substances: 13

a. Standard heat capacity at $T=298.15 \mathrm{~K},\left[H^{\circ}(298.15 \mathrm{~K})\right.$ -

$\left.H^{\circ}\left(T_{2}\right)\right]$ for $T_{2}=288.15 \mathrm{~K}, 288.71 \mathrm{~K}$ and $273.15 \mathrm{~K}$

b. Standard enthalpy of formation at $T=298.15 \mathrm{~K}, 288.15 \mathrm{~K}$, $288.71 \mathrm{~K}$ and $273.15 \mathrm{~K}$

Table 4.. Thermodynamic data for gaseous hydrocarbons (ideal gas, inolar basis)

a. Heat capacity and enthalpy difference between $298.15 \mathrm{~K}$ and 288. $15 \mathrm{~K}, 288.71 \mathrm{~K}$ and $273.15 \mathrm{~K}$

b. Enthalpy of combustion (in $\mathrm{kJ} \mathrm{mol}^{-1}$ ) at $298.15 \mathrm{~K}, 288.15 \mathrm{~K}$, $288.71 \mathrm{~K}$ and $273.15 \mathrm{~K}$

Table 5. Molar volume and density at various reference conditions

Table 6. Combustion data for selected gaseous hydrocarbons

(ideal gas, volumetric basis) in SI units at ISO/ANSI/

ASTM reference conditions of temperature and pressure,

$p=101.325 \mathrm{kPa} ; T=288.15 \mathrm{~K}$ 
Table 7. Combustion data for selected gaseous hydrocarbons (ideal gas, volumetric basis) in SI and U.S. Customary units at ANSI/ASTM/API reference conditions of temperature and pressure $p=101.560 \mathrm{kPa} ; T=288.71 \mathrm{~K}$

Table 8. Virial coefficients for pure substances and mixtures 26

a. Second virial coefficients, $B(T)$, for pure substances

b. Second virial coefficients, $B_{12}(T)$, for binary

mixtures

Table 9. Enthalpy of combustion of real-gas hydrocarbons on molar, mass and volume bases; in SI units and at ISO/ ANSI/ASTM metric reference conditions $p=101.325 \mathrm{kPa}$; $T=288.15 \mathrm{~K}$

Table 10. Enthalpy of combustion of the real-gas hydrocarbons on molar, mass and volume bases; in U.S. Customary units and at ANSI/ASTM/API reference conditions $p=101.560 \mathrm{kPa}$ (14.73 Psi); $T=288.71 \mathrm{~K}\left(60^{\circ} \mathrm{F}\right)$

Tabie 11. Enthalpy correction for the real-gas and molar volume, $V_{\mathrm{m}}$, at ISO/ANSI/ASTM metric reference conditions $p=$ $101.325 \mathrm{kPa} ; T=288.15 \mathrm{~K}$

Table 12. Enthalpy correction for the real-gas and molar volume, $V_{\mathrm{m}}$, at ANSI/ASTM/API U.S. Customary reference conditions $p=101.560 \mathrm{KPa} ; T=288.71 \mathrm{~K}$

Table 13. Sample calculation of enthalpy of combustion of a gaseous mixture assuming ideal gas behavior

Table 14. Sample calculation of enthalpy of combustion of a realgas mixture assuming no interactions between different substances 
Table 15. Estimated uncertainties in thermodynamic properties

Table A1. Proposed composition limits for pipeline quality natural gas

Table A2. Thermodynamic symbols used in this document

Table A4. Measurement quantities defined exactly in terms of

$$
\text { SI units }
$$

Table A5. Atomic masses

a. Recent sets of relative atomic masses of the chemical

elements and their period of recommendation by the

International Union of Pure and Applied Chemistry (IUPAC)

b. Relative molecular masses of some important molecules as formally calculated from different sets of relative atomic masses (rounded to four decimal places)

c. Assignment of uncertainties in relative atomic and molecular masses for the 1981 set recommended by the IUPAC Commission on Atomic Weights and Isotopic Abundances

Table A7a. Heat capacity equations for auxiliary substances and rydrocarbons for the range 268 to $308 \mathrm{~K}$ for the equation $C_{\mathrm{p}} / R=a+b(T-273.15 \mathrm{~K})+c(T-273.15 \mathrm{~K})^{2}$

Table A7b. Enthalpy of combustion of selected hydrocarbons and sources of the data

Table A7c. Heating value of methane: sources of data

Table A7d. Data points and statistics for studies of methane by Rossini and by Pittam and Pilcher 
Table A7e. Enthalpy of combustion of methane as an ideal gas and relative atomic mass scales given in compilations of thermodynamic data

Table A7f. Vapor pressure of water

Table A7g. Estimates of uncertainties ${ }{ }_{C}$ in enthalpy of combustion or $s_{f}$ in enthalpy of formation by various authors

Table A7h. Estimated total uncertainties-first test

Table A7i. Estimated total uncertainties-second test

Table A7j. Estimated uncertainties in $C_{p}^{\circ}$ of hydrocarbons from Scott's correlation of thermodynamic functions

Table A7k. Comparative calculations of $C_{p}^{\circ}$

Table A9a. Constants for quadratic equations for the second virial coefficients as functions of $T$ in the range 273 to $300 \mathrm{~K} 144$

Table A9b. Constants for quadratic equations for the second virial coefficients of interaction, $B(1, i)$, as functions of temperature for the range 273 to $300 \mathrm{~K}$

Table A9c. Enthalpy differences $H-H^{\circ}$ between the real and ideal gases for pure substances $p=101.325 \mathrm{kPa}$ at various reference temperatures

List of figures

Figure 1. Interrelationships among enthalpies of formation and combustion at two temperatures

Figure 2. Relationships among enthalpies of combustion for the real and ideal gas on molar, mass and volume bases 


\section{HEATING VALUES OF NATURAL GAS AND ITS COMPONENTS}

\section{Introduction}

This document provides the basic information for calculating heating values of natural gas mixtures from a knowledge of the gas composition. While it was prepared specifically to meet the needs of the liquefied natural gas industry, the information is equally well applicabie to native or processed natural gas mixtures that have not been liquefied.

The substances treated are the saturated hydrocarbons $c_{1}$ to $\hat{c}_{6}$, a few of the more commonly encountered cyclic and unsaturated hydrocarbons, and some non-hydrocarbon gases frequently found in natural gas. A broader range of materials, but for fewer reference conditicns, is given in an earlier study [1]. ${ }^{a}$

The approximate limits of composition and other properties of gaseous fuel mixtures to which this document should apply are given in Appendix 1.

The presentation is in handbook style, with sufficierit detail to allow the use of the information in a variety of ways to meet various requirements. The information is sufficient to allow calculations at. various base conditions of measurement in use in the natural gas industry, to allow calculations of greater or lesser accuracy, and to a $11 \mathrm{cw}$ the uncertainty of the results to be estimated.

The data and procedures given should not be construed as providing a definitive substitute for laboratory measurement of heating vaiue, which can be reliably performed using well known standard methods of test.

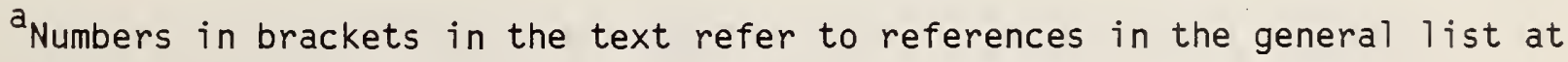
the end of this document. Appendices have their own reference lists. 
In many cases, however, an estimate of the calorific value is adequate. These include engineering design calculations for power plants and power plant components, in establishing the adequacy of fuels from certain sources or processes for selected purposes and in estimating processing requirements or mixing proportions needed to obtain gas mixtures of specified performance. Moreover, the estimates are pertinent and usable in custody transfer operations to the extent agreeable to the parties involved. Indeed, the study made here of the uncertainties in the estimates suggests that the calculation of heating values may be used in many routine conditions.

The organization of this document is described here with the aid of two figures. First there are necessary preliminaries: definition of reference conditions (Table 2), molecular weights and conversion factors for energy units (Table 1 ). Then the basic thermodynamic data are given. The starting point is a set of carefully evaluated enthalpies of formation for the ideal gases at $298.15 \mathrm{~K}\left(25^{\circ} \mathrm{C}\right)$ from which best values for the enthalpies of combustion of selected hydrocarbons are derived and listed in Table 4. Properties of products of combustion and auxiliary substances are listed in Table 3. Three reference temperatures of interest here are different from that at which the basic data are reported. The enthalpies of formation and combustion are corrected from $298.15 \mathrm{~K}$ to these temperatures using the scheme outlined in Figure 1 and Appendix 8 and enthalpy differences from Tables 3 and 4.

The rest of the calculations are summarized in Figure 2. Starting with the molar enthalpy of combustion of the fuel as an ideal gas, point $B$, values are derived for the enthalpy of combustion per unit mass, point $E$, and per unit volume, dry and water saturated, at points $C$ and $D$. These are given, for the ideal gas, in Tables 6 and 7 while the needed molar volumes are in Table 5. The procedures are in Section 9. 
Real gas properties are produced by correcting the ideal gas molar enthalpy of combustion using equation of state data (second viria? coefficients) in Table 8 and procedures described in section 10. This produces the real gas enthalpy of combustion, point. $F$ in Figure 2 . From there the volumetric and mass based quantities are clerived, points $G, H$ and I. The real gas enthalpies of combustion at $15^{\circ} \mathrm{C}$ and $60^{\circ} \mathrm{F}$ are given in Tables 9 and 10, while the molar volumes and enthalpy correction factors are in Tables 11 and 12 . In other tables there is enough information given to permit calculations for other conditions of temoerature and pressure.

Procedures for the calculation of the properties of mixtures are developed in section 12. Both ideal and real gas mixtures are treated, with the latter being considered two ways: as a mixture of non-interacting real gases and as a mixture of interacting real gases. All treatments are based on the virial equation of state.

Uncertainties in the data are discussed in section 13. Those for the enthalpies of combustion are summarized in Table 15 . These are the limiting factors on the accuracy of the data. They should be used in all calculations. The numbers in Table 15 indicate that the uncertainty in the enthalpies of combustion of interest here are of the order of tenths of kilojoules per mole, and, at times, of the order of kilojoules per mole. This means that in most tables of thermodynamic properties given here, the right-most digit is not significant. It is provided for rounding numbers in calculations made by the reader. Differences that are only in the final digit between the numbers here and in other compilations should be ignored. They are the result of slight variations in calculation and rounding procedures. Larger differences usually are due to differing choices for basic data. 
2. Symbols

The symbols used in this work are listed in Appendix 2 in Table A2. They are, so far as practicable, in conformity with the recommendations of the International Union of Pure and Applied Chemistry (IUPAC) $[2,3]$ and of the International Organization for Standardization (ISO) [4]. 


\section{Definitions of terms}

The following terms used in this document are defined in Appendix 3.

\section{Quantitites and concepts.}
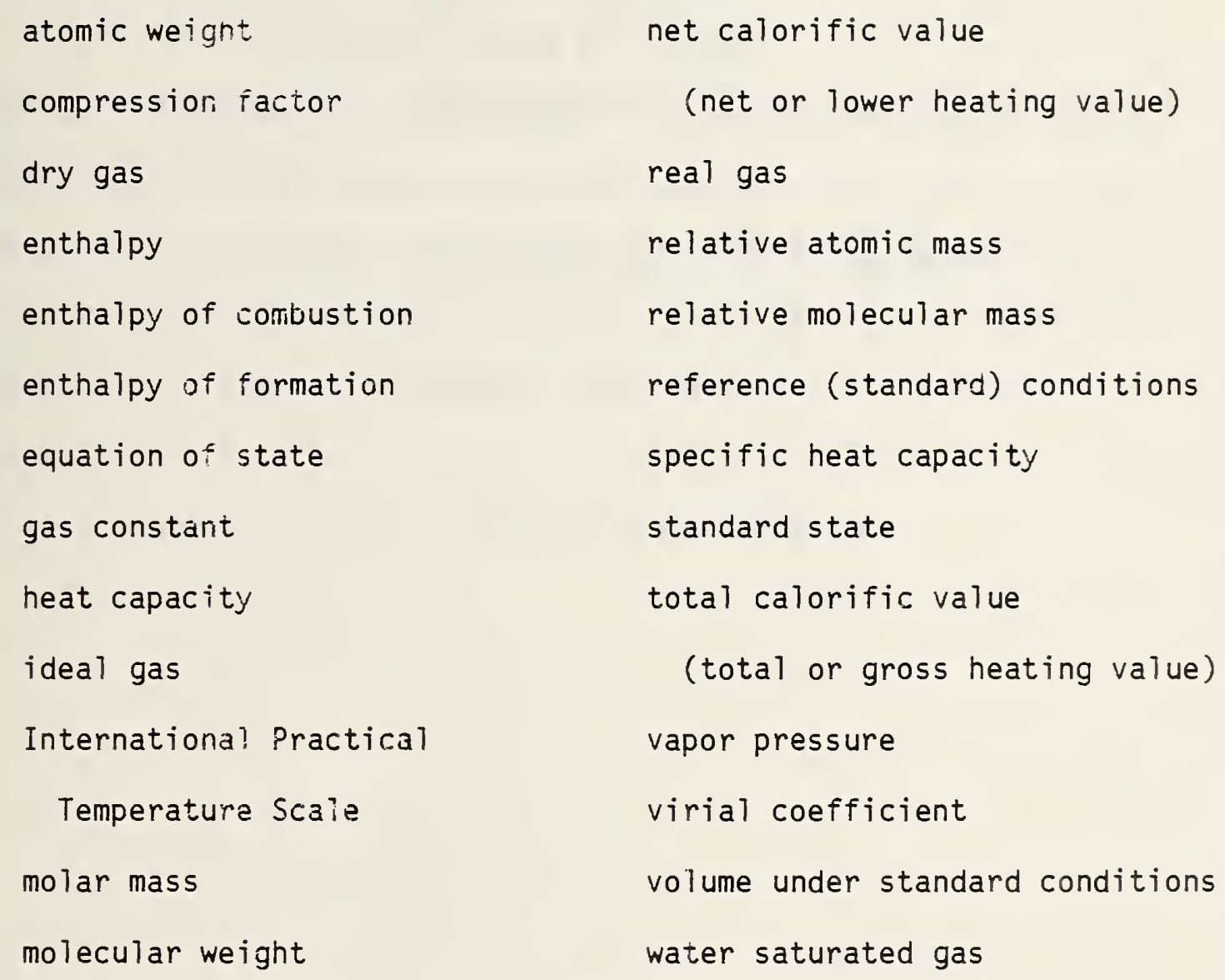

Units of measurement.

atmosphere

British thermal unit

joute

newton pascal

standard cubic foot (of gas)

torr

The usage of terms is intended to represent best current practice and to conform so far as possible to recommendations of IUPAC $[2,3]$, ISO $[4,5]$, and the International Bureau of Weights and Measures (BIPM) [5]. 
4. Units of measurement

The quantities given in this report are based on values measured or expressed in the International System of Units (SI) [5]. The conversion factors used in this document for units of energy are:

$1055.056 \mathrm{~J}=1$ Btu $_{I T}$

$1 \mathrm{MJ} \mathrm{m}^{-3}=26.839192 \mathrm{Btu}_{\mathrm{IT}} \mathrm{ft}^{-3}$

(under identical conditions of temperature and pressure). See Appendix 3, section A3.2.2 for a discussion of the various Btu's. Other conversion factors are found in Table A4 (Appendix 4). 


\section{Physical constants}

Relative atomic and molecular masses. (Atomic and molecular weights). Molecular masses used in this document are listed in Table la. These molecular masses are based on the 1981 recommendations of the International Union of Pure and Applied Chemistry Commission on Atomic Weights and Isotopic Atundancies [6]. Some other sets of relative atomic masses are discussed in Appendix 5a.

Other physical constants. Table lb lists other physical constants used in this document. The value for the gas constant is that recommended by the CODATA Task Group on Fundamental Constants [7]. The acceleration of gravity and the density of mercury are part of the (historical) measurement chain for pressure, which is discussed in Appendix $5 b$. 


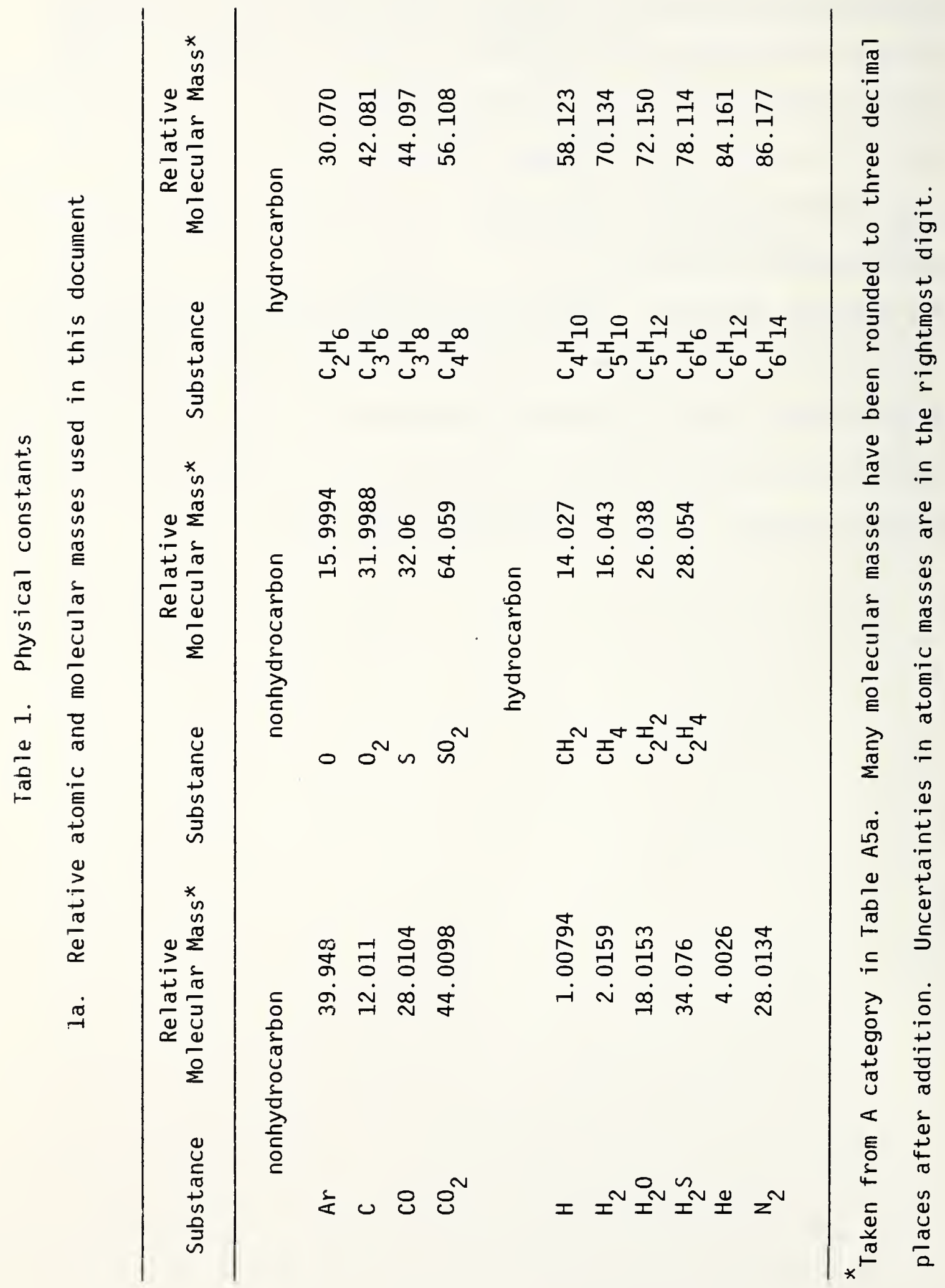


Table 1b. Other physical constants used in this document ${ }^{a}$

$$
\begin{array}{ll}
\text { gas constant }(R) & 8.31441(26) \mathrm{J} \mathrm{mol}^{-1} \mathrm{~K}^{-1} \\
\begin{array}{l}
\text { standard acceleration } \\
\text { of gravity }(g)
\end{array} & 980.665(0) \mathrm{cm} \mathrm{s}^{-2} \\
& \\
\text { standard density of } & 13.5951(0) \mathrm{g} \mathrm{cm}^{-3} \\
\text { mercury at } T=273.15 \mathrm{~K} &
\end{array}
$$

$a_{\text {Numbers }}$ in parentheses indicate the uncertainties in the last figures of the number listed. Zero indicates that the number is defined. 
6. Reference conditions of measurement

Reference conditions of measurement for which this document is specially intended are listed in Table 2. Reference conditions, sometimes referred to as "base conditions" are in a state of flux in the gas industry. Each of the parameters (temperature, pressure, state of gas, and water content) listed in Table 2 is discussed in Appendix 6 . Not all combinations of temperature, pressure, gas ideality, and water content discussed there are of probable use in the gas industry. An attempt has been made to sort out the potentially useful conditions and five conceivably useful sets of reference conditions are listed in Table 2. This document provides information necessary to convert values of properties from one to the other. However, the set labelled "ISO/ASTM/ANSI (metric units)" is considered to be the most useful for the purpose of this document, and combustion data are provided for these conditions, with the exception that real gas properties are not specifically listed for all the substances that are minor components of natural gas. Data are also given at the slightly different conditions customary in the USA, the set is labeled "ANSI/ASTM/API (U.S. Customary units)". 
Table 2. Reference conditions of measurement used in this document.

\begin{tabular}{|c|c|c|c|c|}
\hline Designation & $T^{\mathrm{a}}$ & $p^{a}$ & State of Gas & Water Conitent \\
\hline IUPAC (new)[3] & $298.15 \mathrm{~K}$ & $100 \mathrm{kPa}$ & ideal & dry \\
\hline STP & $\begin{array}{l}273.15 \mathrm{~K} \\
\left(0^{\circ} \mathrm{C}\right)\end{array}$ & $\begin{array}{r}101.325 \mathrm{kPa} \\
(760 \mathrm{mmHg})\end{array}$ & real & dry \\
\hline $\operatorname{IUPAC}(01 \mathrm{~d})[8]$ & $\begin{array}{l}298.15 \mathrm{~K} \\
\left(25^{\circ} \mathrm{C}\right)\end{array}$ & $\begin{array}{l}101.325 \mathrm{kPa} \\
(760 \mathrm{mmHg})\end{array}$ & ideal & dry \\
\hline $\begin{array}{l}\text { ISO/ASTM/ANSI[9] } \\
\text { (metric units) }\end{array}$ & $\begin{array}{l}288.15 \mathrm{~K} \\
\left(15^{\circ} \mathrm{C}\right)\end{array}$ & $101.325 \mathrm{kPa}$ & real & aryisat \\
\hline $\begin{array}{c}\text { ASTM/ANSI/API }[9,10] \\
\text { (U.S. customary) }\end{array}$ & $\begin{array}{l}288.71 \mathrm{~K} \\
\left(60^{\circ} \mathrm{F}\right)\end{array}$ & $\begin{array}{r}101.560 \mathrm{kPa} \\
(14.73 \mathrm{psia})\end{array}$ & real & sat \\
\hline
\end{tabular}

${ }^{a}$ Alternative units for specifying the same temperature should not be taken to mean a different temperature. That is, $25{ }^{\circ} \mathrm{C}$ is identicai to $298.15 \mathrm{~K} ; 15{ }^{\circ} \mathrm{C}$ is identical to $288.15 \mathrm{~K}$, and $60^{\circ} \mathrm{F}$ is identical to $15.555^{\circ} \mathrm{C}$ or $288.7055 \ldots \mathrm{K}$, in which the fraction is continuing. This is rounded to $288.71 \mathrm{~K}$. Similarly, different units for expressing the same pressure should not be construed as different pressures. $101.325 \mathrm{kPa}$ is identical to 760 Torr and to $760 \mathrm{mmHg}$. The value $101.560 \mathrm{kPa}$ is a rounded value corresponding to 14.73 psia. This last value is taken here as exact, although it may have originated as a rounded value for $30 \mathrm{in} \mathrm{Hg}$. (In contrast we use $288.706 \mathrm{~K}$ for $60^{\circ} \mathrm{F}$, not $288.71 \mathrm{~K}$ as appears in most table headings). See Appendix 6 for discussion of reference conditions and Appendix 5b for the interrelationships among pressure units. 
7. Thermodynamic data for auxiliary substances

In this section are given the basic data for products of combustion and components of air. These are enthalpies of formation, enthalpy differences and heat capacities, all for the ideal gases. The latter two types of data are needed to correct the standard enthalpies of formation at $298.15 \mathrm{~K}$ to the various reference conditions of interest in gas technology.

In Table $3 a$ are listed values of $C_{p}^{\circ}(298.15 \mathrm{~K})$ for each of the auxiliary substances and calculated values of $H^{\circ}\left(T_{1}\right)-H^{\circ}\left(T_{2}\right)$, that is $\left\{H^{\circ}\left(T_{2}\right)-H^{\circ}\left(T_{1}\right)\right\}$, for the temperature intervals $T_{1}=298.15 \mathrm{~K} ; T_{2}=$ $288.15 \mathrm{~K} ; T_{2}=288.71 \mathrm{~K}\left(60^{\circ} \mathrm{F}\right)$; and $T_{2}=273.15 \mathrm{~K}$. In Table $3 \mathrm{~b}$ are listed selected vaiues of $\Delta_{f} H^{\circ}(298.15 \mathrm{~K})$ for each of the auxiliary substances and values for $\Delta_{\mathrm{f}} \mathrm{H}^{\circ}(288.15 \mathrm{~K}), \Delta_{\mathrm{f}} H^{\circ}(288.71 \mathrm{~K})$, and $\Delta_{\mathrm{f}} H^{\circ}$ (273.15 K) derived using the data in Table 3a. The sources of the data are discussed in Appendix 7 . How the data are interrelated and how the corrections are made are described in Appendix 8. 
Table 3. Thermodynamic data for selected (auxiliary) substances

Table 3a. Standard heat capacity at $T=298.15 \mathrm{~K}$ and $\left[H^{\circ}(298.15 \mathrm{~K})-\right.$ $\left.H^{\circ}\left(T_{2}\right)\right]$ for $T_{2}=288.15 \mathrm{~K}, 288.71 \mathrm{~K}$ and $273.15 \mathrm{~K}$

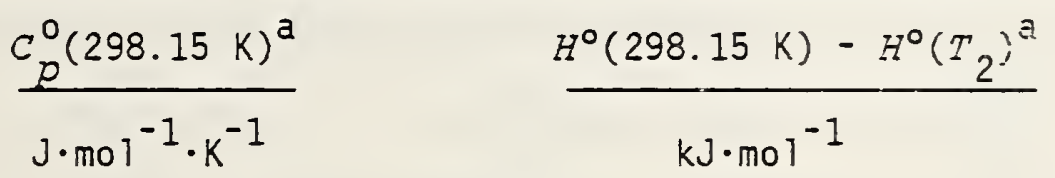

Substance (phase)

$$
T_{2}=288.15 \mathrm{~K} \quad T_{2}^{\prime}=288.71 \mathrm{~K} \quad T_{2}=273.15 \mathrm{~K}
$$

\begin{tabular}{|c|c|c|c|c|}
\hline $\operatorname{Ar}(g)$ & 20.78 & 0.208 & 0.196 & 0.520 \\
\hline$C(c$, graphite $)$ & 8.53 & .083 & .081 & $0.203^{b}$ \\
\hline $\mathrm{CO}(\mathrm{g})$ & 29.15 & .291 & .275 & 0.728 \\
\hline $\mathrm{CO}_{2}(\mathrm{~g})$ & 37.12 & .369 & .348 & 0.914 \\
\hline $\mathrm{H}_{2}(\mathrm{~g})$ & 28.83 & .288 & .272 & 0.717 \\
\hline $\mathrm{H}_{2} \mathrm{O}(\mathrm{g})$ & 33.58 & .336 & .317 & $0.830^{\circ}$ \\
\hline $\mathrm{H}_{2} \mathrm{O}(2)$ & 75.29 & .753 & .711 & $1.888^{\mathrm{C}}$ \\
\hline $\mathrm{H}_{2} \mathrm{~S}(\mathrm{~g})$ & 34.10 & .340 & .321 & 0.849 \\
\hline $\mathrm{He}(\mathrm{g})$ & 20.79 & .208 & .195 & 0.520 \\
\hline $\mathrm{N}_{2}(\mathrm{~g})$ & 29.13 & .291 & .275 & 0.728 \\
\hline $\mathrm{O}_{2}(\mathrm{~g})$ & 29.37 & .293 & .277 & 0.733 \\
\hline$s(c$, rhombic) & 22.64 & .225 & .213 & -- \\
\hline $\mathrm{SO}_{2}(\mathrm{~g})$ & 40.06 & .399 & .376 & 0.989 \\
\hline
\end{tabular}

awithoit, R. C.; [11], except as noted.

DeSorbo, W. ; and Tyler, W. W. ; [13].

Cosborne, N. S.; Stimson, H. F.; Ginnings, D. C.; [12]. 
Table 3b. Standard enthalpy of formation, at $T=298.15 \mathrm{~K}, 288.15 \mathrm{~K}$, $288.71 \mathrm{~K}$ and $273.15 \mathrm{~K}$

\begin{tabular}{|c|c|c|c|c|}
\hline $\begin{array}{c}\text { Substance } \\
\text { (phase) }\end{array}$ & $\frac{\Delta_{f} H^{\circ}(298.15 \mathrm{~K})^{\mathrm{a}}}{\mathrm{kJ} \cdot \mathrm{mo} 7^{-1}}$ & $\frac{\Delta_{\mathrm{f}} H^{\circ}(288.15 \mathrm{~K})}{\mathrm{kJ} \cdot \mathrm{mol}]^{-1}}$ & $\frac{\Delta_{f} H^{\circ}(288.71 \mathrm{~K})}{\mathrm{kJ} \cdot \mathrm{mol}^{-1}}$ & $\frac{\Delta_{\mathrm{f}} H^{\circ}(273.15 \mathrm{~K})}{\mathrm{kJ} \cdot \mathrm{mol} 7^{-1}}$ \\
\hline $\operatorname{Ar}(g)$ & 0.0 & 0.0 & 0.0 & 0.0 \\
\hline C(c,graphite) & 0.0 & 0.0 & 0.0 & 0.0 \\
\hline $\operatorname{co}(g)$ & $-110.53 \pm 0.17$ & -110.59 & -110.59 & -110.69 \\
\hline $\mathrm{CO}_{2}(\mathrm{~g})$ & $-393.51 \pm 0.13$ & -393.50 & -393.50 & -393.49 \\
\hline $\mathrm{H}_{2}(\mathrm{~g})$ & 0.0 & 0.0 & 0.0 & 0.0 \\
\hline $\mathrm{H}_{2} \mathrm{O}(\mathrm{g})$ & $-241.814 \pm 0.042$ & -241.715 & -241.721 & -241.561 \\
\hline $\mathrm{H}_{2} \mathrm{O}(\ell)$ & $-285.830 \pm 0.042$ & -286.148 & -286.131 & -286.634 \\
\hline $\mathrm{H}_{2} \mathrm{~S}(\mathrm{~g})$ & $-20.63 \pm 1.00$ & -20.46 & -20.47 & -- \\
\hline $\mathrm{He}(\mathrm{g})$ & 0.0 & 0.0 & 0.0 & 0.0 \\
\hline $\mathrm{N}_{2}(\mathrm{~g})$ & 0.0 & 0.0 & 0.0 & 0.0 \\
\hline $\mathrm{O}_{2}(\mathrm{~g})$ & 0.0 & 0.0 & 0.0 & 0.0 \\
\hline$S(c$, rhombic) & 0.0 & 0.0 & 0.0 & 0.0 \\
\hline $\mathrm{SO}_{2}(\mathrm{~g})$ & $-296.81 \pm 0.21$ & -296.69 & -296.70 & --- \\
\hline
\end{tabular}

$\mathrm{a}_{\mathrm{Values}}$ at $238.15 \mathrm{~K}$ were taken from CODATA Bulletin No. 28 and CODATA Special Report 8 [14]. 
8. Thermodynamic quantities for hydrocarbons - ideal gas, molar basis In this section are given vaiues for the thermodynamic properties of selected hydrocarbons. The basic data are for the ideal gases and on a molar basis. Those are enthalpies of combustion, heat capacities and enthalpy differences. Combustion data are given at all three reference conditions likely to be used in gas technology.

The ideal-gas values of thermodynamic quantities for the hydrocarbons on a molar basis are listed in Tables $4 a$ and $4 \mathrm{~b}$. The sources of the data and derivation of the tabie are discussed in Appendix 7 . The values of $C_{p}^{\circ}(298.15 \mathrm{~K}),\left[H^{\circ}(298.15 \mathrm{~K})-H^{\circ}(288.15 \mathrm{~K})\right],\left[H^{\circ}(298.15 \mathrm{~K})-\right.$ $\left.H^{\circ}(288.71 \mathrm{~K})\right]$, and $\left[H^{\circ}(298.15 \mathrm{~K})-H^{\circ}(273.15 \mathrm{~K})\right]$, are given for each hydrocarbon in Table 4a. The values of $-\Delta_{C} H^{\circ}(298.15 \mathrm{~K}),-\Delta_{C} H^{\circ}(288.15 \mathrm{~K})$, $-\Delta_{C} H^{\circ}(288.71 K)$, and $-\Delta_{C} H^{\circ}(273.15 K)$ are given in Table 4b. In Appendix 8 is found a discussion of the relationships among quantities in Tables $3 a$, $3 b, 4 a$ and $4 b$ and some illustrative calculations are given. 
Table 4. Thermodynamic data for gaseous hydrocarbons (ideal gas, molar basis) Table 4a. Heat capacity and enthalpy difference between $298.15 \mathrm{~K}$ and $288.15 \mathrm{~K}, 288.71 \mathrm{~K}$ and $273.15 \mathrm{~K}$

\begin{tabular}{|c|c|c|c|c|}
\hline \multirow[b]{3}{*}{$\begin{array}{l}\text { Substance } \\
\text { (phase) }\end{array}$} & \multirow{2}{*}{$\frac{C_{\mathrm{p}}^{0}(298.15 \mathrm{~K})}{\mathrm{J} \cdot \mathrm{mol}^{-1} \cdot \mathrm{K}^{-1}}$} & \multicolumn{3}{|c|}{$H^{\circ}(298.15 \mathrm{~K})-H^{\circ}\left(T_{2}\right)$} \\
\hline & & & $\mathrm{kJ} \cdot \mathrm{mol}^{-1}$ & \multirow[b]{2}{*}{$T_{2} / \mathrm{K}=273.15$} \\
\hline & \multicolumn{2}{|r|}{$T_{2} / K=288.15$} & $T_{2} / K=288.71$ & \\
\hline methane & 35.71 & 0.355 & 0.335 & 0.882 \\
\hline ethane & 52.48 & 0.519 & 0.490 & 1.275 \\
\hline propane & 73.59 & 0.726 & 0.686 & 1.779 \\
\hline n-butane & 98.44 & 0.972 & 0.918 & 2.384 \\
\hline $\begin{array}{l}\text { 2-methy lpropane } \\
\text { (iso-butane) }\end{array}$ & 96.59 & 0.953 & 0.900 & 2.332 \\
\hline$n$-pentane & 119.96 & 1.185 & 1.120 & 2.910 \\
\hline $\begin{array}{l}\text { 2-methylbutane } \\
\text { (iso-Dentane) }\end{array}$ & 118.94 & 1.174 & 1.109 & 2.880 \\
\hline $\begin{array}{l}\text { 2,2-dimethy 1- } \\
\text { propane } \\
\text { (neopentane) }\end{array}$ & 120.96 & 1.194 & 1.128 & 2.923 \\
\hline n-hexane & 142.62 & 1.409 & 1.331 & 3.459 \\
\hline $\begin{array}{l}\text { 2-methy 1- } \\
\text { pentane }\end{array}$ & 142.35 & 1.405 & 1.328 & 3.458 \\
\hline 3-methy 1- & 140.20 & 1.384 & 1.307 & 3.391 \\
\hline $\begin{array}{l}2,2-\text { dimethy } 1- \\
\text { butane }\end{array}$ & 141.55 & 1.396 & 1.319 & 3.419 \\
\hline $\begin{array}{l}2,3-\text { dimethy } 7- \\
\text { butane }\end{array}$ & 139.56 & 1.378 & 1.302 & 3.380 \\
\hline cyclopropane & 55.59 & 0.546 & 0.516 & 1.328 \\
\hline cyclobutane & 70.86 & 0.696 & 0.658 & 1.693 \\
\hline cyclopentane & 83.11 & 0.814 & 0.769 & 1.971 \\
\hline cyclohexane & 105.25 & 1.033 & 0.976 & 2.509 \\
\hline acetylene & 44.06 & 0.437 & 0.413 & 1.077 \\
\hline ethylene & 43.55 & 0.423 & 0.400 & 1.042 \\
\hline propene & 64.41 & 0.636 & 0.601 & 1.561 \\
\hline benzene & 85.58 & 0.841 & 0.795 & 2.050 \\
\hline
\end{tabular}


Table 4b. Enthalpy of combustion (in kJ mol ${ }^{-1}$ ) at $298.15 \mathrm{~K}, 288.15 \mathrm{~K}$, $288.71 \mathrm{~K}$ and $273.15 \mathrm{~K}$

\begin{tabular}{|c|c|c|c|c|}
\hline \multirow[t]{2}{*}{$\overline{\text { Substance }}$} & \multicolumn{3}{|c|}{$-\Delta_{\mathrm{c}} H^{\circ} / \mathrm{kJ} \mathrm{mol}{ }^{-1}$} & \multirow[b]{2}{*}{$T=273.15 \mathrm{~K}$} \\
\hline & $T=298.15 \mathrm{~K}$ & $T=288.15 \mathrm{~K}$ & $T=288.71 \mathrm{~K}$ & \\
\hline methane & 890.31 & 891.24 & 891.19 & 892.65 \\
\hline ethane & 1559.84 & 1561.29 & 1561.21 & 1563.49 \\
\hline propane & 2219.90 & 2221.83 & 2221.72 & 2224.75 \\
\hline butane & 2877.25 & 2879.61 & 2879.48 & 2883.67 \\
\hline 2-methylpropane & 2368.72 & 2871.10 & 2870.97 & 2874.72 \\
\hline n-pentane & 3535.77 & 3538.60 & 3538.44 & 3542.89 \\
\hline 2-methylbutane & 3528.87 & 3531.72 & 3531.55 & 3563.02 \\
\hline $\begin{array}{l}2,2-\text { dimethy?- } \\
\text { propane }\end{array}$ & 3514.50 & 3517.42 & 3517.26 & 3521.71 \\
\hline$n$-hexane & 4194.75 & 4198.04 & 4197.85 & 4203.03 \\
\hline $\begin{array}{l}\text { 2-methy?- } \\
\text { pentane }\end{array}$ & 4137.64 & 4190.94 & 4190.75 & 4195.93 \\
\hline $\begin{array}{l}\text { 3-methyl- } \\
\text { pentane }\end{array}$ & 4190.32 & 4193.64 & 4193.45 & 4198.67 \\
\hline $\begin{array}{l}\text { 2,2-dimethy1- } \\
\text { butane }\end{array}$ & 4176.34 & 4179.65 & 4179.45 & 4184.66 \\
\hline $\begin{array}{l}2,3 \text {-dimethvi- } \\
\text { butane }\end{array}$ & .4184 .17 & 4187.49 & 4187.30 & 4192.53 \\
\hline cyclopropane & 2091.37 & 2092.87 & 2092.78 & 2095.15 \\
\hline cyclobutane & 2745.16 & 2747.19 & 2747.08 & 2750.28 \\
\hline cyclopentane & 3319.59 & 3322.19 & 3322.04 & 3326.14 \\
\hline cyclohexane & 3952.96 & 3956.02 & 3955.84 & 3860.67 \\
\hline ethyne & 1299.59 & 1299.91 & 1299.86 & 1300.40 \\
\hline ethene & 1410.97 & 1411.90 & 1411.85 & 1413.33 \\
\hline propene & 2058.44 & 2059.85 & $2059.77^{\circ}$ & 2061.99 \\
\hline benzene & 3301.51 (API) & 3302.94 & 3302.82 & 3305.11 \\
\hline
\end{tabular}


9. Standard-state volumetric properties of hydrocarbons

The enthalpy of combustion of unit volume of gaseous hydrocarbon is strongly dependent on the temperature and pressure of the gas. In Table 5 are presented conversion factors $\left(V_{m}=\right.$ molar volume and $\rho_{n}=$ amount of substance (molar density) used to convert standard molar enthalpies of combustion to standard enthalpy of combustion per unit volume of the ideal gas for all the various reference conditions listed in Table 2. The relationships between these quantities are discussed in Appendix 8 .

The values of standard volumetric enthalpy of combustion in SI units for the ISO/ANSI/ASTM metric reference conditions are given in Table 6 . The relationship by which these values were calculated is:

$$
\Delta_{\mathrm{c}} H^{\circ}(T, p) / \mathrm{kJ} \mathrm{m}^{-3}=\left[\Delta_{\mathrm{c}} H^{\circ}(T) / \mathrm{kJ} \mathrm{mol}^{-1}\right] /\left[V_{\mathrm{m}}^{\mathrm{id}}(T) / \mathrm{m}^{3} \mathrm{~mol}^{-1}\right],
$$

or

$$
\Delta_{\mathrm{c}} H^{\circ}(T, p) / \mathrm{kJ} \mathrm{m}^{-3}=\left[\Delta_{\mathrm{c}} H^{\circ}(T) / \mathrm{kJ} \mathrm{mol}^{-1}\right] \cdot\left[\rho_{n}(T) / \mathrm{mol} \mathrm{m}^{-3}\right],
$$

with

$$
V_{\mathrm{m}}^{\mathrm{id}}=R T / p
$$

Either equation may be used. The use of these equations to calculate a standard volumetric enthalpy of combustion is illustrated in the next paragraph.

To convert the standard molar enthalpy of combustion of methane at $288.15 \mathrm{~K}$ to the standard volumetric enthalpy of combustion at $T=288.15$ $\mathrm{K}$ and $p=101.325 \mathrm{kPa}$, dry basis:

$$
\begin{aligned}
\Delta_{\mathrm{C}} H^{\circ}\left(\mathrm{CH}_{4}, 288.15\right. & \mathrm{K}, 101.325 \mathrm{kPa}) \\
= & \left(-891.24 \mathrm{~kJ} \mathrm{~mol}^{-1}\right) /\left(0.023645 \mathrm{~m}^{3} \mathrm{~mol}^{-1}\right) \\
= & -37693 \mathrm{~kJ} \mathrm{~m}^{-3} \\
= & -37.693 \mathrm{MJ} \mathrm{m}^{-3}
\end{aligned}
$$


This reproduces the value given for methane in Table 6 . Equation 9.3 has been used to calculate $V_{m}^{i d}$ for this example and for all later conversions. The values in Table 5 have been rounded so that the uncertainty is in the last decimal place shown.

Table 7 gives the standard volumetric enthalpy of combustion for the U.S. Customary reference conditions: $T=60^{\circ} \mathrm{F}(288.71 \mathrm{~K})$ and $p=14.73$ psia (101.560 kPa). The values are given in U.S. Customary units (Btu $\mathrm{ft}^{-3}$ ), but also are given in SI units to permit ready comparison with data in Table 6 . It must be emphasized that both the temperature and pressure are different for the metric base conditions so that the conversion of values From Table 6 to Table 7 involves other factors than the ratio (Btu $\mathrm{ft}^{-3} / \mathrm{MJ}$ $\left.\mathrm{m}^{-3}\right): 1 \mathrm{MJ} \mathrm{m}^{-3}=26.8391924 \mathrm{Btu}^{-3} \mathrm{ft}^{-3}$. The values in Table 7 are calculated directly from the values in Table $4 a$ by use of the appropriate conversion factors, equation 9.3 , as follows:

$\Delta_{c} H^{\circ}\left(C_{a} H_{b}, g, 288.71 \mathrm{~K}, 101.560 \mathrm{kPa}\right) / \mathrm{MJ} \mathrm{m}^{-3}=$

$$
\left[\Delta_{c} H^{\circ}\left(\mathrm{C}_{\mathrm{a}} \mathrm{H}_{\mathrm{b}}, \mathrm{g}, 288.71 \mathrm{~K}\right) / \mathrm{MJ} \mathrm{mol}^{-1}\right] /\left[\mathrm{V}_{\mathrm{m}}(\mathrm{T}) / \mathrm{m}^{3} \mathrm{~mol}^{-1}\right]
$$

The process can be illustrated for methane. From Table $4 b, \Delta_{c} H^{\circ}\left(\mathrm{CH}_{4}, \mathrm{~g}\right.$, $288.71 \mathrm{~K})=-891.19 \mathrm{~kJ} \mathrm{~mol}^{-1}=-0.89119 \mathrm{MJ} \mathrm{mol}^{-1}$. From Table 5 for the dry gas $V_{\mathrm{m}}(T)=0.023635 \mathrm{~m}^{3} \mathrm{~mol}^{-1}$ at $288.71 \mathrm{~K}$ and a pressure of $101.560 \mathrm{kPa}$.

$$
\begin{aligned}
\Delta_{\mathrm{C}} H^{\circ}\left(\mathrm{CH}_{4}, \mathrm{~g}, 288.71 \mathrm{~K}\right. & , 101.560 \mathrm{kPa}, \mathrm{dry}) \\
= & -\left(0.89119 \mathrm{MJ} \mathrm{mol}^{-1}\right) /\left(0.023635 \mathrm{~m}^{3} \mathrm{~mol}^{-1}\right) \\
= & -37.706 \mathrm{MJ} \mathrm{m}^{-3}
\end{aligned}
$$

To convert to units of Btu $\mathrm{ft}^{-3}$ multiply this by the conversion factor $1 \mathrm{MJ} \mathrm{m}^{-3}=26.8391924 \mathrm{Btu}^{-3}$. The product gives:

$$
\begin{aligned}
\Delta_{\mathrm{C}} \mathrm{H}^{\circ}\left(\mathrm{CH}_{4}, \mathrm{~g}, 288.71 \mathrm{~K}\right. & , 101.560 \mathrm{kPa}, \mathrm{dry}) \\
= & -\left(37.706 \mathrm{MJ} \mathrm{m}^{-3}\right) \times\left(26.8392 \mathrm{Btu} \mathrm{ft}^{-3} / \mathrm{MJ} \mathrm{m}^{-3}\right) \\
= & -1012.00 \mathrm{Btu} \mathrm{ft}
\end{aligned}
$$

reproducing two values in the table. 
To find the standard volumetric enthalpy of combustion of the water-saturated gas, use the conversion factor, $0.024054 \mathrm{~m}^{3} \mathrm{mo}^{-1}$, that is appropriate for the water-saturated gas at $288.71 \mathrm{~K}$ and $101.560 \mathrm{kPa}$. Similar calculations can be made for the other gases (or for mixtures of ideal gases) at any of the reference temperatures.

The calculation of the factors found in Table 5 is discussed in Appendix 8. The vapor pressure of water used for calculating the factors for the water-saturated gas, taken from Wexler's correlation [16], is given in Table A7f in Appendix 7. 


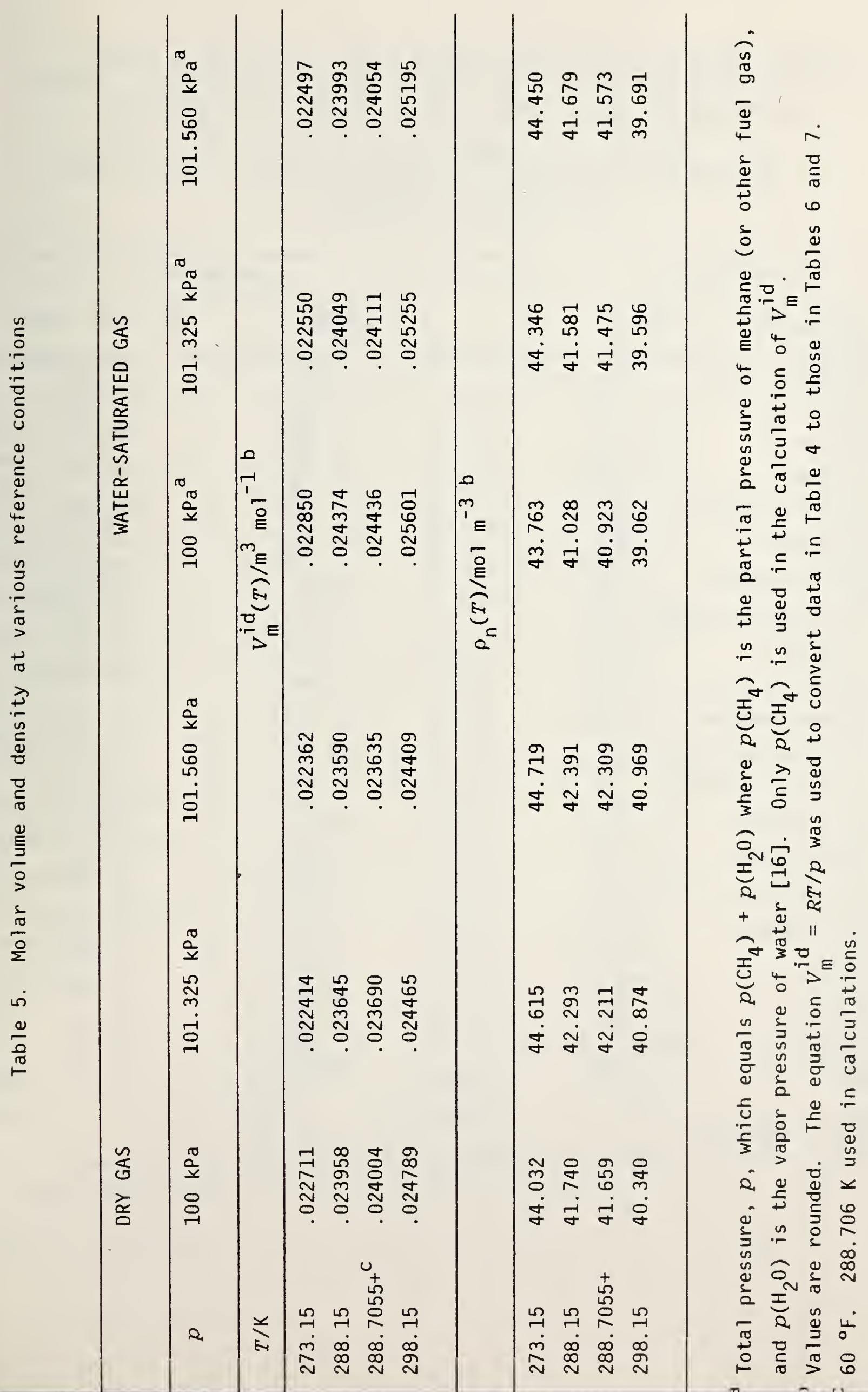


Table 6. Combustion data for selected gaseous hydrocarbons (ideal gas, volumetric basis) in SI units at ISO/ANSI/ASTM reference conditions of temperature and pressure

$$
p=101.325 \mathrm{kPa} ; T=288.15 \mathrm{~K}^{\mathrm{a}}
$$

\begin{tabular}{|c|c|c|c|c|}
\hline \multirow[b]{2}{*}{ Substance } & \multirow[b]{2}{*}{ Formula } & \multicolumn{2}{|c|}{$-\Delta_{c} H^{\circ} / \mathrm{MJ} \mathrm{m}^{-3}$} & \multirow{2}{*}{ Basis (sat) } \\
\hline & & Dry Basis & Wet & \\
\hline methane & $\mathrm{CH}_{4}$ & 37.693 & & 37.059 \\
\hline ethane & $\mathrm{C}_{2} \mathrm{H}_{6}$ & 66.031 & & 64.920 \\
\hline propane & $\mathrm{C}_{3} \mathrm{H}_{8}$ & 93.967 & & 92.386 \\
\hline n-butane & $\mathrm{C}_{4} \mathrm{H}_{10}$ & 121.787 & & 119.737 \\
\hline 2-methylpropane & $\mathrm{C}_{4} \mathrm{H}_{10}$ & 121.426 & & 119.383 \\
\hline$n$-pentane & $\mathrm{C}_{5} \mathrm{H}_{12}$ & 149.657 & & 147.139 \\
\hline 2-methylbutane & $\mathrm{C}_{5} \mathrm{H}_{12}$ & 149.366 & & 146.853 \\
\hline 2,2-dimethylpropane & $\mathrm{C}_{5} \mathrm{H}_{12}$ & 148.762 & & 146.258 \\
\hline n-hexane & $\mathrm{C}_{6} \mathrm{H}_{14}$ & 177.547 & & 174.559 \\
\hline 2-methylpentane & $\mathrm{C}_{6} \mathrm{H}_{14}$ & 172.247 & & 174.264 \\
\hline 3-methylpentane & $\mathrm{C}_{6} \mathrm{H}_{14}$ & 177.361 & & 174.376 \\
\hline 2,2-dimethylbutane & $\mathrm{C}_{6} \mathrm{H}_{14}$ & 176.769 & & 173.794 \\
\hline 2,3-dimethylbutane & $\mathrm{C}_{6} \mathrm{H}_{14}$ & 177.101 & & 174.120 \\
\hline cyclopropane & $\mathrm{C}_{3} \mathrm{H}_{6}$ & 88.513 & & 87.024 \\
\hline cyclobutane & $\mathrm{C}_{4} \mathrm{H}_{8}$ & 116.186 & & 114.231 \\
\hline cyclopentane & $\mathrm{C}_{5} \mathrm{H}_{10}$ & 150.505 & & 138.140 \\
\hline cyclohexane & $\mathrm{C}_{6} \mathrm{H}_{12}$ & 167.311 & & 164.495 \\
\hline ethyne & $\mathrm{C}_{2} \mathrm{H}_{2}$ & 54.977 & & 54.052 \\
\hline ethene & $\mathrm{C}_{2} \mathrm{H}_{4}$ & 59.713 & & 58.708 \\
\hline propene & $\mathrm{C}_{3} \mathrm{H}_{6}$ & 87.117 & & 85.651 \\
\hline benzene & $\mathrm{C}_{6} \mathrm{H}_{6}$ & 139.691 & & 137.340 \\
\hline
\end{tabular}


Table 7. Combustion data for selected gaseous hydrocarbons (ideal gas, volumetric basis) in SI and U.S. Customary units at ANSI/ASTM/API reference conditions of temperature and pressure

$$
p=101.560 \mathrm{kPa} ; T=288.71 \mathrm{~K}^{\mathrm{a}}
$$

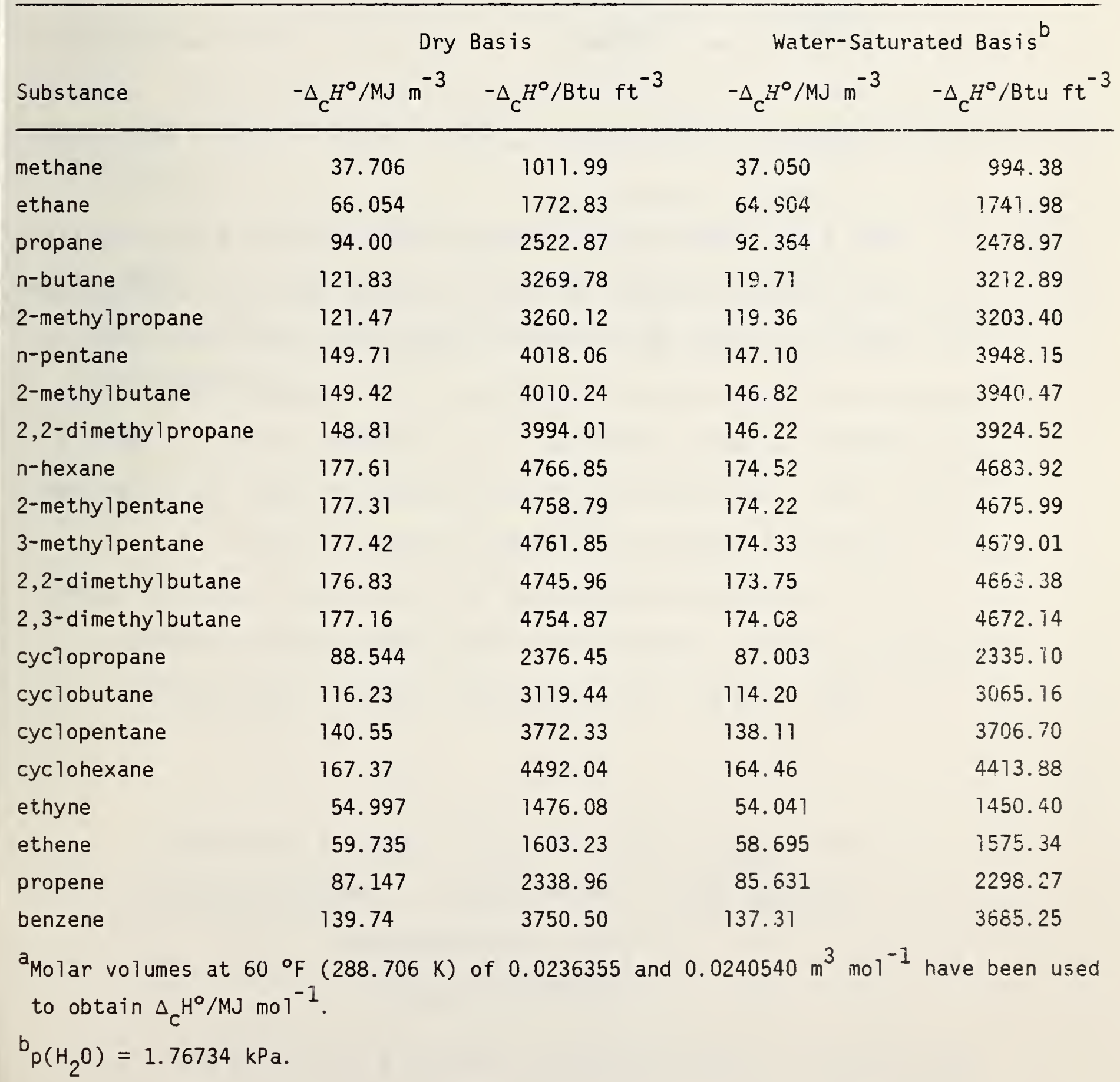


10. Properties of the real gases

The effects of non-ideality on the properties of the real gases are based on the equation of state of the gases as represented by the virial coefficients. The second virial coefficients, $B(T)$, are given for the pure substances in Table $8 a$ at the four temperatures of interest. The derivation of this table and the relationships to the enthalpy and the volume of the real gas are discussed in Appendix 9. In addition, a second degree equation is given there for the virial coefficient of each gas, Table A9a. Table A9c in the Appendix gives the enthalpy increment, $H-H^{\circ}$, on a molar basis caused by the nor-ideality of the gas.

Table 9 gives the real-gas enthalpy of combustion for the hydrocarbons in SI units for the ISO/ANSI/ASTM metric reference conditions of measurement $(T=288.15 \mathrm{~K}, p=101.325 \mathrm{kPa})$ on molar, mass and volume bases. Table 10 gives the real-gas enthalpy of combustion in U.S. Customary units for the ANSI/ASTM/API reference conditions for U.S. Customary units, $T=288.71 \mathrm{~K}$ $\left(60^{\circ} \mathrm{F}\right)$, and $p=101.560 \mathrm{kPa}(14.73 \mathrm{psia})$, also molar, mass and volume bases. The corrections themselves are included in Tables 11 and 12 .

Tabie 9 is derived directly from Table $4 a$ and the virial coefficients using the cycle (all processes at the same temperature and pressure):

$$
\begin{aligned}
& \text { real: } \quad \mathrm{C}_{a} \mathrm{H}_{b}(\mathrm{~g})+(\mathrm{a}+\mathrm{b} / 4) \mathrm{O}_{2}(\mathrm{~g}) \rightarrow \mathrm{aCO}_{2}(\mathrm{~g})+(\mathrm{b} / 2) \mathrm{H}_{2} \mathrm{O}(\mathrm{g}) \\
& \downarrow 1 \quad \downarrow 2 \quad \uparrow 3 \quad \uparrow 4 \\
& \text { ideal: } \quad \mathrm{C}_{a} \mathrm{H}_{b}(\mathrm{~g})+(\mathrm{a}+\mathrm{b} / 4) \mathrm{O}_{2}(\mathrm{~g}) \rightarrow \mathrm{aCO}_{2}(\mathrm{~g})+(\mathrm{b} / 2) \mathrm{H}_{2} \mathrm{O}(\mathrm{g}) \\
& \Delta_{C} H(\text { real gas })=-\left[H-H^{\circ}\right]\left(C_{a} H_{b}, g\right)-(a+b / 4)\left[H-H^{\circ}\right]\left(O_{2}, g\right) \\
& +\Delta_{\mathrm{C}} H^{\circ}+\mathrm{a}\left[H-H^{\circ}\right]\left(\mathrm{CO}_{2}, \mathrm{~g}\right) \\
& +(\mathrm{b} / 2)\left[H-H^{\circ}\right]\left(\mathrm{H}_{2} \mathrm{O}, \mathrm{g}\right)
\end{aligned}
$$

The calculation is made for methane at $288.15 \mathrm{~K}$ and $101.325 \mathrm{kPa}$ as an example. For methane $\mathrm{a}=1, \mathrm{~b}=4 ;\left(H-H^{\circ}\right)=-17.0 \mathrm{~J} \mathrm{~mol}^{-1}$ (Table A9c); for 
oxygen, $H-H^{\circ}=-8.72 \mathrm{~J} \mathrm{~mol}^{-1}$; for $\mathrm{CO}_{2}, H-H^{\circ}=-42.7 \mathrm{~J} \mathrm{~mol}^{-1}$ and for $\mathrm{H}_{2} \mathrm{O}(1)$, $H-H^{\circ}$ is taken to be zero. $\Delta_{\mathrm{C}} H^{\circ}\left(\mathrm{CH}_{4}, \mathrm{~g}, 101.325 \mathrm{kPa}, 288.15 \mathrm{~K}\right)$ is -891.24 kJ mol ${ }^{-1}$ (Table 4b). From these vailues:

$$
\begin{aligned}
\Delta_{c} H\left(\mathrm{CH}_{4}, \mathrm{~g}, 101.325\right. & \mathrm{kPa}, 288.15 \mathrm{k}) / \mathrm{kJ} \mathrm{mol}^{-1}= \\
& -891.24-0.0427 \\
& -(-0.0170)-2(-0.00872)= \\
& -891.2483
\end{aligned}
$$

which rounds to $-891.25 \mathrm{~kJ} \mathrm{mo} !^{-I}$. The adjustment is barely significant in this case.

By a similar procedure, as indicated in Appendixes 8 and $9, \Delta_{C} H-\Delta_{C} H^{\circ}$ can be calculated for any hydrocarion and any base conditions of temperature and pressure for which data are given, using Table $4 a$ or $4 b$ and Table A9c of the Appendix. 


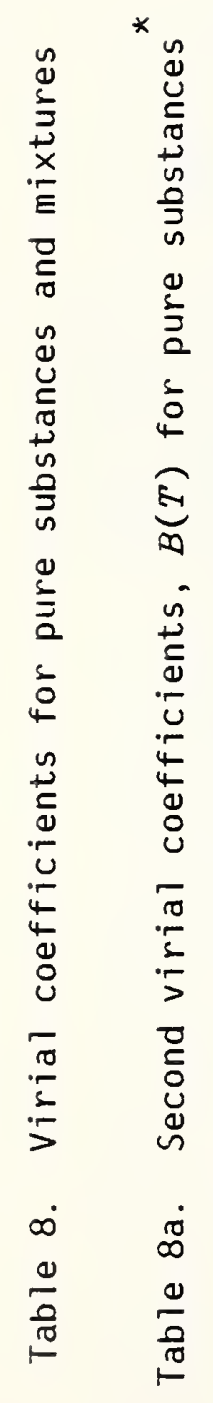

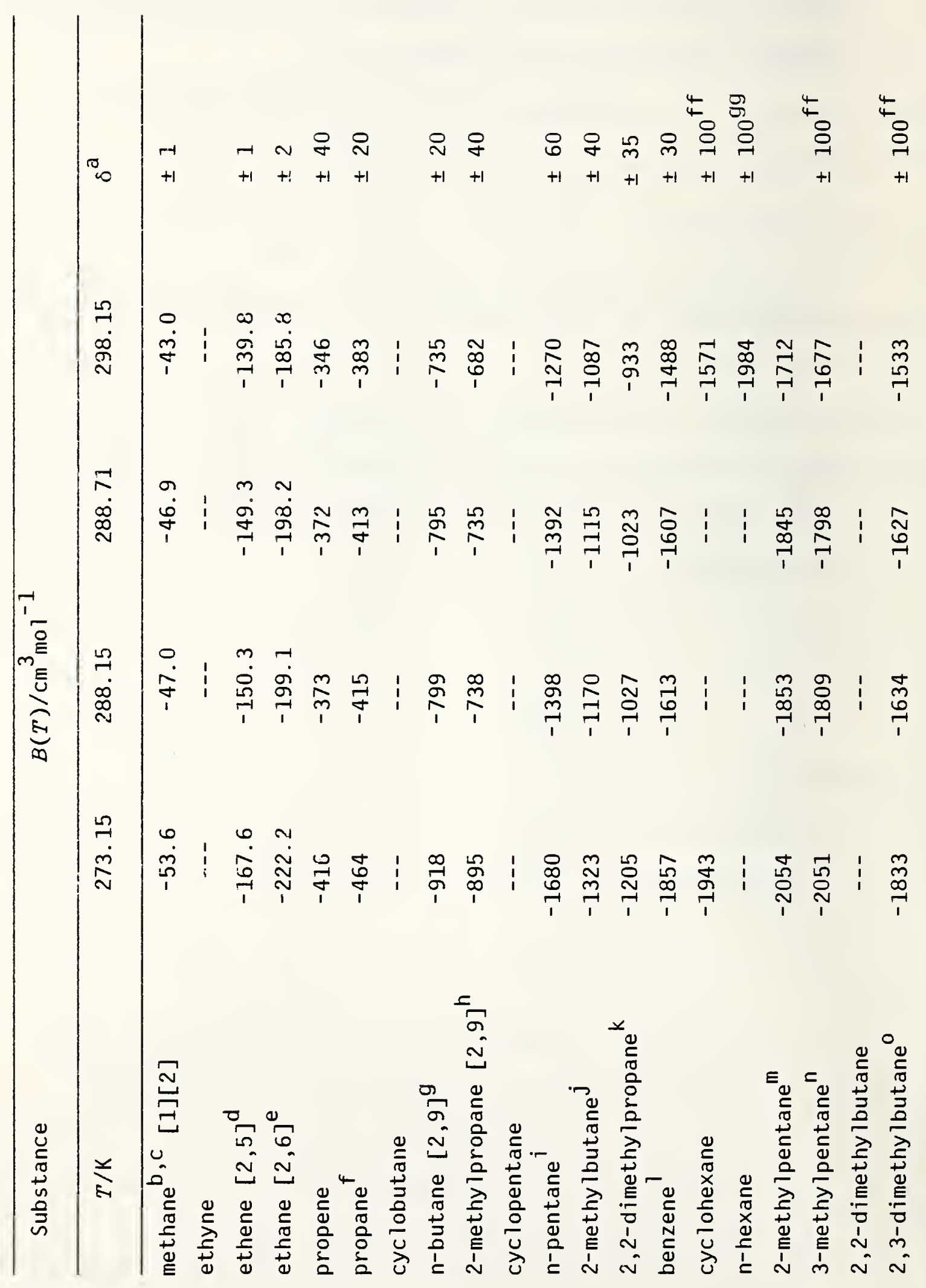




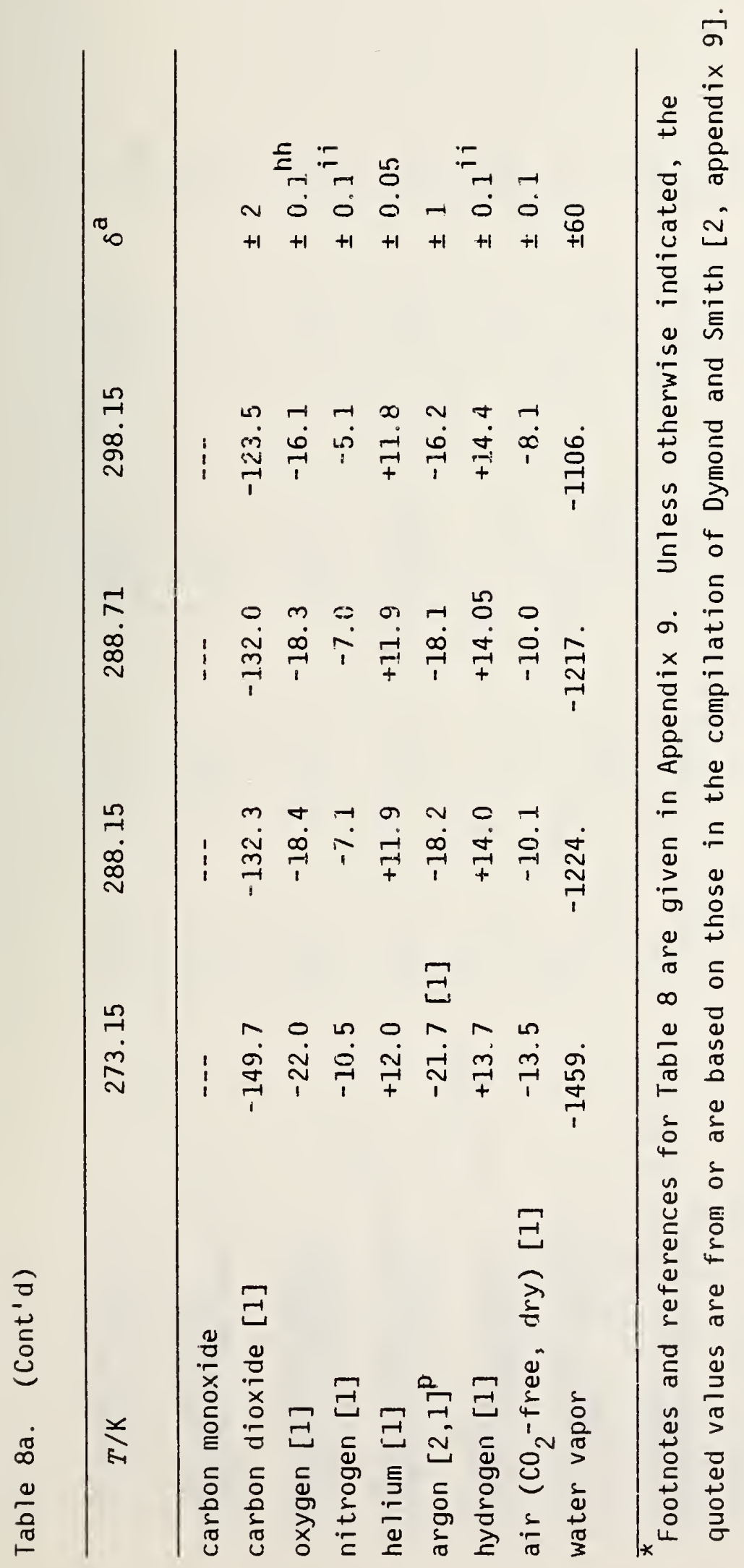




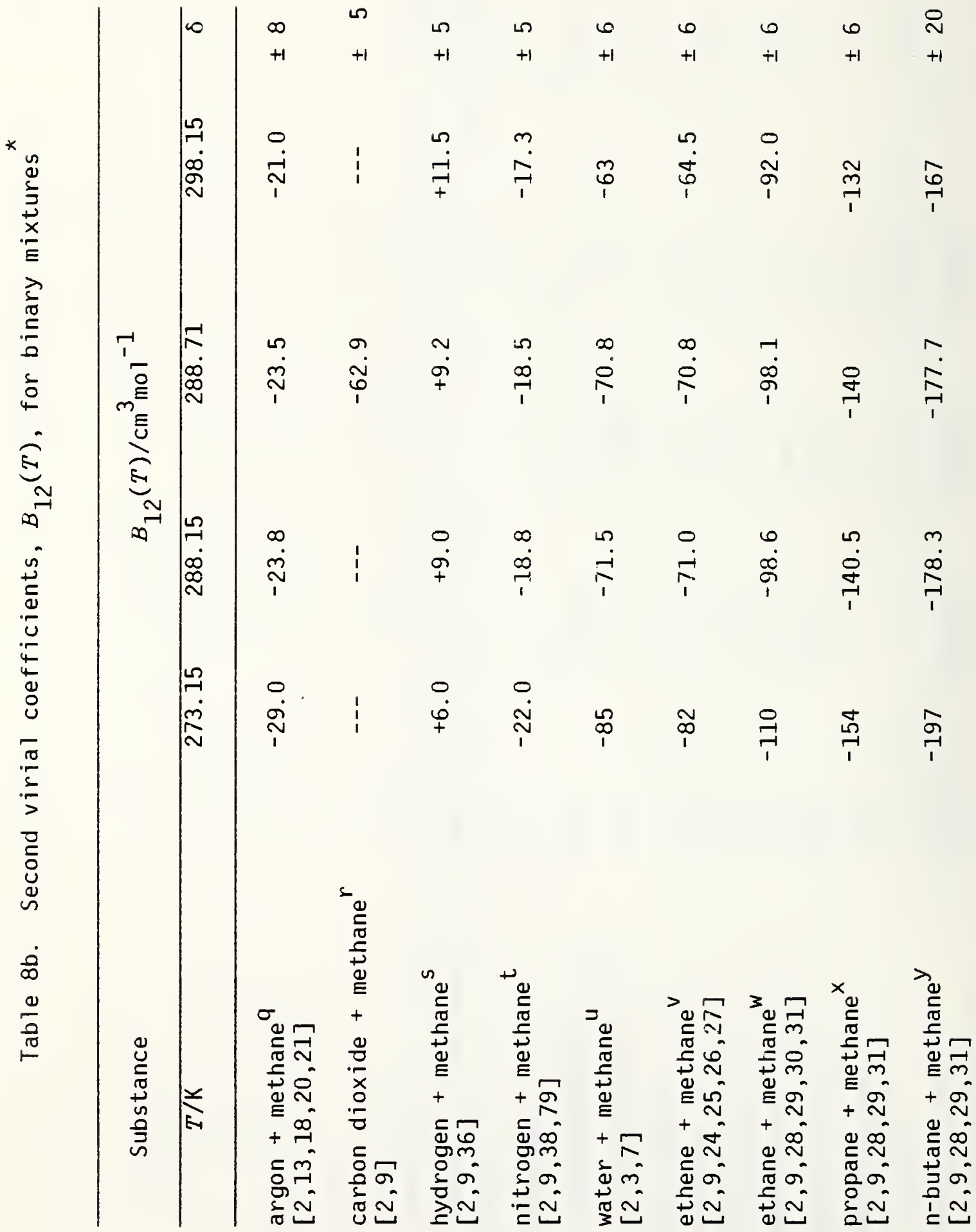




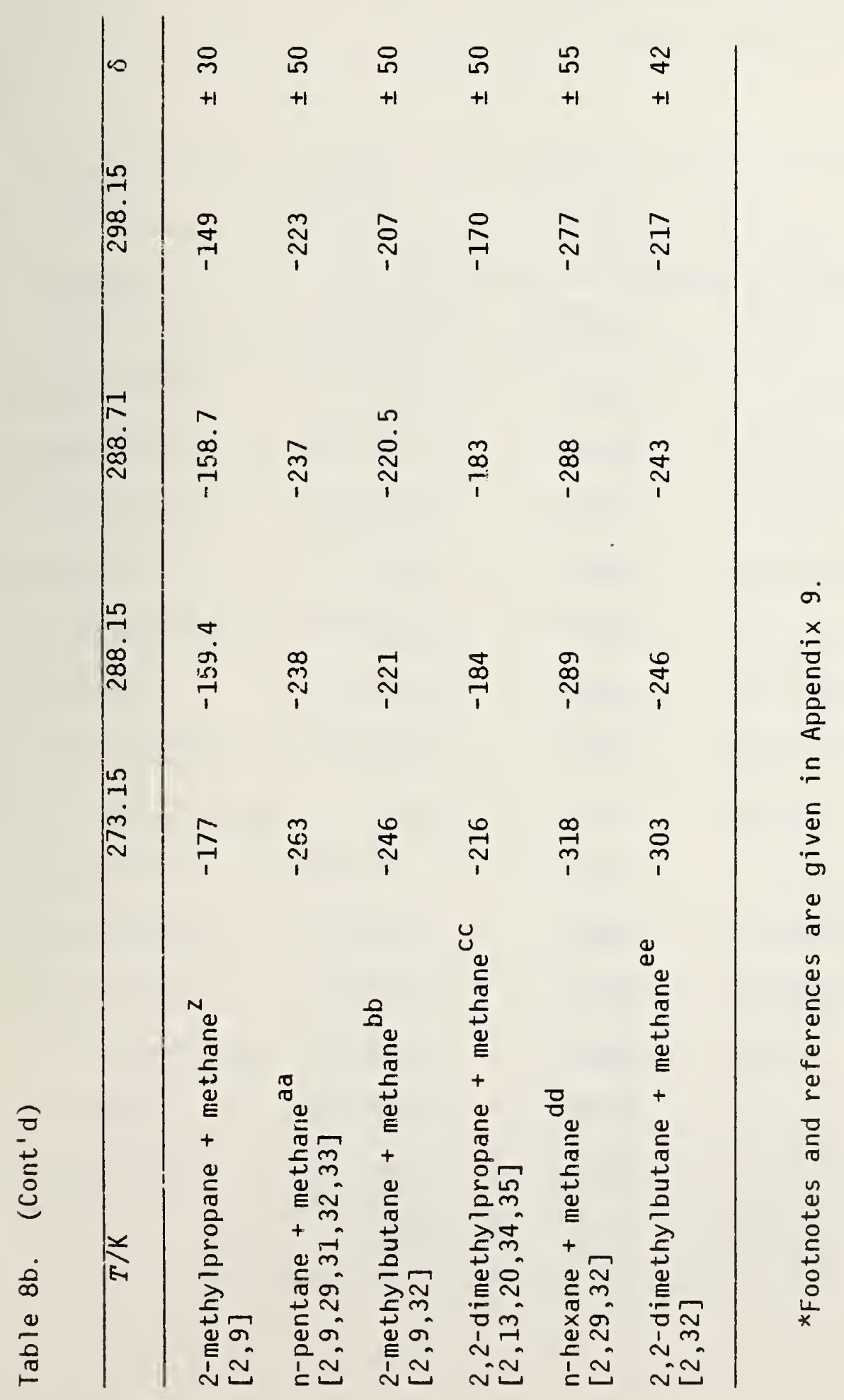


Table 9. Enthalpy of combustion of the real-gas hydrocarbons on molar, mass, and volume bases; in SI units and at ISO/ANSI/ASTM metric reference condition

$$
P=101.325 \mathrm{kPa} ; T=288.15 \mathrm{~K}
$$

\begin{tabular}{|c|c|c|c|}
\hline Substance & $\frac{{ }^{-\Delta_{C} H}}{\mathrm{~kJ} \mathrm{~mol}^{-1}}$ & $\frac{{ }^{-\Delta} c^{H}}{M J ~ k g^{-1}}$ & $\frac{-\Delta c^{-} H}{M J m^{-3}}$ \\
\hline methane & 891.25 & 55.5537 & 37.7688 \\
\hline ethane & 1561.3 & 51.922 & 66.597 \\
\hline propane & 2221.8 & 50.384 & 95.675 \\
\hline n-butane & 2879.4 & 49.540 & 126.197 \\
\hline 2-methylpropane & 2870.9 & 49.394 & 125.468 \\
\hline n-pentane & 3538.1 & 49.038 & 159.726 \\
\hline 2-methylbutane & 3531.5 & 48.946 & 157.583 \\
\hline 2,2-dimethlypropane & 3517.1 & 48.748 & 155.848 \\
\hline n-hexane & --- & -- & -- \\
\hline 2-methylpentane & 4190.4 & 48.626 & 193.840 \\
\hline 3-methylpentane & 4193.1 & 48.657 & 193.475 \\
\hline 2,3 -dimethylbutane & 4187.1 & 48.588 & 191.375 \\
\hline ethene & 1411.9 & 50.328 & 60.0977 \\
\hline propene & 2059.8 & 48.949 & 88.4289 \\
\hline benzene & 3302.5 & 42.278 & 150.785 \\
\hline
\end{tabular}


Table 10. Enthalpy of combustion of the real-gas hydrocarbons on molar, mass, and volume bases; in U.S. Customary units and at ANSI/ASTM/API reference conditions

$$
\begin{gathered}
p=101.560 \mathrm{kPa} ; T=288.71 \mathrm{~K} \\
\left(p=14.73 \mathrm{psia} ; T=60^{\circ} \mathrm{F}\right)
\end{gathered}
$$

\begin{tabular}{|c|c|c|c|c|}
\hline Substance & $\frac{{ }^{-\Delta_{c}{ }^{H}}}{\mathrm{Btu}_{\mathrm{IT}} \mathrm{T}^{\mathrm{mol}}{ }^{-1}}$ & $\frac{{ }^{-\Delta} c^{H}}{B^{H t u_{I T}}{ }^{1 b^{-1}}}$ & $\frac{{ }^{-\Delta} c^{H} v}{M J m^{-3}}$ & $\frac{{ }^{-\Delta_{c} H_{v}}}{\text { Btu } f t^{-3}}$ \\
\hline methane & 844.69 & 23882.4 & 37.7804 & 1014.00 \\
\hline ethane & 1479.7 & 22321 & 66.6159 & 1787.92 \\
\hline propane & 2105.7 & 21660 & 95.6987 & 2568.48 \\
\hline n-butane & 2729.0 & 21298 & 126.218 & 3387.59 \\
\hline 2-methylpropane & 2721.0 & 21235 & 125.488 & 3367.99 \\
\hline$n$-pentane & 3353.3 & 21082 & 159.714 & 4286.59 \\
\hline 2-methylbutane & 3347.0 & 21042 & 157.598 & 4229.81 \\
\hline 2,2-dimethiypropane & 3333.4 & 20957 & 155.858 & 4183.11 \\
\hline n-hexane & --- & --- & --- & --- \\
\hline 2-methylpentane & 3971.6 & 20905 & 193.828 & 5202.19 \\
\hline 3-methylpentane & 3974.2 & 20918 & 193.458 & 5192.28 \\
\hline 2,3-dimethylbutane & 3968.5 & 20888 & 191.378 & 5136.44 \\
\hline ethylene & 1338.2 & 21637 & 60.1167 & 1613.49 \\
\hline propene & 1925.3 & 21043 & 87.2863 & 2342.62 \\
\hline benzene & 3130.1 & 18176 & 150.776 & 4046.72 \\
\hline
\end{tabular}


11. Volumetric enthalpy of combustion of the real gas

The molar volume of the real gas and the volumetric enthalpy of combustion at ISO/ANSI/ASTM metric reference conditions $(p=101.325 \mathrm{kPa} ; T=$ 288. $15 \mathrm{~K}$ ) are given in Table 11. An estimate of the fractional uncertainty of the molar volume is also given. The uncertainty of the molar volume determines the uncertainty in the volumetric enthalpy of combustion.

The molar volume of the real gas and the volumetric enthalpy of combustion at ANSI/ASTM/API U.S. Customary reference conditions are given in Table 12. An estimate of the uncertainty of the molar volume is also given. This factor also gives the approximate contribution of the uncertainty in the volumetric enthalpy of combustion. The molar volume is given both in cubic metres and cubic feet, and the enthalpy of combustion is given in both megajoules per cubic metre and in British thermal units per cubic foot.

The calculation of the real gas molar volume is based on the equation:

$$
p V_{\mathrm{m}} / R T=1+B(T) / V_{\mathrm{m}}
$$

for which values of $B(T)$ are taken from Table 8a. This calculation will be $i$ llustrated for methane for the conditions $p=101.325 \mathrm{kPa} ; T=299.15$ K. From Table $8 \mathrm{a}, B(288.15 \mathrm{~K})=-(47.0 \pm 1) \mathrm{cm}^{3} \mathrm{~mol}^{-1}$ for methane. The exact quadratic solution of this equation is:

$$
V_{\mathrm{m}} / V_{\mathrm{m}}^{\mathrm{id}}=\frac{1}{2}+\frac{1}{2}\left(1+4 B / V_{\mathrm{m}}^{\mathrm{id}}\right)^{1 / 2},
$$

where $V_{\mathrm{m}}^{\mathrm{id}}$, the ideal gas volume is $R T / P$,

$$
\begin{aligned}
V_{m}^{i d} & =(8.31441 \times 288.15 / 101325) \\
& =0.02364468 \mathrm{~m}^{3} \mathrm{~mol}^{-1}
\end{aligned}
$$

or may be obtained from Table 5. To make $V_{m}^{i d}$ commensurate with $B, V_{m}^{i d}$ is converted to $23644.7 \mathrm{~cm}^{3} \mathrm{~mol}^{-1}$. Substitution of these values gives: 


$$
\begin{aligned}
V_{\mathrm{m}} / 23644.7 \mathrm{~cm}^{3} \mathrm{~mol}^{-1} & =\frac{1}{2}+\frac{1}{2}(1-4 \times 47.0 / 23644.7)^{1 / 2} \\
& =\frac{1}{2}+\frac{1}{2}(0.992049)^{1 / 2} \\
& =0.9980083 \\
V_{\mathrm{m}}= & 23644.7 \mathrm{~cm}^{3} \mathrm{~mol}^{-1} \times 0.998008=23597.6 \mathrm{~cm}^{3} \mathrm{~mol}^{-1} \\
V_{\mathrm{m}}= & 10^{-6} \mathrm{~m}^{3} \mathrm{~cm}^{-3} \times 23597.6 \mathrm{~cm}^{3} \mathrm{~mol}^{-1}, \\
= & 0.023598 \mathrm{~m}^{3} \mathrm{~mol}^{-1},
\end{aligned}
$$

in conformity with the value in Table 11.

The volumetric enthalpy of combustion of the real gas is obtained from the molar enthalpy of combustion of the real gas at the same reference conditions (Tables 9 and 10) using the following relationstip:

$$
\Delta_{\mathrm{c}} H / \mathrm{MJ} \mathrm{m}^{-3}=0.001\left(\Delta_{\mathrm{c}} H / \mathrm{kJ} \mathrm{mol}^{-1}\right) /\left(V_{\mathrm{m}} / \mathrm{m}^{3} \mathrm{~mol}^{-1}\right)
$$

This may be illustrated for methane for which $\Delta_{\mathrm{C}} \mathrm{H} / \mathrm{kJ} \mathrm{mol} \mathrm{l}^{-1}=-891.248$ (from Tables 4 and 9) and $V_{\mathrm{m}} / \mathrm{m}^{3} \mathrm{~mol}^{-1}=0.0235976$ (from Table 1i). The value of:

$$
\begin{aligned}
\Delta_{\mathrm{C}} \mathrm{H} / \mathrm{MJ} \mathrm{m}^{-3} & =-891.248 / 0.0235976, \\
& =-37768.6 \mathrm{~kJ} \mathrm{~m}^{-3}, \\
& =-37.769 \mathrm{MJ} \mathrm{m}^{-3} .
\end{aligned}
$$

in conformity with Table 9.

The volumetric enthalpy of combustion in Btu $\mathrm{ft}^{-3}$ in Table 10 is obtained from the volumetric enthalpy of combustion in $M J \mathrm{~m}^{-3}$ in Table 12 using the units Btu $I T$ and foot defined exactly in Table A4 in terms of the joule and the metre.

The molar volumes have an ascribed uncertainty because of the uncertainty in the virial coefficients. This uncertainty is significant, particularly in the cases of the higher hydrocarbons. The uncertainty in the molar volume may be calculated by differentiating equation (11.2) to obtain the relative error: 


$$
\delta V_{\mathrm{m}} / V_{\mathrm{m}}^{i \mathrm{~d}}=\left(\delta B / V_{\mathrm{m}}^{i \mathrm{~d}}\right) /\left(1+4 B / V_{\mathrm{m}}^{i \mathrm{~d}}\right)^{0.5}
$$

and substituting $\delta B$ from Table $8 a$ (last column). Taking the value $1 \mathrm{~cm}^{3}$ $\mathrm{mol}^{-1}\left(=10^{-6} \mathrm{~m}^{3} \mathrm{~mol}^{-1}\right)$ for methane from Table $8 \mathrm{a}$, we calculate

$$
\begin{aligned}
\delta V_{\mathrm{m}} / V_{\mathrm{m}}^{i d} & =(1 / 23645) /(1+4 \cdot(-47) / 23645)^{0.5} \\
& =3.79 \times 10^{-5} / 0.992 \\
& =3.8 \times 10^{-5}
\end{aligned}
$$


Table 11. Enthalpy correction to the real gas and molar volume, $V_{m}$, at ISO/ANSI/ASTM metric reference conditions

$$
\begin{gathered}
p=101.325 \mathrm{kPa} ; T=288.15 \mathrm{~K} \\
V_{\mathrm{m}}^{i d}=0.023544 .7
\end{gathered}
$$

\begin{tabular}{|c|c|c|c|}
\hline Substance & $\frac{\Delta_{c} H-\Delta_{c} H^{\circ}}{\mathrm{J} \mathrm{mol}^{-1}}$ & $\frac{v_{m}}{m^{3} m o l^{-1}}$ & $\delta V_{\mathrm{m}} / V_{\mathrm{m}}^{\mathrm{a}}$ \\
\hline methane & -8.3 & 0.0235976 & $4 \times 10^{-5}$ \\
\hline ethane & 7.0 & 0.0234439 & $8 \times 10^{-5}$ \\
\hline propane & 54.5 & 0.0232222 & $8.6 \times 10^{-4}$ \\
\hline n-butane & 154.9 & 0.0228167 & $8.6 \times 10^{-4}$ \\
\hline 2-methylpropane & 191.9 & 0.0228815 & $1.8 \times 10^{-3}$ \\
\hline n-pentane & 482.3 & 0.0221511 & $2.7 \times 10^{-3}$ \\
\hline 2-methylbutane & 260.1 & 0.0224102 & $1.8 \times 10^{-3}$ \\
\hline 2,2-dimethy 7 propane & 284.3 & 0.0225677 & $1.5 \times 10^{-3}$ \\
\hline n-hexane & --- & $\cdots$ & --- \\
\hline 2-methy 7 pentane & 473.6 & 0.0216181 & $9.2 \times 10^{-4}$ \\
\hline 3-methylpentane & 482.6 & 0.0216727 & --- \\
\hline 2,3-dimethy 1 butane & 363.6 & 0.0218792 & --- \\
\hline ethene & -12.0 & 0.0234936 & $4 \times 10^{-5}$ \\
\hline propene & 32.1 & 0.0232935 & --- \\
\hline benzene & 428.0 & 0.0219024 & $1.4 \times 10^{-3}$ \\
\hline
\end{tabular}

${ }^{\text {a }}$ Relative error in the real-gas molar volume. 
Table 12. Enthalpy correction to the real gas and molar volume, $V_{m}$, at ANSI/ASTM/API U.S. Customary reference conditions

$$
\begin{gathered}
P=101.560 \mathrm{kPa} ; T=288.71 \mathrm{~K} \\
\left(V_{i d}=0.0236354 \mathrm{~m}^{3} \mathrm{~mol}^{-1} ; 1 \mathrm{ft}^{3}=0.028316847 \mathrm{~m}^{3}\right)
\end{gathered}
$$

\begin{tabular}{|c|c|c|c|c|}
\hline \multirow{2}{*}{ Substance } & \multirow{2}{*}{$\frac{\Delta_{c} H-\Delta_{c} H^{\sigma}}{\mathrm{J} \mathrm{mol}^{-1}}$} & $V_{\mathrm{m}}$ & \multirow{2}{*}{$\frac{V_{m}}{f t^{3}}$} & \multirow[t]{2}{*}{$\delta V_{\mathrm{m}} / V_{\mathrm{m}}$} \\
\hline & & $\mathrm{m}^{3} \mathrm{~mol}^{-1}$ & & \\
\hline methane & -8.0 & 0.0235889 & 0.833034 & $4 \times 10^{-5}$ \\
\hline ethane & 7.4 & 0.0234359 & 0.827631 & $8 \times 10^{-5}$ \\
\hline propane & 55.2 & 0.0232152 & 0.819837 & $8.6 \times 10^{-4}$ \\
\hline n-butane & 181.7 & 0.0228121 & 0.805602 & $8.6 \times 10^{-3}$ \\
\hline 2-methylpropane & 186.7 & 0.0228770 & 0.807894 & $1.8 \times 10^{-3}$ \\
\hline n-pentane & 476.3 & 0.0221519 & 0.782287 & $2.7 \times 10^{-3}$ \\
\hline 2-methlybutane & 261.3 & 0.0224069 & 0.791292 & $1.8 \times 10^{-3}$ \\
\hline $\begin{array}{l}\text { 2,2-dimethyi- } \\
\text { propane }\end{array}$ & 285.3 & 0.0225652 & 0.796883 & $1.5 \times 10^{-3}$ \\
\hline$n$-hexane & -- & --- & -- & --- \\
\hline 2-methylpentane & 476.9 & 0.0216185 & 0.763450 & $9.2 \times 10^{-4}$ \\
\hline 3-methy 1 pentane & 480.9 & 0.0216737 & 0.765399 & -- \\
\hline $\begin{array}{l}2,3 \text {-dimethyl- } \\
\text { butane }\end{array}$ & 361.9 & 0.0218778 & 0.772607 & --- \\
\hline ethene & -11.7 & 0.0234854 & 0.829379 & $4 \times 10^{-5}$ \\
\hline propene & 33.0 & 0.0235982 & 0.833362 & --- \\
\hline benzene & 425.5 & 0.0219026 & 0.773483 & $1.4 \times 10^{-3}$ \\
\hline
\end{tabular}


12. Calculating the heating values of gas mixtures

The heating value of any fuel gas mixture can be calculated from the molecular composition of the gas and information about the heating values and volumetric behavior of the individual components. It is impractical to calculate heating values for all probable compositions and so the information presented here is limited to procedures for making the calculations.

Composition. It is essential that the composition of the gas be known in order to use these procedures. The composition values must be identifiable as mole fraction or mass fraction of each component and these fractions must account for all of the gas.

The most useful description of the composition is the mole fraction, $x$, and most of the procedures described here are based on this parameter. The mole fraction of component $i$ is $x(i)$, where $i$ has the values 1 to $n$, and $n$ is the total number of components. It is necessary that:

$$
x(1)+x(2)+\ldots+x(n)=1 \text {. }
$$

Methods of analysis based upon calibration with mixtures of known composition give results in the same terms as the calibration sample. Therefore the meaning of the composition of the calibration sample should be unambiguous if the results of analyses are to be used for the calculation of heating value. Volumetric analyses of gases, give volume fractions of the components that approximate the mole fractions. It should be realized however that volumes of gases are not precisely additive when the gases are mixed, and so voiume fraction is somewhat ambiguous. Masses are additive and amounts of substance (moles) are additive and so compositions of gases stated as mass fraction or mole fraction are unambiguous. 
Three procedures for calculating heating value based on information in this document will be described:

(1) The heating value of an ideal gas mixture.

(2) The heating value of a reäl gas mixture, neglecting molecular interactions between different substances.

(3) The heating values of real gas mixtures including molecular interactions between different substances. 
12. 1 Heating value of an ideal gas mixture

The composition of the gas mixture in terms of the mole fractions $x(i)$ of the individual substances present is presumed to be given, and the sum of the $x(i)$ is unity (equation 12.1).

The erithalpy of combustion of the ideal gas mixture is calculated by adding the molar enthalpies of combustion of the individual components weighted according to their mole fractions using the equation:

$\Delta_{c} H_{m}^{\circ}($ mixture $)=x(1) \Delta_{c} H_{m}^{\circ}(1)+x(2) \Delta_{c} H_{m}^{\circ}(2)+\ldots+x(n) \Delta_{c} H_{m}^{\circ}(n),(12.2)$

where $\Delta_{\mathrm{c}} H_{\mathrm{m}}^{\circ}$ is the enthalpy of combustion per mole, of the ideal gas. The enthaipies of combustion are taken from Table 4 b. By summation of terms as illustrated in Table 13 for a typical gas, the ideal-gas heating value is calculated.

For the example, the value found by this procedure is $\Delta_{\mathrm{c}} H_{\mathrm{m}}^{\circ}$ (mixture) $=$ $-922.01 \mathrm{~kJ} \mathrm{~mol}^{-1}$. Using the appropriate molar volume from Table 5 , this can be converted as shown in Table 13 to $\Delta_{C} H_{v}^{\circ}=-38.994 \mathrm{MJ} \mathrm{m}^{-3}$ or $=-1046.6$ Btu $\mathrm{ft}^{-3}$, where $\Delta_{\mathrm{c}} H_{\mathrm{v}}^{\circ}$ is the enthalpy of combustion of unit volume of the gas mixture (dry).

For ideal gases the volume fractions are proportional to the mole fractions, and so an alternative approach may be used. Heating value per unit volume $\Delta_{\tau} H_{V}^{\circ}$ can be taken from Table 6 , and the same form of equation can be used.

$\Delta_{C} H_{V}^{\circ}($ mixture $)=x(1) \Delta_{C} H_{V}^{\circ}(1)+x(2) \Delta_{C} H_{V}^{\circ}(2)+\ldots+x(n) \Delta_{C} H_{V}^{\circ}(n)$

As shown in Table 13 these data lead to the same result.

For U.S. Customary reference conditions, Table $4 b$ and Table 5, or Table 7 , may be used in the same way using either alternative approach. 
Table 13. Sample calculation of enthalpy of combustion of

a gaseous mixture assuming ideal gas behavior

$$
\begin{gathered}
(p=101.325 \mathrm{kPa} ; T=288.15 \mathrm{~K}) \\
\left(V_{\mathrm{m}}=0.0236447 \mathrm{~m}^{3} \mathrm{~mol}^{-1}\right)
\end{gathered}
$$

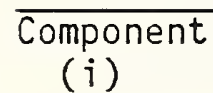

$$
M(i)^{a} \times(i)^{a} \frac{{ }^{-}{ }_{c} H_{m}^{o}(i)}{k J m o l^{-1}} \quad \frac{-x(i) \Delta_{c} H_{m}^{o}(i)}{k J m o l^{-1}} \quad \frac{{ }^{-\Delta_{c} H_{v}^{o}(i)}}{M J m^{-3}}
$$

$\frac{-x(i) \Delta c_{v} H_{v}^{\circ}(i)}{M J m^{-3}}$

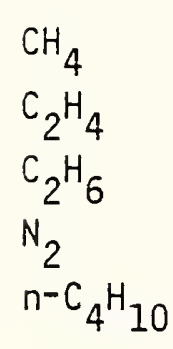

Sums $\begin{array}{lll}16.043 & 0.9000 \quad 891.24\end{array}$

28.054

0.0037

1411.90

802.116

5.224

85.871

0.0

28.01340 .0313

$58.123 \quad \underline{0.0100}$

1.0000
1561. 29

$0.0^{b}$

2879.61
37.693

33.9237

59.713

0.2209

66.032

3.6318

0.0

0.0

121.787

1.2179

$$
\begin{aligned}
-\Delta_{C} H_{\mathrm{m}}^{\circ} \text { (mixture) } & =922.007 \mathrm{~kJ} \mathrm{~mol}^{-1} \\
& \div 0.0236447 \mathrm{~m}^{3} \mathrm{~mol}^{-1}=38994.2 \mathrm{~kJ} \mathrm{~m}^{-3} \\
-\Delta_{C^{2} H^{\circ}} \text { (mixture) } & =38994.2 \mathrm{~kJ} \mathrm{~m}^{-3} \cdot 26.839192\left(\mathrm{Btu} / \mathrm{ft}^{3}\right) /\left(\mathrm{MJ} \mathrm{m}^{-3}\right) \\
& =1046.6 \mathrm{Btu} \mathrm{ft}^{-3}
\end{aligned}
$$

a $M(i)$ is molecular weight and $x(i)$ is mole fraction.

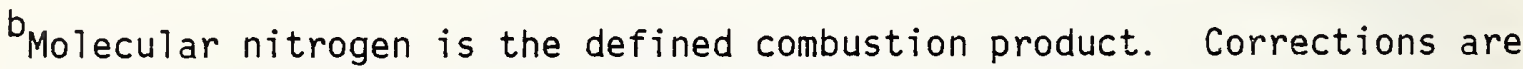
made for nitrogen oxides in the calorimetric experiments. 
12.2 Heating value of a real gas mixture, neglecting interactions between different substances

The composition of the gas mixture in terms of the mole fractions $x(i)$ of the individual substances present or in terms of the mass fractions $w(i)$ of the individual substances present is presumed to be known and $\Sigma x(i)$ is unity (equation 12.1) or $\Sigma w(i)$ is unity (equation 12.4).

$$
w(1)+w(2)+\ldots+w(n)=1
$$

The enthalpy of combustion of the real gas mixture on a molar basis, $\Delta_{\mathrm{c}} H_{\mathrm{m}}$ (mixture) is calculated by the equation:

$\Delta_{c} H_{m}(m i x t u r e)=x(1) \Delta_{c} H_{m}(1)+x(2) \Delta_{c} H_{m}(2)+\ldots+x(n) \Delta_{c} H_{m}(n)$.

Similarly the enthalpy of combustion of the real gas mixture on a mass basis, $\Delta_{C} H_{w}$ (mixture) is calculated by the equation:

$\Delta_{C} H_{w}($ mixture $)=w(1) \Delta_{C} H_{w}(1)+w(2) \Delta_{C} H_{w}(2)+\ldots+w(n) \Delta_{C} H_{w}(n)$.

Values for $\Delta_{c} H_{m}(i)$ or $\Delta_{c} H_{w}$ (i) are obtained from Table 9 for ISO/ANSI/ASTM metric reference conditions and from Table 10 for ANSI/ASTM/API U.S. Customary reference conditions.

The enthalpy of combustion of the real gas mixture on a volumetric basis, $-\Delta_{C} H_{v}$ (mixture), is obtained from $-\Delta_{c} H_{m}$ (mixture) using the relationship

$$
-\Delta_{c} H_{v} \text { (mixture) }=-\Delta_{c} H_{m} \text { (mixture) } / V_{m} \text { (mixture). }
$$

The value for $-\Delta_{C} H_{v}$ (mixture) to use in equation (12-7) is obtained from equation (12-5). The value of $V_{m}$ (mixture) is obtained from equation $(12-8)$

$$
V_{m}(\text { mixture })=x(1) V_{m}(1)+x(2) V_{m}(2)+\ldots+x(n) V_{m}(n)
$$


This equation assumes that volumes of real gases are additive in mixtures. These calculations for a simple mixture are illustrated in Table 14. 
Table 14. Sample calculation of enthalpy of combustion of a real-gas mixture assuming no interactions between different substances

$$
(p=101.325 \mathrm{kPa} ; T=288.15 \mathrm{~K})
$$

Component

(i)

$M(i) \quad x(i)$

$\frac{-\Delta_{C} H_{m}(i)}{k J m o l^{-1}} \frac{-x(i) \Delta_{C} H_{m}(i)}{k J \mathrm{~mol}^{-1}} \frac{x(i) V_{m}(i)}{\mathrm{dm}^{3} \mathrm{~mol}^{-1}}$

(Table 11) (Table 9)

\begin{tabular}{lcccccc}
\hline $\mathrm{CH}_{4}$ & 16.043 & 0.9000 & 23.5976 & 891.25 & 802.125 & 21.2378 \\
$\mathrm{C}_{2} \mathrm{H}_{4}$ & 28.054 & 0.0037 & 23.4936 & 1411.9 & 5.224 & 0.0869 \\
$\mathrm{C}_{2} \mathrm{H}_{6}$ & 30.070 & 0.0550 & 23.4439 & 1561.3 & 85.872 & 1.2834 \\
$\mathrm{~N}_{2}$ & 28.0134 & 0.0313 & 23.6376 & $0.0 \mathrm{a}$ & 0.0 & 0.7389 \\
$\mathrm{n}_{4} \mathrm{C}_{4} \mathrm{H}_{10}$ & 58.123 & $\underline{0.0100}$ & 22.8167 & 2879.4 & $\underline{28.794}$ & $\underline{0.2282}$ \\
& & & 1.0000 & & $-\Delta_{\mathrm{C}} H_{\mathrm{m}}=922.015 \quad V_{\mathrm{m}}=23.5821$
\end{tabular}

$$
\begin{aligned}
-\Delta_{C} H_{v} \text { (mixture) } & =-\Delta_{c} H_{\mathrm{m}} \text { (mixture) } / V_{\mathrm{m}} \text { (mixture) } \\
& =0.922015 / 0.0235821 \\
& =39.098 \mathrm{MJ} \mathrm{m}^{-3}
\end{aligned}
$$

This is greater than $-\Delta_{C} H_{v}^{\circ}$ (mixture) (38.994 MJ m $\mathrm{m}^{-3}$ from Table 13) on the assumption of ideal-gas behavior by a factor of 1.0027 , or different by 2.7 parts in 1000 .

${ }^{a}$ See note $b$, Table 13 . 
12.3 Heating value of a real gas mixture including molecular interactions between different substances

The composition of the gas mixture in terms of the mole fractions $x(i)$ of the individal substances present, or in terms of the mass fractions $w(i)$ of the individual substances present, is presumed to be known, and $\Sigma x(i)$ is unity (equation 12.1) or $\Sigma w(i)$ is unity (equation 12.4).

The calculation of the heating value involves five steps: (1) the calculation of the ideal gas molar heating value of the mixture using equation (12.2); (2) the calculation of the virial coefficient of the gas mixture and its temperature derivative using equations taken from Appendix 9; (3) calculation of the molar volume of the real gas mixture based upon the virial coefficient of the gas mixture from Step 2; (4) adjustment of the molar heating value for the term $H-H^{\circ}$ based on the virial coefficient of the gas mixture and its derivative; (5) calculation of the heating value on a mass basis and the volumetric heating value of the real gas mixture. The molar heating value $\Delta_{c} H_{m}$ (mixture) can be converted to the heating value on a mass basis $\Delta_{c} H_{w}$ (mixture) by use of the mass fractions of the substances in the gas. From the molar volume calculated in step 3 , the molar enthalpy of combustion can be converted to the volumetric enthalpy of combustion, $\Delta_{C} H_{V}$ (mixture).

This calculation procedure is considered to be the most accurate of those presented. It is applicable to both dry and humid gases, including the water-saturated gas.

Step 1. Calculation of heating value of the ideal gas mixture. This step is carried out as described in Section 12.1 and illustrated in Table 13. 
Step 2. Calculation of the second virial coefficient $B$ (mixture) of the real gas mixture, and its derivative $\mathrm{d} B / \mathrm{d} T$. As described in Appendix 9 , the second virial coefficient $B$ (mixture) is a function of $T$ and of the virial coefficients of the components and of the virial coefficiants of the binary mixtures of the components. From Appendix 9 we use the simplified equation (12.9) for which data are given in Tabies 8 a and 8 b.

$$
\begin{aligned}
& B(\text { mixture })=[x(1)]^{2} B(1)+[x(2)]^{2} B(2)+\ldots+[x(n)]^{2} B(n) \\
& +2 x(1) x(2) B(1,2)+2 x(1) x(3) B(1,3)+\ldots 2 x(1) x(n) B(1, n)
\end{aligned}
$$

Component 1 is taken to be methane in every case (See Appendix 8). This equation is applicable only to natural gas containing methane as the major component. For other gases See Appendix 9.

Using values of $x(i)$ from Step 1 , values of $B(i)$ from Table $8 a$ and values of $B(1, i)$ from Table $8 b$, calculate $B$ (mixture) using equation (12.9). The values of $B(i)$ and $B(1, i)$ must be those for the temperature at which the heating value is desired. For calculations at temperatures other than those listed in Table 2, see the procedures described in Section 10 and Appendix 9. Calculate $d B$ (mixture)/dT using equation $(12-10)$

$$
\begin{aligned}
\mathrm{d} B(\text { mixture }) / \mathrm{d} T= & {[x(1)]^{2}[\mathrm{~d} B(1) / \mathrm{d} T]+[\mathrm{x}(2)]^{2}[\mathrm{~d} B(2) / \mathrm{d} T] } \\
& +\ldots+[\mathrm{x}(n)]^{2}[\mathrm{~d} B(n) / \mathrm{d} T] \\
& +2 x(1) x(2)[\mathrm{d} B(1,2) / \mathrm{d} T]+2 x(1) x(3)[\mathrm{d} B(1,3) / \mathrm{d} T] \\
& +\ldots+2 x(1) x(n)[\mathrm{d} B(1, n) / \mathrm{d} T] .
\end{aligned}
$$

For equation (12.10) obtain values of $\mathrm{d} B(i) / \mathrm{d} T$ and $\mathrm{d} B(1, i) / \mathrm{d} T$ at the desired temperature from Table A9b in the appendix. The calculation of 
$\mathrm{d} B$ (mixture)/dT may be omitted if step 4 , calculation of the value $H-H^{\circ}$, is omitted.

Step 3. Calculate $V_{\mathrm{m}}$ (mixture) for the gas mixture using equation (12.11).

$$
V_{m}(\text { mixture }) / V_{m}(\text { idea } 1)=\frac{1}{2}+\frac{1}{2}\left[1+4 B(\text { mixture }) / V_{m}^{i d}\right]^{1 / 2}
$$

where $V_{\mathrm{m}}^{\text {id }}$ may be taken from Table 5 or may be calculated as $V_{\mathrm{m}}^{\text {id }}=R T / p$, and $B$ (mixture) is obtained from equation (12.9).

Step 4. Correct to the real gas by calculating $H-H^{\circ}$ for the gas mixture using equation (12.12)

$$
H-H^{\circ}=\left(R T / V_{\mathrm{m}}\right)[B-T(\mathrm{~d} B / \mathrm{d} T)]
$$

For this equation use $B$ (mixture) and $d B$ (mixture)/dT from step $2, V_{m}$ (mixture) from step 3 and $T$, the selected temperature for which the heating value is required. Caiculate $\Delta_{\mathrm{c}} H_{\mathrm{m}}-\Delta_{\mathrm{c}} H_{\mathrm{m}}^{\circ}$ as described in Section 10 . In order to do this, calcuiate the equivalent molecular formula of the gas mixture $C_{a} H_{b}$ to be used in the equation:

$$
\mathrm{C}_{a} \mathrm{H}_{b}+(\mathrm{a}+\mathrm{b} / 4) \mathrm{O}_{2}(\mathrm{~g})=\mathrm{a} \mathrm{CO}_{2}(\mathrm{~g})+(\mathrm{b} / 2) \mathrm{H}_{2} \mathrm{O}(1) \text {. }
$$

Step 4 and the required calculation of $\mathrm{d} B$ (mixture)/d$T$ can be omitted with errors not exceeding an estimated $50 \mathrm{~J} \mathrm{~mol}^{-1}$.

Step 5. Calculate $\Delta_{c} H_{m}$ (mixture), and $\Delta_{c} H_{v}$ (mixture) using equations (12.13) and (12.14) 


$$
\begin{aligned}
& \Delta_{c} H_{m} \text { (mixture) }=\Delta_{c} H_{m}^{\circ}(\text { mixture })+\left(\Delta_{c} H_{m}-\Delta_{c} H_{m}^{\circ}\right) \text { (mixture) } \\
& \text { Step } 1 \quad \text { Step } 4
\end{aligned}
$$

$$
\begin{aligned}
& \Delta_{C} H_{v} \text { (mixture) }=\Delta_{c} H_{m} \text { (mixture) } / V_{m} \text { (mixture) } \\
& \text { Step } 5 \quad \text { step } 3
\end{aligned}
$$

(or alternatively obtain $\Delta_{c} H_{m}^{\circ}$ (mixture)/V ${ }_{m}$ (mixture) as described in step 4). 


\section{Uncertainties}

The following sources of uncertainty are considered in this document:

(1) Uncertainty in the standard molar enthalpy of combustion of the pure substance at reference temperature $T=298.15 \mathrm{~K}$.

(2) Uncertainty introduced by conversion of data at the reference temperature $298.15 \mathrm{~K}$ to $T=288.15 \mathrm{~K}, 288.71 \mathrm{~K}$, and $273.15 \mathrm{~K}$, for the pure substances.

(3) Uncertainty introduced by the conversion of the standard molar enthalpy of combustion to standard specific enthalpy of combustion for the pure substances (mass basis).

(4) Uncertainty introduced by conversion of the standard molar enthalpy of combustion to the standard volumetric enthalpy of combustion of the pure substances.

(5) Uncertainty in the relation of the molar or specific enthalpy of combustion of the real gas to that of the ideal gas for the pure substances.

(6) Uncertainty in the relation of the volumetric enthalpy of combustion of the reai gas to that of the ideal gas for the pure substances.

(7) Uncertainty in the enthaipic effects of mixing of components of a gas mixture.

(8) Uncertainty in the volumetric effects of mixing of components of a gas mixture.

The inaccuracy in the enthalpy of combustion of a given quantity of gas depends upon errors in actuai measurements of mass or volume, temperature, pressure, and composition of the gas under consideration. The detailed consideration of these errors is considered to be beyond the scope of this document. 
The uncertainties in the source data are included in various tables: (a) Uncertainties of enthalpies of formation of auxiliary substances, Table 3t; (b) Uncertainties in enthalpies of combustion, heat capacities and enthalpy increments, Table 15; (c) Uncertainties in virial coefficients, Tables 8a and 8b; (d) Uncertainties in physical constants Table 1 and later in this section. In addition some discussions of these uncertainties are given in Appendixes 7 and 10 .

Propagation of uncertainties.

The propagation of uncertainties in the calculation of the quantities in this document is carried out using the equation recommended by the IUPAC Commission on Thermodynamics [17].

For the function:

$$
F=F(X, Y, Z)
$$

that is a function of three independent variables, the estimated uncertainty $s_{F}$ in $F$ is given by:

$$
\begin{gathered}
\left(s_{F}\right)^{2}=(\partial F / \partial X)^{2}\{s(X)\}^{2}+(\partial F / \partial Y)^{2}\{s(Y)\}^{2}+ \\
(\partial F / \partial Z)^{2}\{s(Z)\}^{2} .
\end{gathered}
$$

The application of this propagation-of-error equation is discussed in Appendix 10 for particular classes of functions important in this document.

The variables are considered to be independent in each step of calculation except in the case of fuel mixtures for which there is a constraint:

$$
\sum x_{i}=1
$$

The procedure for reducing this set of variables to an independent set is discussed in Appendix 10 in connection with the propagation of errors for virial coefficients of mixtures. 
The calculation of desired quantities from observed data follows a logical sequence in this document. The flow charts of the calculations showing many of the equations used are given in figures 1 and 2 which reflect the order used in the presentation of the material in the main text to this point. The calculation of uncertainties and their propagation is carried out stepwise, as listed above, the uncertainty of each quantity incorporating the uncertainties in the variables involved, for which the uncertainties would have been calculated in a previous step. 


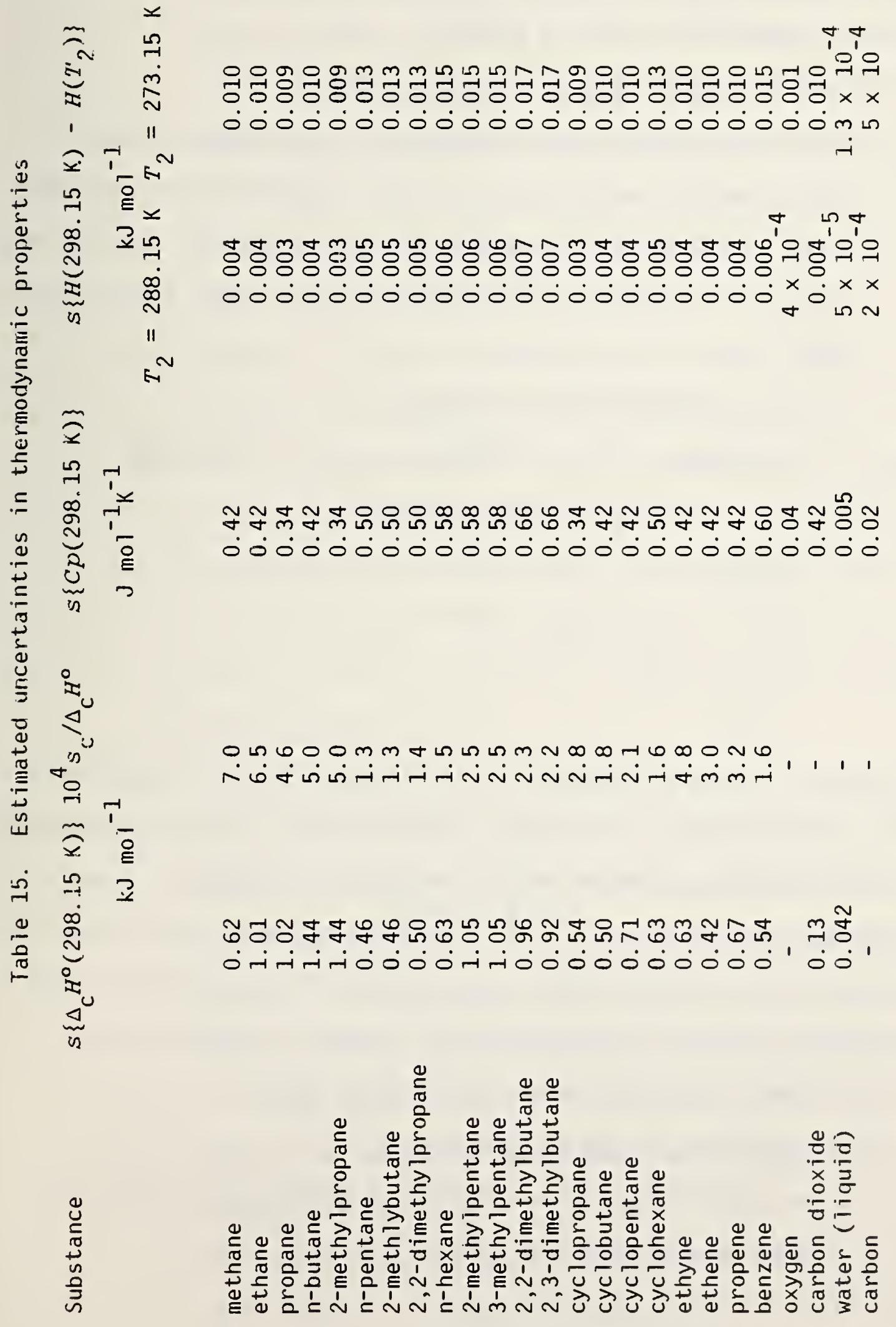


In order to place the overall uncertainties of the values at various stages listed above in proper perspective, the sources of uncertainty are first discussed for specific factors:

(1) Relative atomic masses (atomic weights)

On the basis that the uncertainties in the atomic masses of the elements have the values given in Table A3d the uncertainties in the molecular weights of the compounds of interest are as follows, where $s$ is the uncertainty in atomic weight units and

$S / M$ is the fractional uncertainty.

Substance

$10^{4} \mathrm{~s}$ $10^{4} s / M$ atomic mass unit

$\begin{array}{lll}\mathrm{CH}_{4} & 6.2 & 0.4 \\ \mathrm{CH} & 3.8 & 0.3 \\ \mathrm{CO}_{2} & 9 & 0.2 \\ \mathrm{H}_{2} \mathrm{O} & 4.6 & 0.3\end{array}$

The values for $\mathrm{CH}_{4}$ and $\mathrm{CH}$ represent the extremes of $\mathrm{C}: \mathrm{H}$ ratios encountered in this document, and relative uncertainties for other hydrocarbons will fall in between. The relative uncertainty introduced by those of the atomic masses is 3 or $4 \times 10^{-5}$. The calculation of these values by simple addition of uncertainties, and an alternative calculation based on quadratic addition of uncertainties are shown in Table A5d, along with some comments about the sources of the estimates.

(2) Uncertainty in the gas constant $R$ The uncertainty in $R$ is 0.00026 in $8.31441 \mathrm{~J} \mathrm{~mol}^{-1} \mathrm{~K}^{-1}$ or a relative uncertainty of $31 \times 10^{-6}$. 
(3) Uncertainty in the temperature scale

The practical temperature scale is exactly equal to the thermodynamic temperature scale at $T=273.15 \mathrm{~K}$. At $T$ near $294 \mathrm{~K}$, the international practical temperature scale differs from the thermodynamic temperature scale by amounts estimated by Guildner and Edsinger [18] at about 0.0025 to $0.0030 \mathrm{~K}$ and at $T$ near $315 \mathrm{~K}$ by about 0.0065 to $0.0082 \mathrm{~K}$, with deviations decreasing to very small values as $T$ approaches $273.15 \mathrm{~K}$. From these we can estimate that at $T=298.15 \mathrm{~K}$ the error will be about $0.004 \mathrm{~K}$, which corresponds to a fractional error in temperature of $1.3 \times 10^{-5}$. This is the maximum error that would be expected in the temperature scale in the range $273.15 \mathrm{~K}$ to $298.15 \mathrm{~K}$. In addition, by rounding $288.7055 \mathrm{~K}\left(60^{\circ} \mathrm{F}\right)$ to $288.71 \mathrm{~K}$ an additional error of $0.0045 \mathrm{~K}$ can be introduced if this approximation is made, and additional relative error of $1.6 \times 10^{-5}$. (Usually, we have avoided this by using $288.706 \mathrm{~K}$ ).

(4) Relative uncertainties in the ideal gas molar volume $V_{m}^{\text {id }}$ We use equation (25) Appendix 10 to calculate the relative uncertainties $S_{V(T, p)}^{i d} / V_{T, p}^{i d}$. For defined reference conditions $p$ is defined constant and so $S_{p}=0 ; T$ can be considered as defined constant or as defined by IPTS-68 which differs from $T$ (thermodynamic) as described in paragraph 3 . Thus $s$ can be taken as zero or $s / T$ can be taken as 0 at $T=273.15 \mathrm{~K}$, and $1.3 \times 10^{-5}$ at other temperatures used in this document. For $s_{R}$ we take the uncertainty stated above for $R, 26 \times 10^{-5} \mathrm{~J} \mathrm{~mol}^{-1} \mathrm{~K}^{-1}$, or $\mathrm{s}_{R} / R=31 \times 10^{-6}$. Using these data, and assuming the additive worst case of calculations using $T=288.70555$ rounded to 288.71 and an error of $1.3 \times$ $10^{-5}$ in the deviation of $T$ at $60^{\circ} \mathrm{F}$, we obtain the relative errors 
in molar volume tabulated in the last column below, valid at all standard pressures at the temperatures indicated.

$T / K$

$$
10^{6} s_{R} / R \quad 1{ }^{6} s_{T} / T \quad s_{p} / p \quad S_{V(T, p)}^{\text {id }}{ }_{p, T}^{i d}
$$

273.15

31

0

0

$31 \times 10^{-6}$

288. 15

31

8

$32 \times 10^{-6}$

288.71

31

29

$42 \times 10^{-6}$

298.15

31

13

$34 \times 10^{-6}$

For the equations to be used for calculation of uncertainties of types 2 through 8 , listed at the beginning of this section see the section on propagation of uncertainties in Appendix 10. 
General list of references

[1] (a) Armstrong, G. T.; Domalski, E. S.; Minor, J. L. Jr.; "Standarc combustion data for the fuel gas industry," 1972 Operating Section Proceedings, American Gas Association, Arlington, VA., PP. $0-74$ to D-87. (b) Armstrong, G.T.; "Calculation of the heating value of a sample of high purity methane for use as a referenca material"; Nat. Bur. Stand. (U.S.) Technical Note 299, U.S. Government Pririting Office, Washington, D.C.

[2] McGlashan, M. L. ; Paul, M. A.; Whiffen, D. H.; "Manual of symbols and terminology for physicochemical quantities and units", Pergarion Press; 0xford (1979). See also: Pure Appl. Chem. (1979), 51, 1-41.

[3] IUPAC Commission on Thermodynamics; "Manual of symbols and terminology for physicochemical quantities and units. Appendix. IV; Notation for states and processes, significance of the word standard in chemical thermodynamics and remarks on commonly tabulated forms of thermodynamic functions."; Pure and Applied Chemistry, (1982) in press. Provisional version in Pure and Applied Chemistry, (1979) 51 393-400.

[4] International Organization for Standardization.; "Quantities and units of physical chemistry and molecular physics," Internationa? Standard ISO 31/VIII First edition 1973-04-01.

[5] (a) International Organization for Standards; "SI units and recommendations for the use of their multiples and of certain other units"; IS0/1000-1973. (b) Page, C. H.; Vigoureux, P. editors; "The International system of units (SI)"; NBS Special Publication 330, (1974). (c) American Society for Testing and Materials (ASTM). "Standard for metric practice"; ANSI/ASTM E 380-76; IEEE Std 268-1976. 
[6] IUPAC Commission on Atomic Weights and Isotopic Abundances; "Atomic weights of the elements 1981"; Pure and Applied Chemistry (1982) in oress.

[7] CODATA Task Group on Fundamental Constants; "Recommended consistent values of the fundamental constants, 1973"; CODATA Bulletin 11, December 1973. See also Cohen, E.R.; Taylor, B.N.; J. Phys. Chem. Ref. Data (1973), 2, 663 .

[8] IUPAC Commission on Thermodynamics and Thermochemistry; "A guide to procedures for the publication of thermodynamic data."; Pure and Applied Chemistry (1972), 29, 399-408.

[9] (a) International Organization for Standardization; "Petroleum liquids and gases - Measurement - Standard reference conditions"; ISO 50241975 (E). (b) ASTM Committee D-3 on Gaseous Fuels; "Standard methods for volumetric measurement of gaseous fuel samples"; ANSI/ASTM D 107178a, Am. Soc. Testing and Materials, Philadelphia 1980. In Annual Book of ASTM Standard's, (1980), part 26.

[10] ANSI Committee $Z$ 132, "Base conditions for the volumetric measurement of natural gas"; American National Standard Z 132.1 - 1969; API Standard 2562, First Edition.; "Base conditions of pressure and temperature for the volumetric measurement of natural gas"; American Petroleum Institute, New York, N.Y. 10020. But see also "Measuring, Sampling, Testing, and Base Conditions for Natural Gas Fluids"; API Publ 2529, 3d Edition, (1979), p. 1.

[11] Wiihoit, R. C; Private communication 5 October 1981.

[12] Osborne, H. S.; Stimson, H. G.; Ginnings, D. C.; J. Research Nat. Bur. Standards (1939), 23, 127.

[13] Desorbo, W.; Tyler, W.W.; J. Chem. Phys. (1953), 21, 1660. See also CODATA Task Group, J. Chem. Thermodynamics (1972), 4, 331-336. 
[14] (a) CODATA Task Group on Key values for Thermodynamics; "CODATA recommended key values for thermodynamics 1977"; CODATA Bulletin No. 28, (April 1978). (b) CODATA Special Report 8, (1980).

[15] Domalski, E. S.; J. Phys. Chem. Reference Data (1972), 1, 221-277.

[16] Wexler, A.; J. Research Nat. Bur. Standards. A. Phys. Chem. (1971), $75 A, 213-230$.

[17] 0lafsson, G.; Angus, S.; Armstrong, G.T.; Kornilov, A.N.; J. Chem. Thermodynamics (1981), 13, 603.

[18] Guildner, L.A.; Edsinger, R.E.; J. Research Nat. Bur. Standards (1976), $\underline{80 A}, 703-738$. 


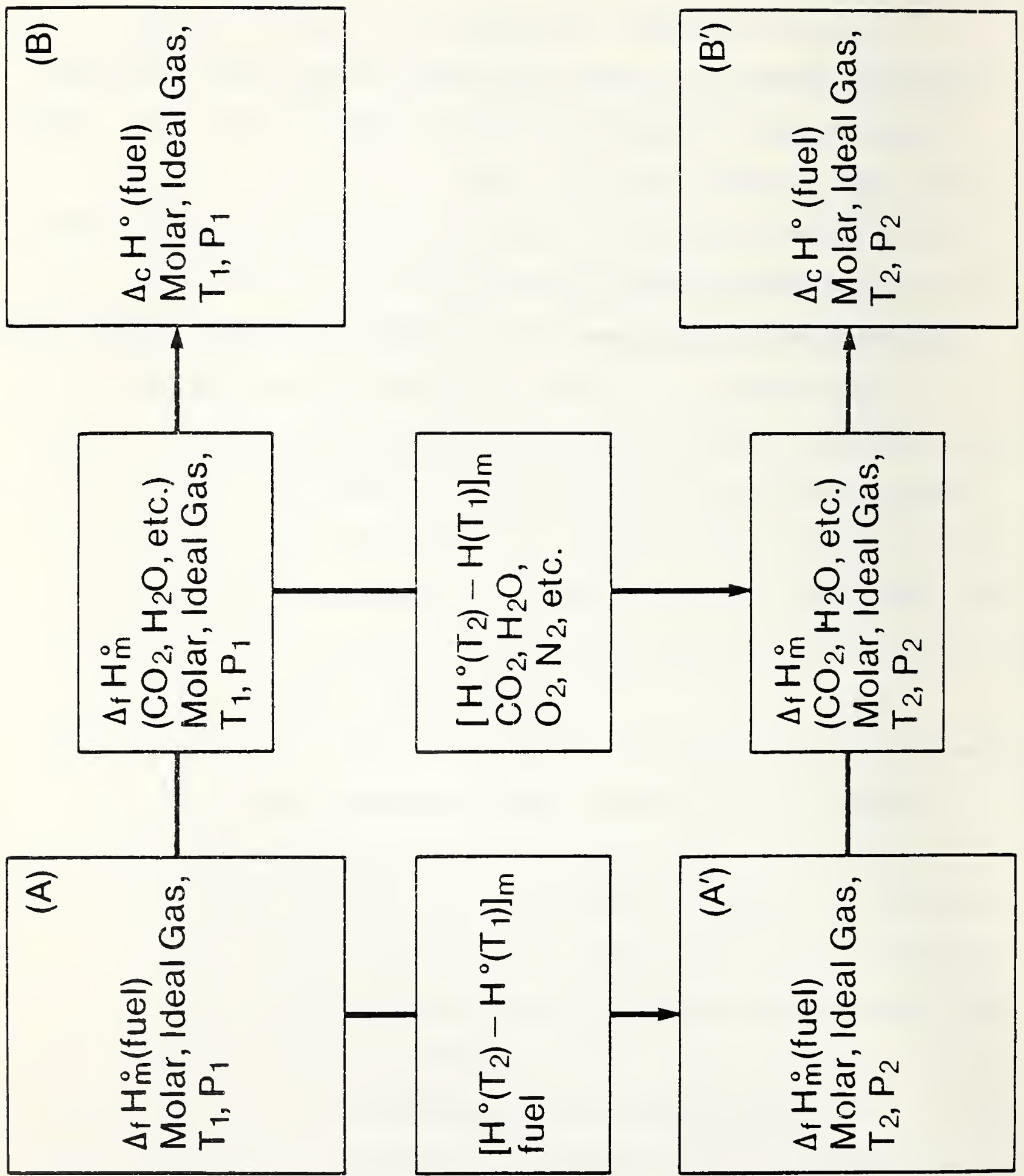



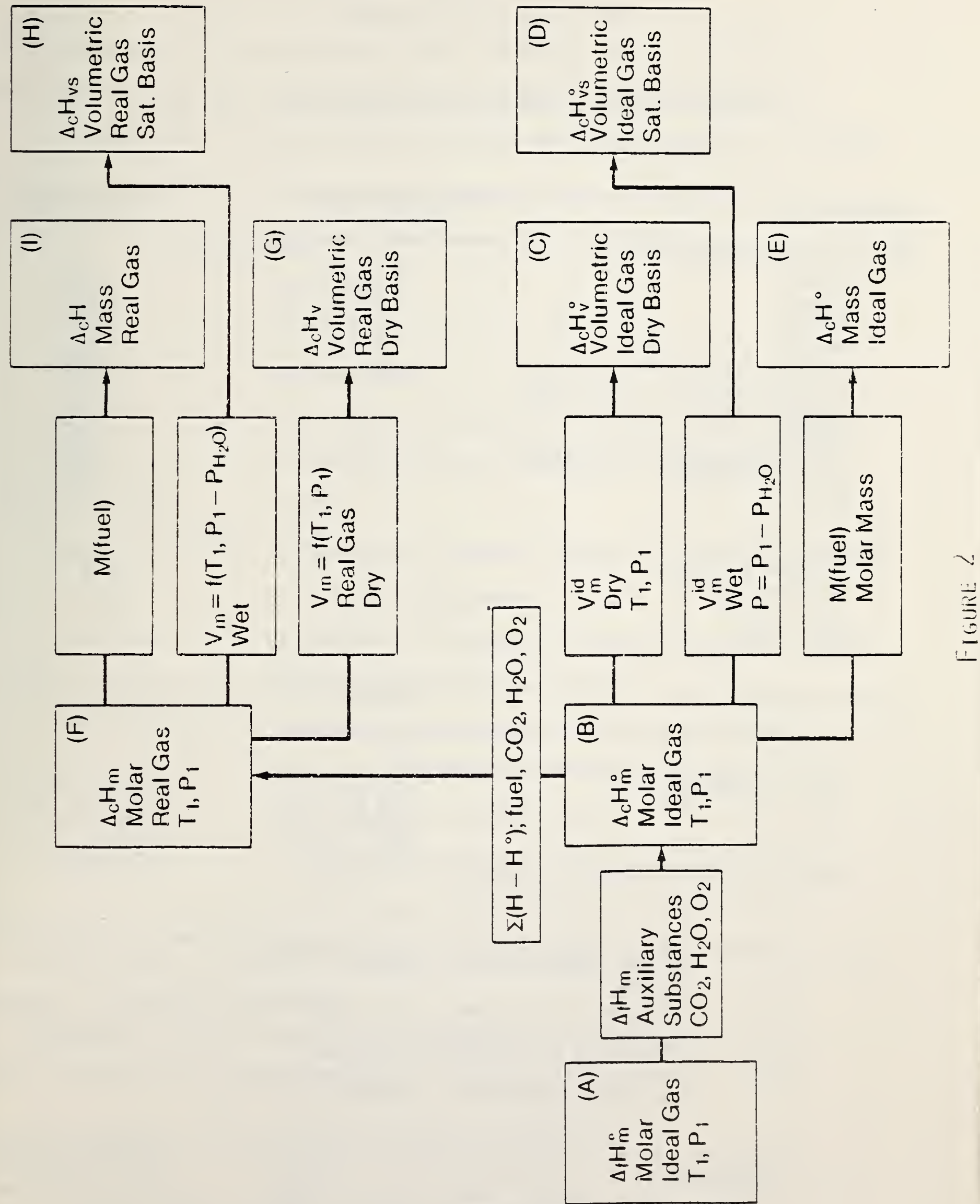
Appendix 1. Proposed composition Timits

Table Al gives composition limits suggested by ASTM Committee D-3 [1] on Gaseous Fuels in a proposed modei specification for pipeline quality gas.

Table A1. Proposed composition limits for pipeline quality natural gas

\begin{tabular}{lcc}
\hline Composition & Minimum Value & Maximum Value \\
\hline Major and Minor Components & 0.65 & Mole fraction \\
Methane & -- & 1.00 \\
Ethane & -- & 0.14 \\
Propane & -- & 0.05 \\
Butanes & -- & 0.02 \\
Pentanes and Heavier & -- & 0.005 \\
Nitrogen and other Inert Gases & -- & 0.18 \\
Carbon Dioxide & -- & 0.03 \\
Hydrogen & -- & 0.005 \\
Total Unsaturated Hydrocarbons & -- & 0.001 \\
Carbon Monoxide & - & $0.001\left(1000 \times 10^{-6}\right)$ \\
Oxygen & & \\
Trace Components & -- & $\mathrm{mg} / \mathrm{m}^{3}$ \\
Hydrogen Sulfide & -- & 5.7 \\
Mercaptan Sulfur & -- & 11.5 \\
Total Sulfur & -- & 22.9 \\
Water Vapor & & 110.
\end{tabular}

Heating value under standard conditions (a)

$\begin{array}{lcc}\text { Heating value under standard conditions } & 35.4 \mathrm{MJ} \mathrm{m}^{-3} & 42.8 \mathrm{MJ} \mathrm{m}^{-3} \\ \text { Gross, saturated } & \left(950 \mathrm{Btu} \mathrm{ft}^{-3}\right) & \left(1150 \mathrm{Btu} \mathrm{ft}^{-3}\right) \\ \text { Gross, dry } & \left.36.0 \mathrm{MJ} \mathrm{m}^{-3}\right) & 43.6 \mathrm{MJ} \mathrm{m}^{-3} \\ & \left(967 \mathrm{Btu} \mathrm{ft}^{-3}\right) & \left(1170 \mathrm{Btu} \mathrm{ft}^{-3}\right) \\ \text { Relative density (specific gravity) } & 0.530 & 0.790\end{array}$

Liquids: The gas shall be free of water and hydrocarbons in liquid form at the temperature and pressure at which it is delivered to a purchaser.

Solids: The gas shall be free of solid particulate substances in amounts deleterious to the materials normally encountered in transportation and utilization of the gas.

Gases: The gas shall be free of other gases that could adversely effect the transportation or utilization of the gas.

(a) factor $1 \mathrm{MJ} \mathrm{m}^{-3}=26.839192 \mathrm{Btu} \mathrm{ft}^{-3}$ under identical temperature and pressure.

[1] Anon; "New standard: D4087. Specification for pipeline quality natural gas"; ASTM Standardization News (Dec. 1981) $\underline{9}$, [12], p. $38 \mathrm{E}$. 
Appendix 2. Symbols

Table A2. Thermodynamic symbols used in this document

T

$p$

(g)

(1)

(c)

$\rho_{n}$

$\rho_{n}\left(\mathrm{CH}_{4}\right.$, ary $)$

$\rho_{n}\left(\mathrm{CH}_{4}, \mathrm{sat}\right)$

$c\left(\mathrm{H}_{2} \mathrm{O}\right.$, id $\left.\mathrm{g}\right)$

$V_{\mathrm{m}}^{1 \mathrm{~d}}$

$V_{\text {in }}$

$r$ (sat/dry)

Q

$Q($ totai)

$H_{T}^{\circ}$ or $H^{\circ}(T)$

$H_{T}$ or $H(T)$ thermodynamic temperature (Kelvin scale)

pressure (absolute)

gas phase

liquid phase

crystal phase

concentration or amount-of-substance density (amount

of substance per unit volume, i.e., moles per unit

volume )

concentration or amount of substance density of methane with no water present

concentration or amount of substance density of methane when saturated with water vapor

concentration of saturated water vapor, ideal gas

molar volume of ideal gas in standard state

molar volume of non-ideal gas

ratio of concentration of fuel in saturated gas to

concentration of fuel in dry gas

heat. released per unit quantity of fuel in a specified

process

total heat of reaction, i.e. with fuel in gaseous

state and water formed as a liquid

standard enthalpy at temperature $T$

enthalpy in a non-standard state at temperature $T$,

e.g. enthalpy of the real gas 


$$
\begin{array}{ll}
H\left(\mathrm{C}_{a} \mathrm{H}_{b}, \mathrm{~g}, 298.15 \mathrm{~K},\right. & \\
101.325 \mathrm{kPa}) & \text { enthalpy in a non-standard state of the substance } \\
& \mathrm{C}_{a} \mathrm{H}_{b} \text { at } T=298.15 \mathrm{~K}, p=101.325 \mathrm{kPa}
\end{array}
$$

$H$ (state 2) -

$H($ state 1$)$

enthalpy difference or increment, written here for non standard states. Measurable, while $H$ (state) is not

$\Delta_{f} H^{\circ}$

standard enthalpy of formation from the elements

$\Delta f H$

enthalpy of formation from the elements in a nonstandard state

$\Delta_{f} H^{\circ}(T)$

standard enthalpy of formation at temperature $T$

$\Delta_{f} H^{\circ}\left(\mathrm{C}_{a} H_{b}, \mathrm{~g}\right.$,

$298.15 \mathrm{~K})$

standard enthalpy of formation of the gaseous substance

$\mathrm{C}_{a} \mathrm{H}_{b}$ at $T=298.15 \mathrm{~K}$

$\Delta_{C} H^{\circ}$

standard enthalpy of combustion (ideal gas)

$\Delta_{\mathrm{C}} H$

enthalpy of combustion (real gas)

$\Delta_{C} H^{\circ}(T)$

standard enthalpy of combustion at temperature $T$

$\Delta_{C} H(T, p)$

Enthalpy of combustion at temperature $T$ and pressure $p$.

$B$

Second virial coefficient in volumetric units

$B^{*}$

Second virial coefficient in pressure units

$B(T)$ or $B^{\star}(T)$

Second virial coefficient, indicating that it is a function of temperature

$B(i)$

Second virial coefficient of substance $i$

$B(1, i)$

Virial coefficient for binary interaction of methane (1)

with another substance (i)

$B$ (mixture)

The virial coefficient of a mixture

Note: For methane (1) - mixed with one other component

(i): $B\left(\right.$ mixture) $=[x(1)]^{2} B(1)+2 x(1) x(i) B(1, i)+$

$[x(i)]^{2} B(i)$ 


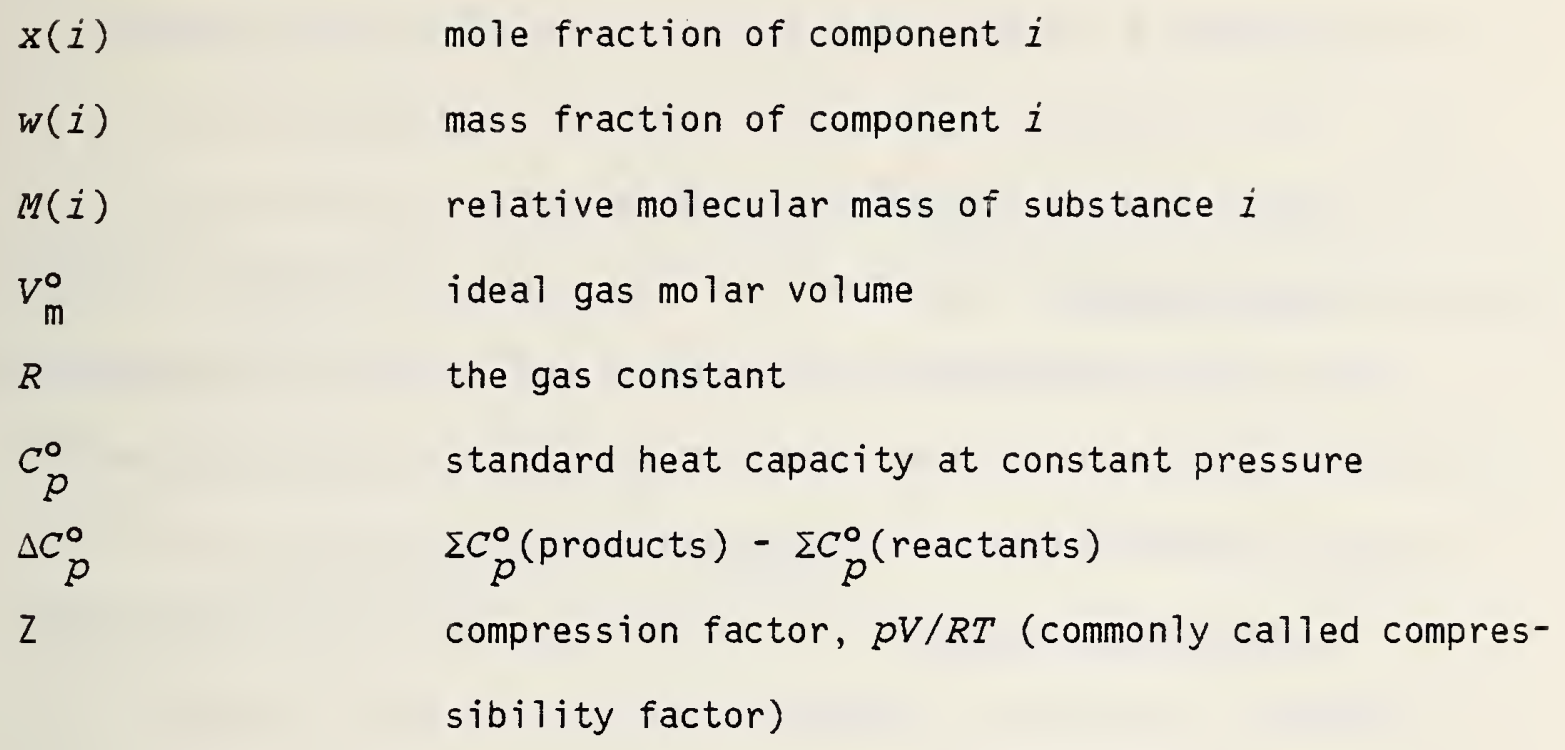


Appendix 3. Definitions of terms as used in this document.

\section{A3.1 Terms relating to quantities and concepts.}

A3.1.1 Atomic weight - the atomic weight is the dimensionless relative mass of an atom or of a mole of atoms of normal isotopic composition based on a scale in which the isotope ${ }^{12} \mathrm{C}$ has a relative mass of 12. Preferred name is relative atomic mass, q.v.

A3.1.2 Compression factor - The compression factor (symbol $Z$ ) is the ratio

$$
z=p V_{\mathrm{m}} / R T
$$

For an ideal gas $Z=1$, but for real gases, $Z$ differs from unity by amounts that are small but significant at reference conditions.

A3.1.3 Dry gas - Dry gas is a gaseous substance or mixture containing little or no water vapor.

A3.1.4 Enthalpy - Enthalpy (symbol $H$ ) is a thermodynamic property of a material, representing the internal energy $U$ plus the $p V$ work associated with its volume and pressure.

$$
H=U+p V .
$$

Enthalpy is often called heat content. Enthalpy, per se, is not measurable but enthalpy differences are.

\section{A3.1.5 Enthalpy of combustion - The enthalpy change occurring when a} combustion reaction occurs with all reactants and products reduced to the same specified temperature. It is often called heat of combustion and has a negative value for all fuels. The negative of the enthalpy of combustion of a fuel is often called calorific value, heating value, net calorific value (q.v.), or total calorific value (q.v.). Standard enthalpy of combustion is the enthalpy of 
combustion calculated for the condition when all substances are in their thermodynamic standard states (see standard state). For gaseous substances this state is the ideal gaseous state.

A3.1.6 Enthalpy of formation - The enthalpy of formation is the enthalpy change occurring when a substance is formed from the elements; the elements and the substance being at the same specified temperature. The standard enthalpy of formation is the enthalpy of formation when the substance and the elements are in their thermodyramic standard states. For gaseous elements this state is the ideal gaseous state.

A3.1.7 Equation of state - The equation of state of a substance is the mathematical expression expressing the relationship among the amount of substance $n$, the volume it occupies $V$, the thermodynamic $T$ and the pressure $p$. For an ideal gas. $V / n=R T / p$, where $R$ is the gas constant. See also virial coefficient.

A3.1.8 Gas constant - The gas constant (symbol $R$ ) is the proportionality factor relating the thermodynamic temperature $T$ to the $p V$ work associated with the pressure $p$ and the volume per mole $v_{m}=(V / n)$ of an ideal gas.

A3.1.9 Heat capacity - The heat capacity at constant pressure, $C_{p}$, of a substance is an extensive property that is the rate of increase of enthalpy of the substance with temperature; $c_{p}=(\partial H / \partial T)_{p}$. If the amount of substance is one mole, then it is more properly termed the molar heat capacity, an intensive property.

A3.1.10 Ideal gas - An ideal gas is a hypothetical gas that conforms exactly to the ideal gas law:

$$
p V_{m}=R T
$$


in which $p$ is the pressure, $V_{\mathrm{m}}$ is the molar volume, $T$ is the thermodynamic temperature, and $R$ is the gas constant.

\section{A3.1.11 International Practical Temperature Scale - The International}

Practical Temperature Scale (IPTS) is the closest feasible approximation to the thermodynamic temperature scale as realized by a series of defined fixed temperatures and interpolation formulas and agreed upon at intervals by the International Bureau of Weights and Measures (BIPM) with advice from the Consultative Committee on Thermometry (CCT). The scale is changed slightly from time to time, and the date of adoption of a new set of values is specified; e.g., IPTS-68 is the International Practical Temperature Scale of 1968. For very precise work the temperature $T$ may also be identified by the year of the IPTS; thus $T_{68}$ is a temperature measured on the scale IPTS-68.

\section{A3.1.12 Molar mass - The molar mass of a substance is the mass of a} mole of the substance of specified formula, based on a scale on which one mole of the isotope ${ }^{12} \mathrm{C}$ has a mass of 12 grams (exactly).

\section{A3.1.13 Molecular weight - A dimensionless relative mass of a molecule} (or of a mole of molecules in which all the atoms have their normal isotopic compositions) based on a scale in which the isotope ${ }^{12} \mathrm{C}$ has a relative mass of 12 . Preferred name is relative molar mass, q. v.

A3.1.14 Net calorific value - The net calorific value (net, lower or inferior heating value) is the heat evolved by the complete combustion, at constant pressure, of a unit amount of gas with air, when the gas, air, and products of combustion all are at a specified reference temperature and pressure, and all the water formed by the combustion reaction remains in the the vapor state. See notes under total calorific value. 
A3.1.15 Real gas - "Real gas" is a descriptive term identifying actual gas behavior as contrasted with the hypothetical ideal gas (q.v.) The actual volume occupied by a given amount of a real gas at a given temperature deviates from that calculated by the ideal gas law by amounts that are small but significant at reference conditions.

A3.1.16 Relative atomic mass - The relative atomic mass is the dinensionless relative mass of an atom (or of a mole of atoms of normal isotopic composition) based on a scale in which the isotope ${ }^{12} \mathrm{C}$ has a relative atomic mass of 12 . This term is preferred to "atonic weight", but is identical in meaning.

A3.1.17 Relative molecular mass - The relative molecular mass, formerly called "molecular weight", is the ratio of the average mass per formula unit of a substance to $1 / 12$ of the mass of an atom of nuclide ${ }^{12} \mathrm{C}$.

\section{A3.1.18 Reference (standard) conditions - Reference (standard) conditions} are conditions of temperature, pressure, and degree of saturation with water to which measurements of gas volimes or proparties are reduced to allow comparability among measurements made under possibly different conditions. See table 2 .

A3.1.19 Specific heat capacity - The specific heat capacity of a material is the heat capacity (q.v.) per unit mass of material. The term "specific heat" is ambiguous and incomplete and is now deprecated.

A3.1.20 Standard state - The standard thermodynanic properties for a gaseous substance, whether pure or in a gaseous mixture, apply to the pure substance at the standard state pressure and in a hypothetical state in which it exhibits ideal gas behavior. These conditions of temperature, pressure and ideal behavior define the standard state. When a property of a gas refers to the gas in its standard state it is designated with 
a superscript ${ }^{\circ}$, i.e. $H^{\circ}$ is the enthalpy of a substance in the standard state.

A3.1.21 Total calorific value - The total calorific value (total, superior or gross heating value) of a gas is the heat evolved by the complete combustion, at a constant pressure, of a unit amount of gas with air, when the gas, air and products of combustion all are at a specified referi temperature and pressure, and all the water formed by the combustion reaction is condensed to the liquid state.

Note 1. The heat evolved is the negative of the enthalpy change for the specified process. The heat may be measured in jouies or British thermal units.

Note 2. The amount of a gas may be measured as an amount of substance (moles), as a mass (kilograms or pounds), or as a volume measured under standard reference conditions (cubic meters or cubic feet).

Note 3. See table 2 for reference conditions that are in use or have been used.

Note 4 . The gross heating value of a gas is greater than the gross heating value of the liquid of the same composition by the enthalpy of vaporization of the liquid.

Note 5. The gross heating value of a gas is greater than its net heating value by the enthalpy of vaporization of the water formed in the combustion.

\section{A3.1.22 Vapor pressure - The vapor pressure of a substance is the} pressure in the vapor of a substance when equilibrium exists between the vapor and a condensed phase of the substance.

A3.1.23 Virial coefficient - The virial coefficients are the constants $B, C, D$ or $B^{*}, C^{*}, D^{*}$, in the virial equation of state which describes the behavior of a real gas and which may take the form: 


$$
p V_{\mathbf{m}} / R T=1+B(T) / V+C(T) / V^{2}+D(T) / V^{3}+\ldots
$$

or the form:

$$
p V \prime R T=1+B^{*}(T) \cdot p+C^{*}(T) \cdot p^{2}+\ldots
$$

The virial coefficients are functions of temperature $T . B(T)$ or $B^{*}(T)$ is the second virial coefficient; $C(T)$ or $C^{\star}(T)$ is the third virial coefficient, and so on. In this document no terms higher than $B$ are used. See Section 10 and Appendix 9.

A3.1.24 Volume under standard conditions - The volume under standard conditions, symbol $V_{\text {std }}$, is the volume occupied by a measured or specified amount of gas when under standard conditions of temperature, pressure and degree of saturation with water. (cf. standard cubic foot). This is a volume and as such has the unit cubic metre or cubic foot.

A3.1.25 Water-saturated gas - A gaseous mixture in which water vapor is present at the saturation vapor pressure for the temperature and other conditions of measurement.

A3.2 Terms that are units of measurement.

A3.2.1 Atmosphere - The atmosphere (symbol atm) is an obsolescent unit of pressure, equivalent in various usages to $760 \mathrm{mmHg}, 30 \mathrm{inHg}$, and 14.7 psia (more or less). It has been most recently defined as $101.325 \mathrm{kPa}$ (exactly).

A3.2.2 British thermal unit (symbol Btu) - The British thermal unit is a customary (U.S. or British) unit for the measurement of amounts of energy, particularly when observed as heat. It was initially defined in terms of the specific heat capacity of water as the amount of heat needed to raise the temperature of one pound (mass) of water one degree Fahrenheit, but is now by consensus usually defined in terms of the joule. The International Tables British 
thermal unit (symbcl Btu ${ }_{I T}$ ) is used in this document and is defined

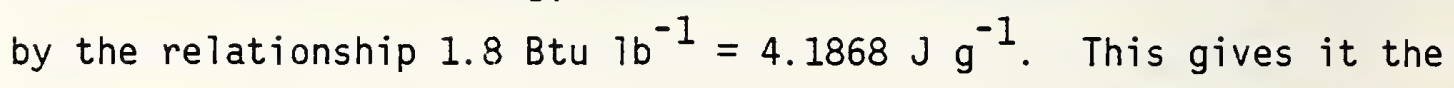
exact value, $1 \mathrm{Btu}_{\mathrm{IT}}=1055.05585262 \mathrm{~J}$, which may be rounded to 1055.056 J. Gas industry measurements until a few years ago were often made using a British thermal unit defined as the heat needed to raise the temperature of one pound of water from 58.5 to $59.5^{\circ} \mathrm{F}$ (the $B u_{59 F}$ ). The value depends upon the value used for the specific heat capacity of water, but differs from the BtuIT by about 0.252 $\mathrm{J}$, a significant amount, See ref. [1] in the General List. This unit is now deprecated. For each defined Btu there is a corresponding calorie. They are related by $1 \mathrm{Btu} / 1 \mathrm{~b} \cdot{ }^{\circ} \mathrm{F}=1 \mathrm{cal} / \mathrm{g} \cdot{ }^{\circ} \mathrm{C}$.

A3.2.3 Joule - The joule is the work done when the point of application of a force of one newton is displaced a distance of one metre in the direction of the force. It is also the value of the $p V$ term of a gas occupying a volume $V=1 \mathrm{~m}^{3}$ at a pressure $p=1 \mathrm{~Pa}$.

A3.2.4 Newton - The newton is that force which, when applied to a body having a mass of one kilogram gives it an acceleration of one metre per second per second.

A3.2.5 Pascal - the pascal is the pressure produced by a force of one newton on an area of one square metre.

A3.2.6 Standard cubic foot of gas - The standard cubic foot (symbol scf) of a gas is the quantity of any gas that, at standard temperature and under standard pressure, will fill a space of one cubic foot when in equilibrium with water vapor. See Section 6 for standard conditions. Note that this is a unit of amount of substance. Cf. "volume under standard conditions", which is a preferred term for describing volumetric measurements of gas. 
A3.2.7 Torr - The torr is an obsolescent unit of pressure defined as 1/760 atm. By this definition it is essentially equal to $1 \mathrm{mmHg}$, but the dependence on the value for the density of mercury has been removed. 


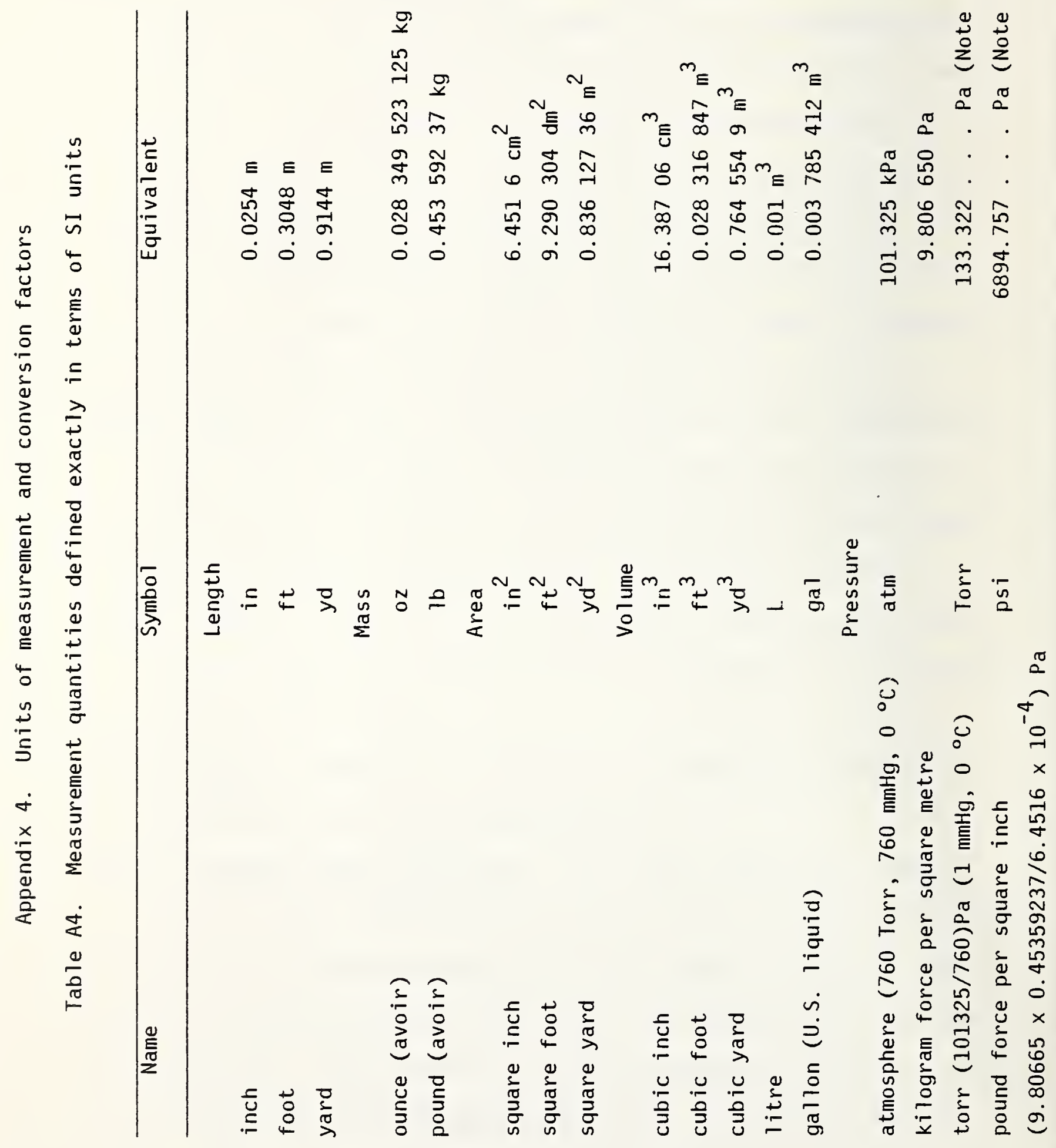




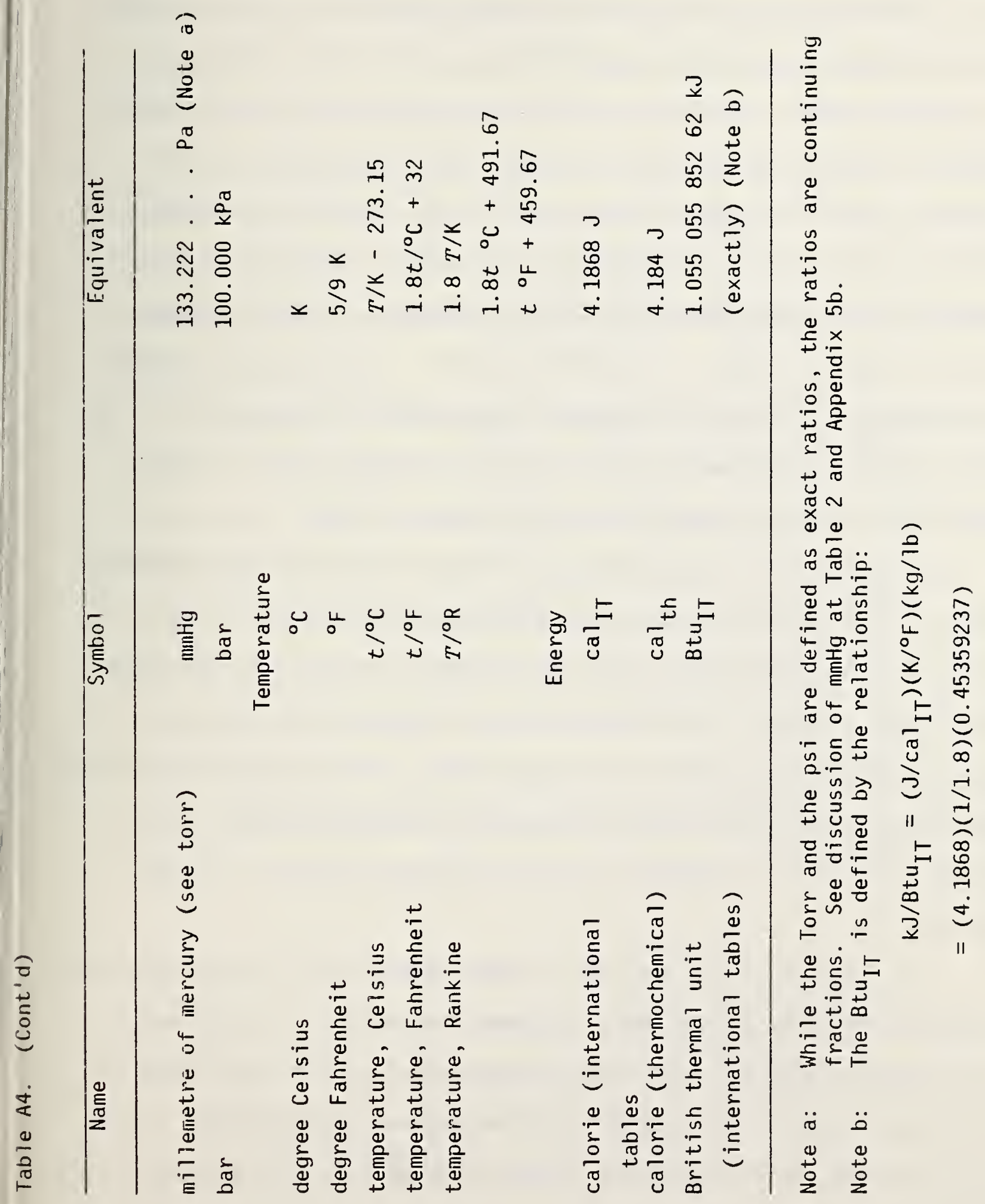


Appendix 5. Discussion of physical constants Appendix 5a. Relative atomic and molecular masses

Table A5a gives a listing of six differing sets of relative atomic masses (atomic weights) for the elements $\mathrm{C}, \mathrm{H}, \mathrm{O}, \mathrm{N}$ that have been recommended since 1941 plus the set used in the International Critical Tables. They are coded $A$ to $G$ in order of increasing age. The set selected for this document is Set A, which was chosen for two reasons: (1) It is the current recommendation of the IUPAC Commission on Atomic Weights and Isotopic Abundances [1] and represents the best estimate based on modern research of the atomic masses. (2) It is only slightly different than the set that has been recommended for ten years [2]. The only noticeable difference is the value for hydrogen which, at five significant figures, rounds to the value given in set $B$.

Lines $A$ and $A^{\prime}$ in Table $A 5 a$ are both part of the current recommendation. The first line (A) gives values to the decimal place in which there is some uncertainty. (The uncertainties are given in Table A5C). Variation in natural terrestrial samples is the principal cause of uncertainty for the elements of interest here. The five-significant-figure set coded $A^{\prime}$ has values that are less accurate, but are more likely to remain constant for a decade, even with continued research into the matter.

Table A5b gives for each set of atomic masses the relative molecular masses of $\mathrm{CH}_{4}, \mathrm{CH}_{2}$ and $\mathrm{CH}$, which represent respectively the maximum $\mathrm{H} / \mathrm{C}$ ratio the limiting $\mathrm{H} / \mathrm{C}$ ratio for homologous series, and the minimum $H / C$ ratio encountered in the common low molecular mass hydrocarbons. Also given are the relative molecular masses calculated for $\mathrm{H}_{2} \mathrm{O}$ and $\mathrm{CO}_{2}$ using each set. 
The uncertainties introduced into the calculations by the variability with time of the recommended atomic masses are indicated in the footnote to Table A5b. This also shows the level of error due to atomic mass changes that can be introduced when measurements made at different times are compared without adjustment for the changes in molar masses.

An examination of compilations of thermodynamic data for hydrocarbons has shown that sets $B, C, D, F$ and $G$ have been used. There has been no clear preference. Nor have the recent recommendations (in the 1970's) been used often. Some examples are given in Appendix 7 where sources of data are presented.

The procedure used in this document to calculate relative molecular masses is to use Set $A$ and then round the value of the molecular mass to the decimal place in which the accumulated error appears. This procedure is displayed in Table A5c. The uncertainties in the atomic masses used in that table are those recommended by the IUPAC Commission. Because those uncertainties allow for samples from many sources, the resulting errors may be considered large for fossil fuels. Nevertheless, the uncertainty in the relative atomic mass of carbon make it appropriace to round molecular masses of the hydrocarbons of interest to three decimal places. 
Table A5. Atomic masses

Table A5a. Recent sets of relative atomic masses of the chemical

elements and their period of recommendation by the International Union of Pure and Applied Chemistry (IUPAC)

\begin{tabular}{llllll}
\hline & $\mathrm{C}$ & $\mathrm{H}$ & $\mathrm{N}$ & $\mathrm{N}$ & Year first recommended \\
\hline $\mathrm{A}$ & 12.011 & 1.00794 & 15.9994 & 14.0067 & $1981[1]$ \\
$\mathrm{A}^{\prime}(\mathrm{a})$ & 12.011 & 1.0079 & 15.999 & 14.007 & $1981[1]$ \\
$\mathrm{B}$ & 12.011 & 1.0079 & 15.9994 & 14.0067 & $1971[2]$ \\
$\mathrm{C}$ & 12.011 & 1.0080 & 15.9994 & 14.0067 & $1969[3 \mathrm{a}]$ \\
$\mathrm{D}$ & 12.01115 & 1.00797 & 15.9994 & 14.0067 & $1961[3 \mathrm{~b}]$ \\
$\mathrm{E}$ & 12.011 & 1.0080 & $\underline{16}{ }^{(b)}$ & 14.008 & 1953 \\
$\mathrm{~F}$ & 12.010 & 1.0080 & $\underline{16}$ & 14.008 & 1941 \\
$\mathrm{G}$ & 12.000 & 1.0077 & $\underline{16}$ & 14.008 & 1923 (c) \\
\hline
\end{tabular}

(a) The $A^{\prime}$ line has the five-significant-figures set given by the IUPAC Commission on Atomic Weights. These are values rounded from Set A.

- Set $A^{\prime}$ also includes $A r, 39.948 ;$ He, 4.0026; S, 32.06. The certainty of the value for sulfur is limited to four significant figures by the range of isotopic compositions in normal terrestrial materials.

(b) The relative atomic mass of oxygen in set $E$ and earlier sets is an integral value by definition.

(c) Prepared by G. P. Baxter for the International Critical Tables. The first international recommendation (1931) gave $C=12.00$ and $H=$ 1.0078. There were several changes during the 1930's. 
Table A5b. Relative molecular masses of some important molecules as formally calculated from different sets of relative atomic masses (rounded to four decimal places). See Table

1 for recommended values

\begin{tabular}{cccccl}
\hline SET & $\mathrm{CH}_{4}$ & $\mathrm{CH}_{2}$ & $\mathrm{CH}$ & $\mathrm{H}_{2} \mathrm{O}^{2}$ & \multicolumn{1}{c}{$\mathrm{CO}_{2}$} \\
\hline & & & & & \\
$\mathrm{A}$ & 16.0427 & 14.0269 & 13.0189 & 18.0153 & 44.0098 \\
$\mathrm{~B}$ & 16.0426 & 14.0268 & 13.0189 & 18.0152 & 44.0098 \\
$\mathrm{C}$ & 16.0430 & 14.0270 & 13.0190 & 18.0154 & 44.0098 \\
$\mathrm{D}$ & 16.0430 & 14.0271 & 13.0191 & 18.0153 & 44.0099 \\
$\mathrm{E}$ & 16.0430 & 14.0270 & 13.0190 & 1.8 .0160 & 44.011 \\
$\mathrm{~F}$ & 16.0420 & 14.0260 & 13.0180 & 18.0160 & 44.010 \\
$\mathrm{G}$ & 16.0308 & 14.0154 & 13.0077 & 18.0154 & 44.00 \\
\hline
\end{tabular}

Maximum relative differences in molecular masses from sets $A$ through $F$. The letters in parenthesis identify the sets giving the maximum deviztion 1 isted.

$$
\begin{aligned}
& \mathrm{CH}_{4}, 4.4 \cdot 10^{-5}(\mathrm{D} / \mathrm{F}) ; \mathrm{CH}_{2}, 7.8 \cdot 10^{-5}(\mathrm{D} / \mathrm{F}) ; \mathrm{CH}, 8.6 \cdot 10^{-5}(\mathrm{D} / \mathrm{F}) ; \mathrm{H}_{2} 0,6.6 \cdot 10^{-5} \\
& (\mathrm{E}, \mathrm{F} / \mathrm{B}) ; \mathrm{CO}_{2}, 4.4 \cdot 10^{-5}(\mathrm{E} / \mathrm{A}) .
\end{aligned}
$$


Table A5c. Assignment of uncertainties in relative atomic and molecular masses for the 1981 set recommended by the IUPAC Commission on Atomic Weights and Isotopic Abundances

Assign s (the estimated uncertainty of values in Table 1) as follows:

$\begin{array}{ccc}\text { Element } & \text { Relative atomic mass } & \begin{array}{c}\text { Uncertainty } \\ \frac{5 \times 10^{4}}{}\end{array} \\ \text { Ar } & 39.948 & 1 . \\ \text { C } & 12.011 & 10 . \\ \text { H } & 1.00794 & 0.7 \\ \text { He } & 4.00260 & 0.1 \\ \text { O } & 15.9994 & 3 . \\ \text { N } & 14.0067 & 1 . \\ \text { S } & 32.06 & 100 .\end{array}$


Table A5c. (continued)

Calculation of absolute and relative errors in relative molecular masses using data in Table A5c.

\begin{tabular}{|c|c|c|c|}
\hline \multirow[t]{3}{*}{ Molecule } & \multirow[t]{3}{*}{ Atoms and weights } & \multicolumn{2}{|c|}{ Uncertainties $^{\mathrm{a}}$} \\
\hline & & Additive & Quadrature \\
\hline & & $10^{4} \mathrm{~s}$ & $10^{8} s^{2} \quad 10^{4} s$ \\
\hline \multirow[t]{2}{*}{$\mathrm{CH}_{4}$} & $\begin{array}{lc}\mathrm{C} & 12.011 \\
\mathrm{H} 4 \times 1.00794\end{array}$ & $4 \begin{array}{c}10 \\
\times 0.7\end{array}$ & $\begin{array}{r}100 \\
8\end{array}$ \\
\hline & 16.04274 & 12 & $\overline{(108)}^{1 / 2}$ \\
\hline
\end{tabular}

Rounded value ${ }^{\mathrm{b}}: \quad 16.043$

Relative uncertainty: divisor $16.04 \quad 0.7 \quad 0.6$

$\mathrm{CH}$

C $\quad 12.011$

H 1.00794

10

$\overline{13.01894}$

0.7

100

0.5

11.

$\left(1 \overline{00}^{1 / 2}=10\right.$.

Rounded value: 13.019

Relative uncertainty: divisor $13.02 \quad 0.3 \quad 0.24$

$\mathrm{CO}_{2}$

$$
\begin{array}{ll}
\text { C } & 12.011 \\
0_{2} & 31.9988 \\
& \frac{44.0098}{}
\end{array}
$$

10
6

100

36

$\overline{10}$

${\frac{(130)^{1 / 2}}{}}^{1 / 2} 12$

Rounded value: 44.010

Relative uncertainty: divisor $44.010 .2 \quad 0.15$

$\mathrm{H}_{2} \mathrm{O}$

\begin{tabular}{cc}
$H 2 \times 1.00794$ \\
0 & 15.9994 \\
\hline & 18.01528
\end{tabular}

$2 \times 0.7$

2

9

$\overline{11}^{1 / 2}=3.3$

Rounded value: 18.0153

Relative uncertainty: divisor $18.02 \quad 0.2$

0.2

${ }^{a}$ The uncertainties by quadrature (square root of sum of squares) are recommended. See Appendix 10 on propagation of errors.

${ }^{b}$ The rounded values also appear in Table I. Other values there were determined by similar procedures. 
References for Appendix $5 a$.

[1] IUPAC Commission on Atomic Weights and Isotopic Abundances; "Atomic weights of the elements 1981"; Pure and Applied Chemistry (1982) in press.

[2] IUPAC Commission on Atomic Weights; "Atomic weights of the elements 1971"; Pure and Applied Chem. (1972), 30, 637-649.

[3] a. IUPAC Commission on Atomic Weights, "Atomic weights of the elements"; Pure and Applied Chemistry (1970), 21, 91-108; and J. Am. Chem. Soc. (1971), 93, 2579. b. Cameron, A. E.; Wichers, E. J.; "Report of the International Commission on Atomic Weights (1961"; J. Am. Chem. Soc. $(1962), 84,4175$. 


\section{Appendix 5b}

The density of mercury, the standard acceleration of gravity, and the significance of the reference pressure $760 \mathrm{mmHg}$.

The density of mercury serves three slightly different purposes:

(1) to convert barometric and manometric pressure measurements using a mercury column to a uniform basis in terms of the standard millimetre of mercury or standard inch of mercury as a unit of pressure; (2) to convert old data reported in standard millimetres or inches of mercury using standard barometric tabies to a pressure unit consistent with the mechanical units of pressure, SI units; and (3) to convert accurate pressure measurements made using a mercury column as a sensor directly to pressure in the SI units. It should be recognized that the actual density of mercury is a function not only of temperature but also of pressure and isotopic composition, and furthermore that the experimental determination of the density as a function of these variables is subject to experimental uncertainties that charge as improved procedures are introduced. We cannot, go into the details of these factors and their treatment over the years, and shall give only a sketch of the principal points related to the usage of the millimetre of mercury as a unit of pressure.

The conclusion that has been drawn from this historical survey is that the standard atmosphere and $760 \mathrm{mmHg}$ are identical today. Except, perhaps, for measurements of the highest precision, the two units have been the same for eighty years.

1. The General Conference on Weights and Measures, CGPM, in 1901 (Resolution 3) adopted the value $980.665 \mathrm{~cm} \mathrm{~s} s^{-2}$ for the standard (normal) acceleration of gravity [1]*. This was confirmed in 1913 [2, p. 16].

References cited here are listed at the end of Appendix 5b. 
2. In 1913, Chappuis [3] presented selected values for the density and coefficient of expansion of mercliry and gave $\rho_{\mathrm{Hg}}\left(t=0{ }^{\circ} \mathrm{C}\right)=13.59515$ $\mathrm{g} \mathrm{cm}^{-3}$, under normal pressure, using the density of water at $4{ }^{\circ} \mathrm{C}=$ $0.999973 \mathrm{~g} \mathrm{~cm}^{-3}$. He cites earlier work (Chappuis (1907), [4]) for the coefficient of expansion and cites Marek (1883), [5] ( $d_{0}=$ 13.5956) and Thiesen and Scheel (1897), [6], $\left(d_{0}=13.59545\right)$ for the density of mercury at $0{ }^{\circ} \mathrm{C}$ relative to that of water at $4{ }^{\circ} \mathrm{C}$. He took the average of these and chose $d_{0}=13.59552$ from which he obtained the value listed above for the absoiute density of mercury. The uncertainty in the value given is \pm 0.00008 based only on the range of values from which it was derived.

3. In 1917 Leduc [7] used for standard conditions in determining the standard density of air: $p=76 \mathrm{~cm} \mathrm{Hg}, g=980.665 \mathrm{~cm} \mathrm{~s}^{-2}$, and $\rho_{H g}\left(\right.$ at $\left.t=0{ }^{\circ} \mathrm{C}\right)=13.5951 \mathrm{~g} \mathrm{~cm}^{-3}$, for which, however, he gave no citation of source.

4. The Smithsonian Meteorological Tables (Fourth Revised Edition, 1918) [8] introduced new tables for converting millimetres of mercury to millibars using the standard acceleration of gravity adopted by the CGPM in 1901 ( $980.665 \mathrm{~cm} \mathrm{~s}^{-2}$ ), and the density of mercury $\rho_{\mathrm{Hg}}\left(\right.$ at $\left.0{ }^{\circ} \mathrm{C}\right)=13.5951 \mathrm{~g} \mathrm{~cm}^{-3}$, taken from Chappuis [3] and Leduc [7]. These tables were widely used in the United States for the correction of manometric and barometric measurements using mercury as an indicator to pressures.

5. N. E. Dorsey (1926), [9] for the Internationai Critical Tables, defined the normal atmosphere as the pressure exerted by a vertical column of 1 iquid $76 \mathrm{~cm}$ long, density $13.5951 \mathrm{~g} \mathrm{~cm}^{-3}$, acceleration of gravity being $980.665 \mathrm{~cm} \mathrm{~s}^{-2}$. Incidentally, the British atmosphere is stated to be based on 30 inches $(76.2 \mathrm{~cm}$ ) rather than $76 \mathrm{~cm}$. 
6. In 1926 Kimbal1 [10], for the International Critical Tables section on barometry and manometry, gave the standard density of mercury as $13.5951 \mathrm{~g} \mathrm{~cm}^{-3}$, and the standard acceleration of gravity of 980.665 $\mathrm{cm} \mathrm{s}^{-2}$ without reference, but his temperature corrections are referred to the International Meteorological Tables [11]. (We have not found those numbers in the IMT, they may have been derived by Kimbal1).

7. In 1927 the Bureau of Standards, the National Physical Laboratory and the Physikalische Technische Reichsanstalt submitted a text of a proposed international temperature scale in which the standard (normale) atmospheric pressure is defined as the pressure exerted by a column $760 \mathrm{~mm}$ in height of mercury having an average density of $13.595 \mathrm{~g} \mathrm{~cm}^{-3}$ under an acceleration of gravity equal to 980.665 $\mathrm{cm} \mathrm{s}^{-2}$; equivalent to 1013250 dynes $\mathrm{cm}^{-2}$ [CGPM 1927, ref. 12]. No source is given for the numbers, but they were modified and reiterated in 1933 [13] with a corrected text in which the density of mercury is changed to $13.5951 \mathrm{~g} \mathrm{~cm}^{-3}$. The number thus conforms to the value given by the Smithsonian Meteorological Tables. The numbers are related by the relationship:

$$
1013250 /(980.665 \cdot 76)=13.595098
$$

or by:

$$
12.5951 \cdot 76 \cdot 980.665=1013250.14
$$

Thus it is apparent that a value for the standard atmospheric pressure had been chosen to be in close accord with a standard height $(76 \mathrm{~cm})$ of a column of mercury of average density equal to the best known value at the time, and under the standard acceleration of gravity. It will be noted that the specified average density is 
slightly less than the value at normal pressure given by Chappuis in 1913 [3]. This is consistent with the fact that the average pressure on the mercury in a barometer is only $1 / 2$ the external pressure and thus the average density should be less than that given by Chappuis. The deviation should be about $3 \times 10^{-5} \mathrm{~g} \mathrm{~cm}^{-3}$ which would reduce Chappuis' value to 13.59512 with an uncertainty of 0.00008 . The value rounded to 13.5951 thus contains the last significant figure.

8. In 1948 the CGPM presented the international temperature scale of 1948 which reiterated the previous standard pressure in all details [14, pg. 93]. However, a change of emphasis occurred. The standard pressure [14, pg. 90] is defined as 1013250 dyries $\mathrm{cm}^{-2}$ and the mercury scale is related to it. It adds that except for work of the highest precision one can accept that the mercury of commerce has the specified average density $13.5951 \mathrm{~g} \mathrm{~cm}^{-3}$ in the column of $760 \mathrm{~mm}$.

9. The CGPM, in 1954 considered the definition of the standard atmosphere in 1948 might be construed as applying only to precision thermometry [15]. It, therefore, adopted a resolution (Resolution 4) defining one standard (normale) atmosphere as 1013250 dynes $\mathrm{cm}^{-2}$ or 101 325 newtons per square metre, thus validating definitively the standard value to be used, and removing any ambiguity about the calculations given in paragraph 7 .

10. In 1957 Cook and Stone [16] reported some measurements of the density of mercury at $20^{\circ} \mathrm{C}$ and reported:

$$
\rho_{\mathrm{Hg}}\left(20^{\circ} \mathrm{C}\right)=13.5458924 \mathrm{~g} \mathrm{~cm}^{-3}
$$


which reduces at $0{ }^{\circ} \mathrm{C}$ to $13.5950889 \mathrm{~g} \mathrm{~cm}^{-3}$. Cook (1961, ref. 17) extended these measurements and reported a summary value including both sets of $\rho_{\mathrm{Hg}}\left(\right.$ at $\left.20{ }^{\circ} \mathrm{C}, 1 \mathrm{~atm}\right)=13.545884 \mathrm{~g} \mathrm{~cm}^{-3}$ which, reduced to $0{ }^{\circ} \mathrm{C}$, becomes:

$$
P_{\mathrm{Hg}}\left(0^{\circ} \mathrm{C}, 1 \mathrm{~atm}\right)=13.595080 \mathrm{~g} \mathrm{~cm}^{-3} \text {, }
$$

with a standard deviation of $0.2 \times 10^{-6}(0.2 \mathrm{ppm})$. These densities at $t=0{ }^{\circ} \mathrm{C}$ round to $13.5951 \mathrm{~g} \mathrm{~cm}^{-3}$. Thus the value used traditionally for barometry and manometry is accurate in the sixth figure.

11. Brombacher, Johnson, and Cross (1960, ref. 18) for the NBS monograph on mercury barometers and manometers used the value $\rho_{\mathrm{Hg}}\left(0{ }^{\circ} \mathrm{C}\right)=13.5951 \mathrm{G}$ $\mathrm{cm}^{-3}$, the standard atmosphere, $1013.250 \mathrm{mbar}$, and the standard acceleration of gravity $980.665 \mathrm{~cm} \mathrm{~s}^{-2}$.

12. In 1960, the eleventh General Conference on Weights and Measures adopted the International Practical Temperature Scale of 1948 amended 1960 [19, pg. 63]. In the amended text [19, p. 127] the statements are made that in practice pressures are determined by means of a column of mercury and that one can assume that the density at $20^{\circ} \mathrm{C}$ of pure mercury is $13545.87 \mathrm{~kg} \mathrm{~m}^{-3}$ as an average in a column of mercury that balances 1 atmosphere. They also recommended the use of the Potsdam system for determination of local gravity for realization of the standard atmosphere.

13. In 1964 Bigg [20] reviewed the density of mercury and used the data of Cook [17] and the thermal expansion formula of Beattie et al [21] which is the same as was used by Cook, to calculate a table of dersities of mercury as a function of temperature at $P=1 \mathrm{~atm}$. He tabulated $\rho_{\mathrm{Hg}}\left(20{ }^{\circ} \mathrm{C}\right)=13.54588 \mathrm{~g} \mathrm{~cm}^{-3}$ and $\rho_{\mathrm{Hg}}\left(0^{\circ} \mathrm{C}\right)=13.59508 \mathrm{~g}$ $\mathrm{cm}^{-3}$ which are the rounded values of Cook. 
14. Bonhoure and Terrien [1968, ref. 22] working at the International Bureau of Weights and Measures, BIPM, used for the density of their mercury column the density at mid height, $\rho$ (mean) ${ }^{\star}$, and used the formula:

$$
\rho \text { (mean) }=\rho_{0} /\left[1-\alpha_{H g}\left(t_{H g}-20{ }^{\circ} \mathrm{C}\right)\right]\left[1-\beta_{H g}\left(p / 2-p_{N}\right)\right]
$$

for which $\rho_{0}$, the density of mercury at $20{ }^{\circ} \mathrm{C}=13.545892 \mathrm{~g} \mathrm{~cm}^{-3}$ obtained from Cook and Stone [13], $\alpha_{\mathrm{Hg}}=181.1 \times 10^{-6} \mathrm{~K}^{-1}, \beta_{\mathrm{Hg}}=39$ $\times 10^{-12} \mathrm{~m}^{2} \mathrm{~N}^{-1}$ and $p_{\mathrm{N}}=101325 \mathrm{~N} \mathrm{~m}^{-2}$. The density given at $20{ }^{\circ} \mathrm{C}$ can be derived from the formula and data of Bonhoure and Terrien. The term $-\beta\left(p / 2-p_{n}\right)$ becomes $+1.975 \times 10^{-6}$, and this leads to $\rho_{\mathrm{Hg}}\left(20^{\circ} \mathrm{C}\right.$, mean $)=13545.8652 \mathrm{~kg} \mathrm{~m}^{-3}$. If the more recent work of Cook $[14]$ is used for $\rho_{\mathrm{O}}, \rho_{\mathrm{Hg}}\left(20^{\circ} \mathrm{C}\right)=13545.884 \mathrm{~kg} \mathrm{~cm}^{-3}$, then $\rho_{\mathrm{Hg}}\left(20{ }^{\circ} \mathrm{C}\right.$, mean $)=13545.857 \mathrm{~kg} \mathrm{~m}^{-3}$.

15. In 1968 the 13th CGPM adopted the International Practical Temperature Scale of 1968 ([23], resolution 8, p. 62, p. 105; full text, pp. AI-A24). The formula for calculating the density of mercury as a function of temperature and pressure is given as: $\rho\left(t_{68}\right.$, mean $)=\rho\left(20{ }^{\circ} \mathrm{C}, p_{0}\right) /\left[1+A\left(t_{68}-20^{\circ} \mathrm{C}\right)+B\left(t_{68}-20^{\circ} \mathrm{C}\right)^{2}\right]$

$$
x\left[1-x\left(p / 2-p_{0}\right)\right]
$$

where $A=18115 \times 10^{-8}{ }^{\circ} \mathrm{C}^{-1} ; B=0.8 \times 10^{-8}{ }^{\circ} \mathrm{C}^{-2}, \mathrm{x}=4 \times 10^{-11} \mathrm{~N}^{-1}$ $\mathrm{m}^{2}$, and $\rho\left(20{ }^{\circ} \mathrm{C}, p_{0}\right)=13545.87 \mathrm{~kg} \mathrm{~m}^{-3}$ for pure mercury when $p_{0}=$ $101325 \mathrm{~N} \mathrm{~m}^{-2}$. The term $-x\left(p / 2-p_{0}\right)$ has the value $+2.0265 x$ $10^{-6}$. The value of $\rho_{\mathrm{Hg}}\left(20{ }^{\circ} \mathrm{C}\right.$, mean $)=13545.842 \mathrm{~kg} \mathrm{~m}^{-3}$. The temperature correction to $t=0{ }^{\circ} \mathrm{C}$ is:

$$
\begin{gathered}
\rho\left(20^{\circ} \mathrm{C}\right) / \rho\left(0{ }^{\circ} \mathrm{C}\right)=1-20 \times 18115 \times 10^{-8}+400 \times 0.8 \times 10^{-8}= \\
1-0.00362300+0.000003_{2}=0.9963802
\end{gathered}
$$

* We use the term $\rho$ (mean) in all cases where authors have referred to pressures at mid height, at $p / 2$ or average densities. 
$\rho_{\mathrm{Hg}}\left(0{ }^{\circ} \mathrm{C}\right.$, mean $)=13595.053 \mathrm{~kg} \mathrm{~m}^{-3}$. The value resulting from a similar calculation but not using the CGPM (1968) formula was found by Armstrong [24] to be $\rho_{\mathrm{Hg}}\left(20{ }^{\circ} \mathrm{C}\right.$, mean $)=13595.052 \mathrm{~kg} \mathrm{~m}^{-3}$ in good agreement.

16. Brown and Lane [25] reviewed the density of mercury in 1976. They cited the formula and constants as given by CGPM in 1968 [23] and presented a table for $\rho_{H g}\left(t_{68}, p_{0}\right)$ derived in the same way as that of Bigg [20] except converted to IPTS-1968. They used $p_{0}=1.01 .32 .5$ $\mathrm{kPa}$ and tabulated $\rho_{\mathrm{Hg}}\left(0^{\circ} \mathrm{C}, p_{\mathrm{O}}\right)=13595.08 \mathrm{~kg} \cdot \mathrm{m}^{-3}$ in exact agreemenc with the value calculated by Cook [17].

As a result of this survey, it is quite clear that for precise measurements of pressure using a mercury column (purpose 3 above) the accurate determination of density by Cook [17] and interpolation formulas such as are given by Brown and Lane [25] should be used. However, it is also clear that the standard millimetre of mercury used in estabTishing the relationship between the standard aimosphere specified as $750 \mathrm{~mm} \mathrm{Hg}$ and the standard atmosphere as $101.325 \mathrm{kPa}$ is not based on the recent measurements of Cook but is based on much earlier measurements. The value used for the density of mercury, $\rho_{\mathrm{Hg}}\left(0^{\circ} \mathrm{C}\right.$, average $)=13.5951 \mathrm{~g} \mathrm{~cm}^{-3}$, was given official standing by CGPM in 1927 (as corrected in 1933) and confirmed in 1948. This density was derived by Chappuis in 1913 from earlier measurements and shortened to the present last significant figure (six figures) by Leduc in 1917 . It was adopted by such internationally used compilations as the International Critical Tables and the Smithsonian 
Meteorological Tables, and finally placed in the status of a defined value by CGPM.

The exact process has not been discovered by which the decision was made that the standard atmosphere should be $101.325 \mathrm{kPa}$ (101 3250 dynes $\mathrm{cm}^{-2}$ ) exactly, rather than a column of height $760 \mathrm{~mm}$ of mercury of density $13.5951 \mathrm{~g} \mathrm{~cm}^{-3}$ in a standard gravity of 980.665 $\mathrm{cm} \mathrm{s} \mathrm{s}^{-2}$.

It is clear however, on the basis of the CGPM decisions in 1933 and 1948 that the selected pressure was, within the limits of accuracy of the measurements, identical on the two bases.

We believe the relationships given in paragraph 7 , above, constitute a definition of the unit, $\mathrm{mmHg}$, which is most applicable to pressure measurements made during the long period from about 1917 to 1957 , that there is no point in refining further an obsolescent unit and that the accuracy of the quantities measured does not warrant defining the mean $\rho_{\mathrm{Hg}}\left(\mathrm{O}^{\circ} \mathrm{C}\right)$, to greater than six figures for the purpose of identifying the pressure reference condition.

The value chosen for this document is therefore:

$$
\rho_{\mathrm{Hg}}\left(0^{\circ} \mathrm{C}, \text { mean }\right)=13595.1 \mathrm{~kg} \mathrm{~m}^{-3}
$$

Within the limits of measurement the unit of pressure, $\mathrm{mmHg}$, is identical to the Torr, i.e.

$$
1 \mathrm{mmHg}=1 \text { Torr } \equiv \frac{101325 \mathrm{~Pa}}{760}=133.322 \mathrm{~Pa} \text {, }
$$

These correspondences are included in the ASTM standard for Metric Practice [26]. On this basis a reference pressure of $760 \mathrm{mmHg}$ is identical to $101.325 \mathrm{kPa}$. 
References to Appendix 5b

1. CGPM (1901); Compt. rend. des seances de la troisieme conference general des poids et mesures, Paris 1901. Paris, Gauthier-Villars (1901); p. 68. (See also Reference 2, page 16).

2. "The international system of units"; NBS Special Publication 330 1977 Edition. Washington, D.C. 20402: U.S. Government Printing Office (1977).

3. Chappuis, P.; "Densite et dilatation du mercure"; Table 40 in $\mathrm{H}$. Abraham and P. Sacerdote editors, Societe Francaise de Physique Recueil de Constantes Physiques, Paris: Gauthier-Villars, (1913), p. 139 .

4. Chappuis, P.; "Dilatation du inercure", Trav. Mem. Bur. Int. Poids Mes. (1907) 13, 1-31.

5. Marek, W. J.; Trav. et Mem. Bureau International des Poids et Mesures (1883), 2 , D1-58, particularly pp. 55-58.

6. Thiesen, M.; Scheel, K.; Se11, L.; "Untersuchungen uber die thermische ausdehnung von festen und tropfbar flüssigen körpern". Wissenschaftliche Abhandlungen der Physikalische-technische Reichs-anstalt,, (1895), p. 73-184. (We have not identified a reference to Thiesen and Scheel in 1897. The present citation contains the pertinent data.)

7. Leduc, A.; Traveaux et memoires du Bureau Internationale des Poids et Measures, (1917), XVI, pp. 1-37 (end of volume).

8. Smithsonian Meteorological Tables; 4th Revised Edition. Washington: The Smithsonian Institution (1918), pp. iii, svi i, xviii.

9. Dorsey, N. E. ; "Selected technical terms"; International Critical Tables, New York: McGraw-Hill Book Company (1926), Volume 1, p. 24. 
10. Kimball, H. H.; "Barometry and manometry"; International Critical Tables. New York: McGraw-Hill Book Company (1926), Volume 1, pp. 68-70.

11. International meteoroiogical committee; "International meteorological tables"; Gauthier-Villars, Paris, (1890).

12. CGPM (1927); Compt. rend. des seances de la septieme conference general des poids et mesures, (1927). Paris: Gauthier-Villars (1927-1928), p. 95.

13. CGPM (1933); Compt. rend. des seances de la huitieme conference general des poids et mesures (1933). Paris: Gauthier-Villars (1934), p. 74 .

14. CGPM (1948); Compt. rend. des seances de la neuvieme conference general des poids et mesures (1948). Paris: Gauthier-Villars (1949), pp. 90 .

15. CGPM (1954); Comptes rendus des séances de la dixiéme conference générale des poides et mesures (1954), pg. 80. See ailso ref. 2. for the same material.

16. Cook, A. H.; Stone, N. W. B.; Phil. Trans. Roy. Soc. (London) (1957), A250 277.

17. Cook A. H.; Phil. Trans. Roy. Soc. (London) (1961), A254, 125-154.

18. Brombacher, W. G.; Johnson, D. P.; and Cross, J. L.; "Mercury barometers and manometers"; Nat. Bur. Standards (1960), Monograph 8.

19. CGPM (1960); Comptes rend. des seances de la onzieme conference general des poids et mesures (1960), p. 63, p. 127.

20. Bigg, P. H.; Brit. J. App 1. Phys. (1964), 15, 1111-1113.

21. Beattie, J. A. ; Blaisde11, B. E.; Kaye, J.; Gerry, H. T.; and Johnson, C. A.; Proc. Amer. Acad. Arts Sci. (1941), 71, 371. 
22. Bonhoure, J.; Terrien, J.; Metrologia (1968), 4, No. 2, pp. 59-68.

23. CGPM (1968); Compt. Rend. des seances de la treizieme conference general des poids et mesures $(1967,1968)$, p. 62, p. 105, pp. A1-A24 (esp. p. A8).

24. Armstrong, G. T.; "Calculation of the heating value of a sample of high purity methane for use as a reference material"; Nat. Bur. Standards (U.S.) Technical Note 299 (U.S. Government Printing Office, Washington, D.C. ), (1966).

25. Brown, I.; Lane, J. E.; (Herrington, E. F. G.; editor). Recommended reference materials for realization of physicochemical properties. Section: Density. Pure and Applied Chemistry (1976), 45, 1-9.

26. ASTM (1976); "Standard for metric practice"; ASTM desgination E-380-76 (also American National Standard Z210.1) pp. 29, 35 Philadeiphia: American Society for Testing and Materials Annual Book of ASTM Standards Parts 41 and others, (1976 and later years). 
Appendix 6. Discussion of reference conditions

The values of pressure, temperature, state of gas, and water content to be used for defining the reference conditions of measurement of natural gas are listed in table 2. Various standardizing bodies have selected different values or conditions of these parameters for "base conditions" or reference conditions. The actual values used in the measurement of the properties of a gas are extremely important in custody transfer as well as in calculations of performance if comparability of the heating value of the gas is to be realized. This is particularly true for volumetric measurement of gas because the volume occupied by a given quantity of the gas is strongly dependent on them. To a lesser extent, though still significantly, the heating value of a given mass of gas is dependent on these parameters. The values for these parameters that have been recommended by various groups are discussed below.

Temperature. For many years in the United States a reference temperature of $60{ }^{\circ} \mathrm{F}\left(155 / 9^{\circ} \mathrm{C}, 288.7055 \ldots \mathrm{K}\right.$, rounded to $\left.288.71 \mathrm{~K}\right)$ has been used both in the natural gas industry, and in petroleum products industries as the temperature to which volumetric measurements and measurements of properties should be referred, whereas European practice has been to use $15{ }^{\circ} \mathrm{C}[9 \mathrm{a}]^{\star}$. In recent years in an attempt to bring greater conformity to U.S. and European measurement practices, U.S. practice has been moving to the adoption of $15^{\circ} \mathrm{C}$ ( $59^{\circ} \mathrm{F}$ or $288.15 \mathrm{~K}$ ) as a reference temperature. See, for instance [1] or [9b]. ASTM Committee D-3 on Gaseous Fuels has recently adopted $15^{\circ} \mathrm{C}$ as the reference temperature for metric measurement of natural gas samples [9b] as has the American Gas Association; and the American Petroleum Institute appears also to be adopting $15{ }^{\circ} \mathrm{C}$ for gas measurements [10].

\footnotetext{
* References cited in this appendix are in the General List.
} 
On the other hand, for many years scientifically oriented measurements universaily have often been referred either to $25{ }^{\circ} \mathrm{C}\left(298.15 \mathrm{~K}\right.$ ) or $0{ }^{\circ} \mathrm{C}$ (273.15 K) as a standard temperature [8]. The former temperature is cited in many compilations of the properties of hydrocarbons. See for exampies Table A7e in Appendix 7. $T=273.15 \mathrm{~K}$ is used in Japan as the reference temperature. Because there is widespread use of each of these four temperatures information is given in this handbook for converting measurements from one of these temperatures to another. However, $15{ }^{\circ} \mathrm{C}$ $(288.15 \mathrm{~K})$ and $60^{\circ} \mathrm{F}(288.7055 \ldots \mathrm{K})$ are the reference temperatures selected for presentation of the tables of heating values measured on a volumetric basis.

Pressure. The situation with respect to reference pressure is much the same as with respect to temperature. European practice has been to use 101. $325 \mathrm{kPa}$ (1 atm). Early gas industry practice in the United States emphasized a pressure base of $30 \mathrm{inHg}$ (762 Torr, $101.5913 \mathrm{kPa}$ ) which converts to $14.7345+p s i a$; and was often rounded to $14.73 \mathrm{psia}$ (101.559.77 $\mathrm{kPa}$ which is rounded to $101.560 \mathrm{kPa}$ ). However usage of other pressure bases has been wi despread.

The pressure 14.73 psia was adopted by ANSI in 1969 (ANSI Z 132.1 1969) [10] apparently without reference to existing standards which defined the base pressure as $30 \mathrm{initg}$, a round number that can be presumed intended to be exact: ASTM D 1071-55; USA Standard Z 77.5 - 1963 (Later American National Standard Z 77.5 - 1973) and ASTM D 900-55; USA Standard Z 68.1 - 1956 (1ater American National Standard Z 68.1 - 1973). It is unclear whether 14.73 psia was intended to be equivalent to $30 \mathrm{inHg}$ or whether it was intended to be exact. Unfortunately the difference is significant in tabulated values of enthalpies of combustion of gaseous hydrocarbon compounds on a volumetric basis. The difference is, however, 
less than other uncertainties in the measurement of total heating value. Because ASTM has followed the lead of ANSI in the use of this number (see ASTM D 1071-78a, ref. 9b) we use the value 14.73 pisa as exact in making the calculations, and not as a shorthand notation for $30 \mathrm{inHg}$.

In scientific work a slightly different pressure, usually called the standard atmosphere ( $1 \mathrm{~atm}=101.325 \mathrm{kPa}$ by definition $[2,5]$ ) has been used for many years. This pressure has been recently adopted in ASTM standards for measurement of gaseous volumes in metric units and by the American Gas Association and is apparently being adopted by the American Petroleum Institute [10]. This pressure has been used also as the standard state pressure for reporting thermodynamic quantities. However, recent action by IUPAC Commission on Thermodynamics [3] recommends that a new pressure, $100.000 \mathrm{kPa}(=1 \mathrm{bar})$, be adopted as the standard pressure to which the thermodynamic standard state would apply. While widespread usage of this new reference pressure may not occur until some time in the future, notice is taken of it in this document.

Information is given to allow calculations to be made for each of these three reference pressures. However, for consistency with gas industry measurement practice the tables are given for the reference pressure of 101.325 and $101.560 \mathrm{kPa}$.

Gas ideality. The use of real gas properties is universal in practical measurements in the gas industry. However, the properties of real gas mixtures are functions of the composition. As a result of the fact that tabulation of the properties of aTl real gas mixtures is impossible, and because the components of natural gas (other than $\mathrm{CH}_{4}$ ) are generally present as a small fraction of the total gas it is more useful to emphasize ideal gas properties for the pure gases and to utilize the virial coefficients and compositions for calculation of the properties of mixtures on an ad hoc basis. 
Water content. Natural gas in production, transmission and distribution usually has a relatively low water content. Hence, for most purposes the dry gas is a better reference state than the water-saturated gas. However, for determination of heating value by the continuous flow recording combustion calorimeter, the measurement devices require the gas to be water-saturated before combustion. This is because the wet test meters used for metering the amount of gas burned are water-filled, and because the entering gases must be water-saturated in order to assure that all the water formed is condensed to the liquid state in the calorimeter in order to determine the gross heating value. Thus for determination of calorific value, the water-saturated gas is a better reference state than the dry gas. (In any custody transfer it is necessary to identify which reference state is used. This document provides factors for converting between dry and water-saturated gas.)

Metric and U.S. Customary reference conditions

Both the temperature and pressure are different in the ANSI/ASTM/API reference conditions ( $60^{\circ} \mathrm{F}, 14.73 \mathrm{Psi} ; 288.71 \mathrm{~K}, 101.560 \mathrm{kPa}$ ) and in the ISO/ANSI/ASTM metric reference conditions (288.15 K, $101.325 \mathrm{kPa}$ ). Conversion of a molar thermodynamic property of an ideal gas from one reference condition to the other requires correction only for temperature. For volumetric properties there are both temperature and pressure corrections. For properties of real gases there always are both temperature and pressure corrections. 
Appendix 7. Thermodynamic data: their sources and uncertainties

7a. Sources of thermodynamic data

Heat capacity and enthalpy increment

Standard heat capacities at constant pressure and at $298.15 \mathrm{~K}$ for the substances in Tables 3 and 4 are taken from Table A7a which summarizes an evaluation by wilhoit $[1]^{\star}$. These are selected instead of those of Rossini et al. [2] because they are based on more recent and more detailed calculations. Wilhoit has presented his results in the form of polynomials of degree two that are valid in the temperature range from 268 to $308 \mathrm{~K}$. The constants of the polynomials, a reference to the method of calculation of $C_{p}$ and the value of $C_{p}^{\circ}(298.15 \mathrm{~K})$ calculated from the polynomial are presented in Table A7a.

The polynomials have the dimensionless form:

$$
c_{p}^{\circ} / R=a+b(T-273.15 \mathrm{~K})+c(T-273.15 \mathrm{~K})^{2}
$$

in which the values of $a, b, c$ are determined by the method of least squares to fit the data given in the references.

The enthalpy difference is calculated from $C_{p}^{0}$ as

$$
\begin{gathered}
H\left(T_{2}\right)-H\left(T_{1}\right)=\int_{T_{1}}^{T_{2}} C_{p}^{0} \mathrm{~d} T \\
=R \int_{T_{1}}^{T_{2}}\left[a+b(T-273.15 \mathrm{~K})+c(T-273.15 \mathrm{~K})^{2} \mathrm{~d} T\right.
\end{gathered}
$$

\footnotetext{
* References are listed at the end of the appendix.

${ }^{* *}$ Tables A7a through $A 7 f$ are at the end of Appendix $7 a$.
} 


$$
\begin{aligned}
H^{\circ}\left(T_{2}\right)-H^{\circ}\left(T_{1}\right) & =R\left[a\left(t_{2}-t_{1}\right)+(b / 2)\left(t_{2}^{2}-t_{1}^{2}\right)\right. \\
& \left.+(c / 3)\left(t_{2}^{3}-t_{1}^{3}\right)\right]
\end{aligned}
$$

where $t=T-273.15 \mathrm{~K}$, i.e. the Celsius temperature.

The values of $C_{p}(298.15 \mathrm{~K})$ in Tables 3,4 and $A 7$ a differ by less than $1 \mathrm{~J} \mathrm{~mol}^{-1} \mathrm{~K}^{-1}$ from those given by Rossini et al. [2] and by Stuli, Westrum and Sinke [3], except for 2-methylpentane, 1.84; 3-methylpentane, 2.89; cyclobutane, 1.36; cyclohexane, 1.02 ; and benzene, $-3.91 \mathrm{~J} \mathrm{~mol}^{-1} \mathrm{~K}^{-1}$. In the last case, the maximum difference the use of the polynomial would cause in the tabulated enthalpy of combustion is $0.04 \mathrm{~kJ} \mathrm{~mol}^{-1}$ (in approximately $3303 \mathrm{~kJ} \mathrm{~mol}^{-1}$ ); or $1.2 \times 10^{-5}$ relative error in the enthalpy of combustion. This is considered to be well within the uncertainty of the measured enthalpy of combustion.

Enthalpies of formation

The values of $\Delta_{f} H^{\circ}(298.15 \mathrm{~K})$ for the auxiliary substances in Table 3 were taken from the recent recommendations of the CODATA Task Group on Key Values for Thermodynamics [15]. These do not differ significantly from those given by Wagman et al., [16], and (except possibly for $\mathrm{H}_{2} \mathrm{~s}$ ) may be expected to be used in the next generation of chemical thermodynamic tables and to be used internationally.

Enthalpy of combustion

The selected values of the standard molar enthalpy of combustion at 298.15 K of each gaseous substance are listed in Table A7b (and are repeated in Table 4). These are taken from an evaluation by Domalski $[17,18 \mathrm{~b}]$ and have been previously published by Armstrong, Domalski and Minor [18a]. If the enthalpy of combustion of the gas depends upon measurements made on the liquid, $\Delta_{c} H^{\circ}$ for the liquid is also given. For each value, references are given to the source of the data used in making the selection as well 
as others examined but not used. The agreement of this selected value with those in several compilations of critically evaluated data is also shown. In most cases, the values presented here are consistent with those in the API tables [2] and their successors $[76,77]$.

Methane is considered here in slightly more detail than the other hydrocarbons, both because of its importance in natural gas and also as an illustration of the problems that must be faced when selecting a "best value."

The sources of original measurements of enthalpy of combustion for methane are given in Table A7c in chronological order. These eight studies provide the entire measurement set. (There are fewer for some of the other hydrocarbons.) Because of the great increase in experimental accuracy and precision in the early 20th century, only the three measurements reported after 1930 are of any importance. Of these, only the studies of Rossini [55] and of Pittam and Pilcher [48] are considered today, because of the method used and the higher precision of measurement.

Those two sets total to 12 experiments, the values for which, corrected to $298.15 \mathrm{~K}$ and ideal conditions, are listed in Table A7d. The results of the two studies overlap, their precisions (separately) are similar, and it is not clear that any of the points can be discarded. If there were no other considerations, it would be appropriate to pool the data and take an average: $890.65 \mathrm{~kJ} \mathrm{~mol}^{-1}$. There are, however, several additional points to be considered.

1. The impurity level of the synthetic methane used by Pittam and Pilchel was less than $5 \mathrm{ppm}^{*}$. Rossini also used a sample of synthetic methane with a measured 1219 ppm impurity of CO, for which a correction was made. The NBS reference sample of methane (83), from a natural gas source and with a $400 \mathrm{ppm}$

We are indebted to Prof. H. A. Skinner for information about this sample. 
ethane impurity, has about the same enthalpy of combustion as that reported by Pittam and Pilcher (using Rossini's value for methane).

2. Pittam and Pilcher measured $\mathrm{CO}_{2}$ production to determine the extent of reaction, a preferred method, while Rossini measured water production. Both used flow calorimetry, with about the same precision. Pittam and Pilcher's value depends, via their calibration, on Rossini's measurement of the enthalpy of formation of water (adding to the uncertainty) while Rossini's value for methane does not.

3. Both Rossini and coworkers $(39,50,51,52,55,56)$ and Pilcher and coworkers $(47,48)$ have measured the enthalpies of the $C_{I}$ to $C_{6}$ hydrocarbons. There is overlap with studies by Good $(31,32)$. There does not seem to be any systematic difference separating the work in Rossini's iaboratory and that in Pilcher's, but there may be more scatter in the eariier work.

4. Correlations of enthalpies of formation for the alkanes favor the more uniform values (with respect to the increment for $\mathrm{CH}_{2}$ ) of Pittam and Pilcher and may favor a value for methane that is between those of the two studies. The latter may be more of an evaluator's decision than a property of the correlations: methane occupies a unique position.

A preliminary analysis of these four factors indicates that both studies should be considered in a reassessment. Neither outranks the

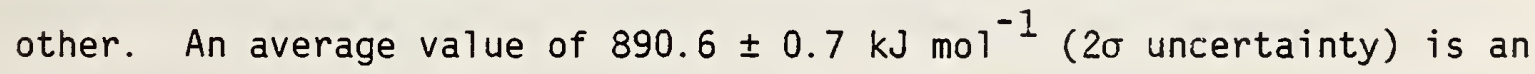
appropriate choice, considering methane alone.

In our opinion, however, there should be a thorough-going reassessment of the thermodynamic properties of the lower alkanes as a group before any, probably sma11, readjustments are made. Somayajulu et al. [98] have suggested a possible revision. It is probable, however, that an improvement can come only from new, highly accurate measurements. There also are additional considerations that are related more to gas technology than to the combustion experiments. 
5. Recording flow calorimeters that are commonly used in determining heating values are calibrated against samples of methane for which the heating vaiues are certified. In the U.S.A., and possibly elsewhere, these certifications are now based on analysis of the gas and calculation of the heating value, using procedures outlined in this document. If the enthalpy of combustion of methane is revised, a plan must be developed to (a) recertify the standard samples and (b) recalibrate the calorimeters (or revise the calibration factors now in use). It would be advisable to develop this plan now and have it agreed upon by the various standardssetting and user groups.

6. Based on existing measurements a revision of the enthalpy of combustion of methane would be to a value that lies within the uncertainty (2 $\sigma$ ) of the present recommendation and the new value would have an equally large uncertainty. It may then be questioned whether a new value, strongly overlapping with the old one, should be introduced in technical practice.

Because of these last two factors and the desirability of a reassessment of the lower alkanes as a group, we have retained the older value which is the basis for many existing tables of calorific values. When a revision is made of $\Delta_{C} H(298.15 \mathrm{~K})$ for any of the gases of interest here, the procedures given in this document and data in the tables will permit straightforward calculation of new heating values at the various reference conditions. Compiled data on methane

Several compiiers, have reevaluated the original data and have reported values (primary compilations). Others have adopted and applied these results (secondary compilations). The more significant compilations of both types are listed in Table A7e, together with the reported value for methane (converted to SI units if originally given in other units).

Except for the selection by Pedley and Rylance [45] all of these values can be traced to Rossini's measurements [55] usually via the API 
tables $[2,76,77]$. Slight differences reflect different reanalyses, weighting, rounding procedures or variant auxiliary data. In the light of the spread of the data they are immaterial.

In this same table is listed the atomic mass scale used by each compilation, if it could be identified. If not, the most recent scale with which molecular masses are consistent is indicated. The atomic mass scale designations are keyed to Table A5a.

Vapor pressure of water

The values used here are given in Table A7f for each of the reference temperatures. The correlation equation given in the table may be used for other temperatures in the same range. 
Table A7a. Heat capacity equations for auxiliary substances and hydrocarbons for the range 268 to $308 \mathrm{~K}$ for the squation $C_{p}^{0} / R=a+b(T-273.15 \mathrm{~K})+$ $c(T-273.15 \mathrm{~K})^{2}[1]^{*}$

\begin{tabular}{|c|c|c|c|c|c|c|}
\hline Compound & Formula & $\bar{a}$ & $100 \mathrm{~b} / \mathrm{K}$ & $10^{5} c / k^{2}$ & $\frac{c_{\left.p^{(298.15} \mathrm{K}\right)}}{\mathrm{Jmol}^{-1} \mathrm{k}^{-1}}$ & Reference \\
\hline methane & $\mathrm{CH}_{4}(\mathrm{~g})$ & 4.1947 & 0.3539 & 1.49 & 35.71 & [4] \\
\hline ethane & $\mathrm{C}_{2} \mathrm{H}_{6}(\mathrm{~g})$ & 5.9569 & 1.377 & 1.69 & 52.48 & {$[5]^{a}$} \\
\hline propane & $\mathrm{C}_{3} \mathrm{H}_{8}(\mathrm{~g})$ & 8.2671 & 2.286 & 1.90 & 73.59 & {$[5]^{a}$} \\
\hline n-butane & $\mathrm{C}_{4} \mathrm{H}_{10}(\mathrm{~g})$ & 11.109 & 2.875 & 1.82 & 98.44 & [6] \\
\hline 2-me thylpropane & $\mathrm{C}_{4} \mathrm{H}_{10}(\mathrm{~g})$ & 10.824 & 3.153 & 0.82 & 96.59 & {$[6]$} \\
\hline n-pentane & $\mathrm{C}_{5} \mathrm{H}_{12}(\mathrm{~g})$ & 13.587 & 3.288 & 2.98 & 119.96 & {$[7]^{b}$} \\
\hline $\begin{array}{l}\text { 2-methylbutane } \\
2,2 \text {-dimethyl- }\end{array}$ & $\mathrm{C}_{5} \mathrm{H}_{12}(\mathrm{~g})$ & 13.412 & 3.540 & 1.40 & 118.94 & {$[7]^{b}$} \\
\hline propane & $\mathrm{C}_{5} \mathrm{H}_{12}(\mathrm{~g})$ & 13.584 & 3.846 & 0.45 & 120.96 & {$[7]^{b}$} \\
\hline n-hexane & $\mathrm{C}_{6} \mathrm{H}_{14}(\mathrm{~g})$ & 16.134 & 3.986 & 3.60 & 142.62 & {$[7]^{b}$} \\
\hline 2-methylpentane & $\mathrm{C}_{6} \mathrm{H}_{14}(\mathrm{~g})$ & 26.064 & 4.172 & 2.21 & 142.35 & {$[7]^{b}$} \\
\hline $\begin{array}{l}\text { 3-methylpentane } \\
\text { 2-2-dimethyl- }\end{array}$ & $\mathrm{C}_{6} \mathrm{H}_{14}(\mathrm{~g})$ & 15.768 & 4.351 & 1.11 & 140.20 & {$[7]^{b}$} \\
\hline butane & $\mathrm{C}_{6} \mathrm{H}_{14}(\mathrm{~g})$ & 15.877 & 4.579 & 0.52 & 141.55 & {$[7]^{b}$} \\
\hline $\begin{array}{l}2,3 \text {-dimethyl- } \\
\text { butane }\end{array}$ & $\mathrm{C}_{6} \mathrm{H}_{14}(\mathrm{~g})$ & 15.739 & 4.139 & 1.77 & 139.56 & {$[7]^{b}$} \\
\hline cyclopropane & $\mathrm{C}_{3} \mathrm{H}_{6}(\mathrm{~g})$ & 6.100 & 2.285 & 2.33 & 55.59 & {$[1]^{C}$} \\
\hline cyclobutane & $\mathrm{C}_{4} \mathrm{H}_{8}(\mathrm{~g})$ & 7.769 & 2.942 & 2.92 & 70.86 & {$[1]^{C}$} \\
\hline cyclopentane & $\mathrm{C}_{5} \mathrm{H}_{10}(\mathrm{~g})$ & 3.966 & 4.101 & 0.82 & 83.11 & [8] \\
\hline cyclohexane & $\mathrm{C}_{6} \mathrm{H}_{12}(\mathrm{~g})$ & 11.490 & 4.600 & 3.00 & 105.25 & {$[1]^{C}$} \\
\hline ethyne & $\mathrm{C}_{2} \mathrm{H}_{2}(\mathrm{~g})$ & 5.063 & 0.985 & -1.59 & 44.06 & {$[1]^{c}$} \\
\hline ethene & $\mathrm{C}_{2} \mathrm{H}_{4}(\mathrm{~g})$ & 4.880 & 1.024 & 1.50 & 42.78 & [9] \\
\hline propene & $\mathrm{C}_{3} \mathrm{H}_{6}(\mathrm{~g})$ & 7.277 & 1.858 & 0.80 & 64.41 & {$[10]$} \\
\hline benzene & $\mathrm{C}_{6} \mathrm{H}_{6}(\mathrm{~g})$ & 9.435 & 3.371 & 2.46 & 85.58 & [11] \\
\hline hel i um & $\mathrm{He}(\mathrm{g})$ & 2.500 & 0.000 & 0.00 & 20.78 & {$[1]^{d}$} \\
\hline argon & $\operatorname{Ar}(g)$ & 2.500 & 0.000 & 0.00 & 20.78 & {$[1]^{d}$} \\
\hline oxygen & $\mathrm{O}_{2}(\mathrm{~g})$ & 3.520 & 0.044 & 0.28 & 29.37 & {$[12]^{e}$} \\
\hline hydrogen & $H_{2}(g)$ & 3.433 & 0.155 & -0.74 & 28.83 & {$[12]^{e}$} \\
\hline nitrogen & $N_{2}(g)$ & 3.502 & 0.006 & 0.00 & 29.13 & [13] \\
\hline hydrogen sulfide & $\mathrm{H}_{2} \mathrm{~S}(\mathrm{~g})$ & 4.070 & 0.118 & 0.28 & 34.10 & {$[12]$} \\
\hline sulfur dioxide & $\mathrm{SO}_{2}(\mathrm{~g})$ & 4.707 & 0.439 & 0.13 & 40.06 & [12] \\
\hline carbon monoxide & $\operatorname{CO}(g)$ & 3.503 & 0.009 & 0.09 & 29.15 & [12] \\
\hline carbon dioxide & $\mathrm{CO}_{2}(\mathrm{~g})$ & 4.324 & 0.580 & -0.65 & 37.12 & [14] \\
\hline
\end{tabular}

${ }^{a}$ Recalculated from the partition coefficient of the molecule, using procedures and molecular parameters in the reference.

${ }^{b}$ Calculated using the procedure in the reference.

Unpublished calculations from the molecular partition function.

${ }^{d} C^{\circ}=2.5 R$ for the monatomic gas at temperatures such that $k T$ is well below the first excited electronic state.

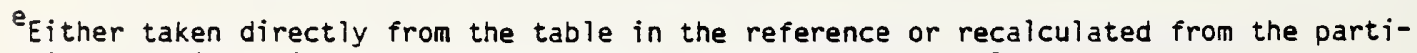
tion function using the same parameters as used for the tables. 
Table A7b. Enthalpies of combustion of selected hydrocarbons and sources of the data

\begin{tabular}{|c|c|c|}
\hline Substance & $\begin{array}{c}-\Delta_{c} H(298.15 \mathrm{~K})^{2} \\
\mathrm{~kJ} \mathrm{~mol}\end{array}$ & Data Sources $b, c, d, e$ \\
\hline methane & $890.31 \pm 0.31$ & $\begin{array}{l}\text { from } 17, \underline{55}, 61,(19,30,41,69,70) \\
\underline{48}, \mathrm{c}:=2,=3,=28, \neq 45,=77\end{array}$ \\
\hline ethane & $1559.84 \pm 0.46$ & $\begin{array}{l}\text { from } 17, \underline{\underline{56}},(23,70), \underline{48}, \mathrm{c}:=2, \\
=3,=28, \neq 45,=77\end{array}$ \\
\hline propane & $22.19 .90 \pm 0.54$ & $\begin{array}{l}\text { from } 17, \underline{56},(23,70), \underline{48}, \mathrm{C:}=2, \\
=3,=28, \neq 45,=77\end{array}$ \\
\hline n-butane & $2877.25 \pm 1.2$ & $\begin{array}{l}\text { from } 17, \underline{56}, \underline{50}, \underline{48}, \mathrm{c:}=2,=3, \\
\neq 28, \neq 45,=77\end{array}$ \\
\hline 2-methylpropane & $2868.72 \pm 2.0$ & $\begin{array}{l}\text { from 18b, } \underline{\underline{57}}, \underline{\underline{50}}, \underline{\underline{46}},(70), \underline{48}, \\
c:=2,=3, \neq 28, \neq 45,=77\end{array}$ \\
\hline$n$-pentane & $\begin{array}{l}3535.77 \pm 0.5(\mathrm{~g}) \\
3509.04 \pm 0.5(\ell)\end{array}$ & 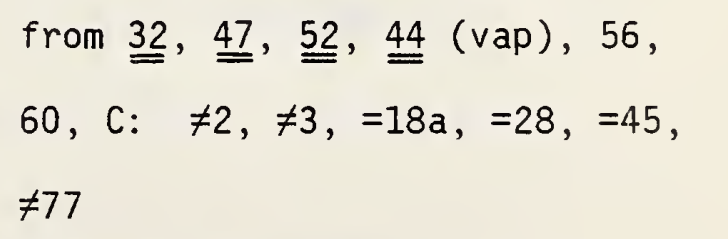 \\
\hline 2-methylbutane & $\begin{array}{l}3528.87 \pm 0.4(\mathrm{~g}) \\
3503.64 \pm 0.4(\ell)\end{array}$ & $\begin{array}{l}\text { from } \underline{32}, \underline{47}, \underline{39}, \underline{\underline{63}} \text { (vap) }, 60 \\
62, \mathrm{c:} \neq 2, \neq 3, \sim 28,=45, \neq 77\end{array}$ \\
\hline 2,2-dimethylpropane & $\begin{array}{l}3514.60 \pm 0.6(g) \\
3492.22 \pm 0.6(\ell)\end{array}$ & $\begin{array}{l}\text { from } \underline{\underline{32}}, \underline{47}, \underline{39}=\mathrm{C:} \neq 2, \neq 3, \\
\neq 28, \sim 45, \neq 77\end{array}$ \\
\hline n-hexane & $\begin{array}{l}4194.75 \pm 0.6(\mathrm{~g}) \\
41.63 .12 \pm 0.6(\ell)\end{array}$ & $\begin{array}{l}\text { from 18b, } \underline{\underline{31}}, \underline{\underline{52}}, \underline{34}, \underline{44}=(\text { vap ), } \\
71(\text { vap }),(68,=74,65) \mathrm{c}:=2, \\
=3,=28,=45,=76, \sim 77\end{array}$ \\
\hline 2-methylpentane & $\begin{array}{l}4187.64 \pm 1.0(\mathrm{~g}) \\
4157.68 \pm 1.0(\mathrm{l})\end{array}$ & $\begin{array}{l}\text { from } 18 b, 51,44(v a p), 71(v a p), \\
\text { c: }=2,=3,=28,=45,=76, \sim 77\end{array}$ \\
\hline
\end{tabular}


Table A7b (cont'd)

Substance

3-methylpentane

2,2-dimethylbutane

2,3-dimethylbutane

cyclopropane

cyclobutane

cyclopentane

cyclohexane

ethyne

ethene

$$
\begin{gathered}
-\Delta_{\mathrm{C}} H(298.15 \mathrm{~K})^{\mathrm{a}} \\
\mathrm{kJ} \mathrm{mol}
\end{gathered}
$$

$4190.32 \pm 0.9(\mathrm{~g})$

$4159.94 \pm 0.9(2)$

$4176.34 \pm 1.0(\mathrm{~g})$

$4148.52 \pm 1.0(\ell)$

$4184.17 \pm 0.9(\mathrm{~g})$

$4154.92 \pm 0.9(2)$

$2091.37 \pm 0.5$

$2745.16 \pm 0.5(\mathrm{~g})$

$2720.52 \pm 0.5(\ell)$

$3319.59 \pm 0.8(\mathrm{~g})$

$3290.93 \pm 0.8(\ell)$

$3952.96 \pm 0.7(\mathrm{~g})$

$3919.86 \pm 0.7(\ell)$

$1299.59 \pm 0.8$

$1410.97 \pm 0.4$
Data Sources ${ }^{b, c}, d, e$

from 18b, $\underline{=}, 44(v a p), 71(v a p)$,

$\mathrm{C}:=2,=3,=28,=45,=76, \sim 77$

from 18b, $\underline{\underline{51}}, \underline{44}$ (vap), 38(vap),

C: $=2,=3,=28,=45,=76, \neq 77$

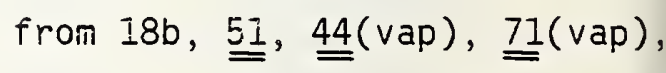

$(69,70), \mathrm{L}:=2,=3,=28, \neq 45$,

$=76, \neq 77$

from $17, \underline{\underline{40}},(21,23,29) \mathrm{C}:=$ $=28,=45$

from 18b, $\underline{\underline{35}}=\underline{\underline{26}}, \underline{\underline{54}}$ (vap),

C: $\neq 3, \neq 28, \neq 45, \neq 77$

from $17 \& 18 b, \underline{33}, \underline{\underline{8}}$ (vap), $35,64,(68=74), \mathrm{C}:=2$,

$=3,=28, \neq 45,=77$

from $17 \& 18 \mathrm{~b}, \underline{31}, \underline{33}$,

$44(\mathrm{vap}), \sim 35, \sim 64, \sim 43, \quad(68=$

$75,59,66,67), \mathrm{C}:=2, \sim 3$,

$=28,=45,=77$

from $17, \underline{\underline{72}}=\underline{\underline{25}},(21,23,41$,

42), $\mathrm{C}:=2,=3, \neq 28, \neq 45,=77$

from $17, \underline{\underline{58}}, \underline{\underline{53}}=\underline{\underline{36}}, \sim 78,79$

$(19,21,23,29,30,41,42)$

$C:=2,=3, \neq 28, \neq 45,=76, \neq 77$ 
Table A7b (cont'd)

\begin{tabular}{|c|c|c|}
\hline Substance & $\begin{array}{c}-\Delta_{\mathrm{c}} H(298.15 \mathrm{~K})^{\mathrm{a}} \\
\mathrm{kJ} \mathrm{mol}\end{array}$ & Data Sources ${ }^{b, c}, d, e$ \\
\hline propene & $2058.44 \pm 0.6$ & $\begin{array}{l}\text { from } 18 b, \underline{58}, \stackrel{37}{=}, \stackrel{73}{=}, \sim 51,(21, \\
23,69,70), c:=2,=3, \neq 28 \\
\neq 45,=77\end{array}$ \\
\hline benzene & $\begin{array}{l}3301.51 \pm 0.5(\mathrm{~g}) \\
3267.71 \pm 0.5(\ell)\end{array}$ & $\begin{array}{l}\text { from } 2 \& 17, \underline{31}, \stackrel{49}{=}, 44 \text { (vap), 27, } \\
c:=2,=3,=28,=45,=77\end{array}$ \\
\hline
\end{tabular}

${ }^{a}$ The uncertainty is that given in the source from which the value has been taken. See Appendix 7b for those assigned here.

Deferences are given in the list at the end of this appendix.

${ }^{C}$ References are marked to show how data in them were used or correspond to the selected values "from 10" - the value was taken from reference 10. 17 (double underline): used in making the selection (in the source cited); 20 : recent value, not used but to be considered in new evaluations; 31 (unmarked): examined but not used: $=2$; same value; $\sim 7$ : approximately the same; $\neq 3$; not the same value; (17): not used, of historical interest only; C: compilations of data follow this sign.

The entry for n-pentane should be read as follows. The selected value was taken from [32]. It was based on data in [32, 47, 52 and 44], the last being for the vaporization enthalpy. References [56] and [60] were not used. The present value agrees with the compilations [18a], [28] and [45], while it differs from [2], [3] and [77].

${ }^{d}$ Some references not cited in the sources quoted have been added during the preparation of this table. They are mainly for enthalpy of vaporization and for compilations of data. 
Table A7b (cont'd)

EThree references are to the API project 44 tables and successors: [2], (1953) [76], (1967); [77], (1981). The 1967 version is cited only of the other two are significantly different. 
Table A7c. Heating value of methane - sources of data

Experimental Measurements

A. Andrews, 1848 [19]

B. Favre and Silberman 1852 [30]

C. Thomsen, $1880,1886,[69,70]$

D. Berthelot, 1881, [21]

E. Mixter, 1901, [41]

F. Rossini, 1931, [55]

G. Roth and Banse, 1932, [61]

H. Pittam and Pilcher, 1972, [48]
$-\Delta_{\mathrm{c}} H^{\circ}(298.15 \mathrm{~K}) / \mathrm{kJ} \mathrm{mol}^{-1}$

[883.6]

$$
\text { a }
$$

[864.1] a $887.0 \pm 3 \quad b$ $892.3 \pm 9 \quad b$

[888.6] $890.31 \pm 0.6$ d $891.8 \pm 2$. e $890.71 \pm 0.8$ f

Notes for Table A7C

${ }^{\mathrm{a}}$ Not comparable to the later measurements. Corrected from $\sim 15^{\circ} \mathrm{C}$ by comparison to authors' measurements of $\Delta_{f} H\left(H_{2} \mathrm{O}, 2\right)$.

${ }^{b}$ As recalculated by Rossini [55] to $30^{\circ} \mathrm{C}$ and corrected by us to $25^{\circ} \mathrm{C}$.

${ }^{C}$ From heat of decomposition, in the presence of acetylene. Corrections are approximate.

duncertainty is precision only, $2 \sigma$. Corrected from $30^{\circ} \mathrm{C}$ to $25^{\circ} \mathrm{C}$.

${ }^{e}$ As recalculated by Cox and Pilcher [28].

iuncertainty is precision only, $2 \sigma$. 
Table A7d. Data points and statistics for studies of methane by Rossini and by Pittam and Pilcher

\begin{tabular}{|c|c|c|}
\hline Author & $-\Delta_{c} H^{\circ}(298.15$ & $\mathrm{mol}^{-1}$ \\
\hline & Individual Points & Averages \\
\hline Rossini $[55]^{a}$ & $891.823^{b}$ & \\
\hline Pittam and Pilcher $[48]^{C}$ & 891.23 & \\
\hline Pittam and Pilcher & 891.17 & Ave $(P \& P): \quad 890.71 \pm 0.43^{d}$ \\
\hline Rossini & 890.633 & Ave $(12$ pts ): $890.65 \pm 0.37$ \\
\hline Pittam and Pilcher & 890.62 & \\
\hline Pittam and Pilcher & 890.61 & Ave $(\mathrm{R}-6 \mathrm{pts}): \quad 890.56 \pm 0.66$ \\
\hline Rossini & 890.503 & Ave (11 pts): $890.52 \pm 0.27$ \\
\hline Pittam and Pilcher & 890.36 & \\
\hline Pittam and Pilcher & 890.34 & . \\
\hline Rossini & 890.340 & Ave $(R-5$ pts $): 890.31 \pm 0.33$ \\
\hline Rossini & 890.061 & \\
\hline Rossini & 890.013 & \\
\hline
\end{tabular}

${ }^{a}{ }_{\Delta_{c}} H(298.15 \mathrm{~K})=$ tabulated points in [55] $-0.613 \mathrm{~kJ} \mathrm{~mol}^{-1}$.

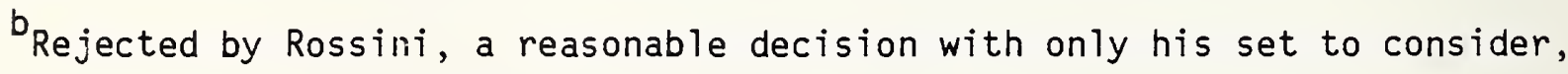
but borderline for the combined set.

${ }^{c_{\Delta}}{ }_{c} H^{\circ}(298.15 \mathrm{~K})=$ tabulated points in [48] $-0.02 \mathrm{~kJ} \mathrm{~mol}^{-1}$.

duncertainties are $95 \%$ confidence level for the mean but for precision only. 
Table A7e. Enthalpy of combustion of methane as an ideal gas and relative atomic mass scales given in compilations of thermochemical data

\begin{tabular}{|c|c|c|}
\hline \multirow[b]{2}{*}{ Compilation } & \multirow{2}{*}{$\begin{array}{c}\text { Atcmic Masss } \\
\text { Scaite }\end{array}$} & \multirow{2}{*}{$\frac{-\Delta_{c} H^{\circ}(298.15 k)^{b}}{k^{\prime} \mathrm{mol}^{-1}}$} \\
\hline & & \\
\hline International Critical Tables (1929) [87] & $1923(G)$ & 882.37 \\
\hline NBS Circular C461 (1947) [88] & $1341(F)$ & 890.35 \\
\hline NES Circular C500 (1952) [89] & $1341(F)$ & 890.35 \\
\hline Rossini et al. (1953) [2] (API Project 44) & $1941(F)$ & $890.35^{C}$ \\
\hline Landolt-Bornstein (1961) [90] & $1953(E)^{\mathrm{C}}$ & $890.36^{c}$ \\
\hline NBS Tech. Note 270-3 (1968) [16] & 1961 (D) & 890.36 \\
\hline Stul1, Westrum, Sinke (1969) [3] & $1941(F)$ & $890.34^{c}$ \\
\hline Cox, Pilcher (1970) [28] & $1961(D)$ & 890.32 \\
\hline JANAF Thermochemical Tables (1971) [81] & 1961 (D) & 890.33 \\
\hline ASTM DSAA (1971) [97] & 1969 (C) & $890.36^{\circ}$ \\
\hline Domalski (1972) [17] & 1961 (D) & 890.31 \\
\hline NBS Tech. Note 653 (1974) [91] & 1969 (C) & -- \\
\hline NBS Tech. Note 684 (1976) [92] & 1969 (C) & $-\infty$ \\
\hline ASTM D-3588 (1977) [93] & 1971 (B) & $890.36^{\circ}$ \\
\hline Pedley, Rylance (1977) [45] & 1971 (B) & 890.7 \\
\hline GPA Publication 2145-77 (1977) [94a] & $1961(0)$ & $890.40^{c, e}$ \\
\hline CODATA Key Values (1978) [95] & 1969 (C) & --- \\
\hline Robie, Hemmingway, Fisher (1978) [95] & 1971 (B) & $890.36^{c}$ \\
\hline GPA Publication 2145-SI-80 (1980) [94b,c] & $1969(C)$ & $890.33^{c, e}$ \\
\hline GPA Engineering Data Book (1980) [96] & 1969 (C) & $890.33^{c, e}$ \\
\hline This work & $1981(A)$ & 890.31 \\
\hline
\end{tabular}

ayear the scale was established and the code given in Table A5a.

balues reported in other units or at other temperatures have been convertec ising factors in this document.

$c^{\mathrm{C} a l u e}$ for methane taken from another compilation.

$d_{\text {Physical scale }}{ }^{16} 0=16$ indicated without elaboration. Atomic mass scale may be earlier than 1953. Reported enthalpy has been multiplied by 4.184/4.1855 to convert to current absolute joules.

${ }^{e}$ Calculated from values at $288.15 \mathrm{~K}$ or $288.71 \mathrm{~K}$ from enthalpies of combustion in MJ $\mathrm{m}^{-3}$ using thermodynamic properties developed in this work. Values in $\mathrm{MJ} \mathrm{kg}^{-1}$ in the 
Table A7f. Vapor pressure of water, $p\left(\mathrm{H}_{2} \mathrm{O}\right)$, used in this document

\begin{tabular}{cc}
\hline$T / K$ & $p\left(\mathrm{H}_{2} \mathrm{O}\right) / \mathrm{Pa}^{\mathrm{a}}$ \\
\hline 273.15 & 611.213 \\
288.15 & 1705.32 \\
288.706 & 1767.34 \\
298.15 & 3168.74 \\
\hline
\end{tabular}

${ }^{a}$ Using the 1968 International Practical Temperature Scale and the Vapor Pressure Equation [84]:

$$
\begin{aligned}
\ln p\left(\mathrm{H}_{2} \mathrm{O}\right)=\sum_{i=0}^{6} g_{i} T_{68}^{i-2}+g_{7} \ln T_{68}, \text { where } \\
g_{0}=-0.29912729 \times 10^{4}, g_{1}=-0.60170128 \times 10^{4}, \\
g_{2}=0.1887643854 \times 10^{2}, g_{3}=-0.28354721 \times 10^{-1}, \\
g_{4}=0.17838301 \times 10^{-4}, g_{5}=-0.84150417 \times 10^{-9}, \\
g_{6}=0.44412543 \times 10^{-12}, \text { and } g_{7}=0.2858487 \times 10^{1} .
\end{aligned}
$$


Appendix $7 b$. Uncertainties in thermodynamic quantities

Uncertainties in the standard enthaipies of combustion at $T=298.15 \mathrm{~K}$

Cox and Pilcher [28], Good [32], Domaiski [18a], Pedley and Rylance

[45] and Chao [80] have estimated uncertainties in some or all of the standard enthalpies of combustion or the enthalpies of formation at $T=298.15 \mathrm{~K}$ of the hydrocarbons 1 isted in Table 4 . Their estimates are given in Table A7g. Where necessary these have been converted to kilojoules per mole.

The selected uncertainties ${ }_{c}$ and relative urcertainties ${ }_{c}{ }_{C} /{ }_{C} H^{\circ}$ for this work are listed in the right harid columns of Table A7g. They are considered to represent 95 percent confidence limits for the values of $\Delta_{c} H^{\circ}$ at $298.15 \mathrm{~K}$.

When the enthalpy of formation is derived from the enthalpy of combustion, the estimated uncertainty in the entrialpy of formation $s_{f}$ is related to the estimated uncertainty in the enthalpy of combustion ${ }^{c}$ by the relationship

$$
s_{f}^{2}=s_{c}^{2}+\left[\operatorname{as}_{f}\left(\mathrm{CO}_{2}\right)\right]^{2}+\left[(\mathrm{b} / 2) s_{f}\left(\mathrm{H}_{2} \mathrm{O}\right)\right]^{2}
$$

where $s_{f}\left(\mathrm{CO}_{2}\right)$ is $0.13 \mathrm{~kJ} \mathrm{mcl}^{-1}, s_{f_{2}}\left(\mathrm{H}_{2} \mathrm{O}\right)=0.042 \mathrm{~kJ} \mathrm{~mol}^{-1}$ and $\mathrm{a}$ and $b$ give the stoichiometric coefficients in the equation of combustion.

$$
\mathrm{C}_{\mathrm{a}} \mathrm{H}_{\mathrm{b}}+(\mathrm{b} / 4+\mathrm{a}) \mathrm{O}_{2}=\mathrm{aCO}_{2}+(\mathrm{b} / 2) \mathrm{H}_{2} \mathrm{O}
$$

Because $s_{f}\left(\mathrm{CO}_{2}\right)$ and $s_{f}\left(\mathrm{H}_{2} \mathrm{O}\right)$ are substantially smalier than $s_{f}$ or $s_{c}$ for the hydrocarbons the difference $s_{f}-{ }^{5} c$ is generally quite small. The sign of the difference depends on whether $s_{f}$ is derived from $s_{c}$ or vice versa. Typical differences may be found in the column labeled C\&P in Table A7g. For the purpose of this discussion, little distinction will be made between $s_{f}$ and $s_{c}$. However $s_{c}$ is used preferentially if it is available. 
Table A7g. Estimates of uncertainties ${ }^{s_{c}}$ in enthalpy of combustion or $s_{f}$ in enthaipy of formation by various authors

\begin{tabular}{|c|c|c|c|c|c|c|c|}
\hline \multicolumn{2}{|c|}{$C \& P$} & $G$ & $D$ & $P \& R$ & Chao & This Work & $10^{4} \mathrm{~s}$ \\
\hline$s_{f}$ & ${ }^{s} c_{c}$ & $s_{c}$ & ${ }^{s} \mathrm{c}$ & ${ }^{s}{ }_{C}$ & ${ }^{s} \mathrm{C}$ & ${ }^{s} \mathrm{c}$ & $\Delta_{c} H^{\delta}$ \\
\hline
\end{tabular}

\begin{tabular}{|c|c|c|c|c|c|c|c|}
\hline methane & 0.29 & 0.25 & - & $0.29(.50)$ & 0.4 & $0.50^{b}$ & 0.62 \\
\hline ethane & 0.50 & 0.46 & - & 0.46 & $0.2^{b}$ & $0.59^{b}$ & 1.01 \\
\hline propane & 0.59 & 0.54 & - & 0.54 & 0.3 & $0.63^{b}$ & 1.02 \\
\hline n-butane & 0.67 & 0.63 & - & 1.26 & 0.6 & $0.67^{b}$ & 1.44 \\
\hline 2-methlypropane & 0.54 & 0.46 & - & $2.09(1.26)$ & 0.5 & - & 1.44 \\
\hline n-Dentane & 0.63 & $(0.63)$ & 0.46 & 0.46 & 0.7 & - & 0.46 \\
\hline 2-methlybutane & 0.63 & $(0.63)$ & 0.46 & 0.46 & 0.6 & - & 0.46 \\
\hline 2,2-dimethylpropane & 1.05 & 0.96 & 0.50 & 0.63 & $0.7^{b}$ & - & 0.50 \\
\hline n-hexane & 0.75 & $(0.75)$ & - & $0.63^{a}$ & 0.4 & - & 0.63 \\
\hline 2-methyipentane & 1.00 & 0.92 & - & $1.05^{a}$ & 0.9 & - & 1.05 \\
\hline 3-methlypentane & 1.00 & 0.92 & - & $1.05^{\mathrm{a}}$ & 0.9 & - & 1.05 \\
\hline 2,2-dimethylbutane & 1.00 & 0.92 & - & $0.96^{a}$ & $0.8^{b}$ & - & 0.96 \\
\hline 2,3-dimethylbutane & 1.00 & 0.92 & - & 0.92 & $0.7^{b}$ & - & 0.92 \\
\hline cyclopropane & 0.59 & 0.54 & - & - & 0.5 & - & 0.54 \\
\hline cyclobutane & 0.59 & 0.50 & - & - & $0.5^{b}$ & - & 0.50 \\
\hline cyclopentane & 0.84 & 0.71 & - & - & $0.8^{\mathrm{b}}$ & - & 0.71 \\
\hline cyclohexane & 0.63 & $(0.63)$ & - & - & $0.3^{b}$ & - & 0.63 \\
\hline ethyne & 0.79 & 0.63 & - & - & 1.0 & - & 0.63 \\
\hline ethene & 0.42 & $(0.42)$ & - & - & $1.2^{b}$ & - & 0.42 \\
\hline propene & 0.67 & $(0.67)$ & - & - & 0.4 & - & 0.67 \\
\hline benzene & 0.54 & $(0.54)$ & - & - & $0.3^{b}$ & - & 0.54 \\
\hline
\end{tabular}

oxygen

carbon dioxide

0.13

water (1 iquid)

$0.042^{b}$

Parentheses in the C\&P column indicates that $s_{c}$ was set equal to $s_{f}$ (for which a value is given)

${ }^{a}$ Value for gas phase combustion is taken as the same as for the liquid.

bindicates the value for $s_{f}$ is used.

Code to heading: C\&P, Cox and Pilcher [28]; G, Good [32]; D, Domalski [18b]; P\&R, Pedley and Rylance [45], Chao [80]. 
The following procedure was used in arriving at the estimated uncertainties ${ }_{\mathrm{C}}^{\mathrm{s}}$ (this work) given in Table A7g. Two tests were made for the normal hydrocarbons $C_{I}$ to $C_{4}$. Both combine estimates of accuracy made by evaluators with the spread between the means of the two sets of experiments. The uncertainties of Domalski and Chao were averaged and added quadratically to the difference between the average values of $\Delta_{c} H^{\circ}$ presented by Domalski [18b] and by Pittam and Pilcher [48]. Domalski's estimate of $s_{c}$ for methane was considered to be low as a result of the difference $0.4 \mathrm{~kJ}$ $\mathrm{mol}^{-1}$ between the work of Pittam and Pilcher and the previously accepted values for methane. Therefore, Chao's estimate alone was used in the quadratic addition.

Table A7h. Estimated total uncertainties - first test

Substance

Chao

$$
\mathrm{s}_{\mathrm{c}} / \mathrm{kJ} \mathrm{mol}^{-1}
$$
0.50

$(0.29) 0.50$

0.59

0.46

0.54

0.63

0.67

1.26

propane

n-butane

0.67

$\mathrm{s}_{\mathrm{c}} / \mathrm{kJ} \mathrm{mol}^{-1}$

$$
10^{4} \mathrm{~s}_{\mathrm{c}} / \Delta_{\mathrm{c}} H^{\circ}
$$

this work

The result sent the two estimated err values selected by Domalski (these tables) and the results presented by Pittam and Pilcher. The value of ${ }^{5} \mathrm{C}$ is calculated as

$$
s_{c}=\left[\left\{\left(s_{C h a o}+s_{D}\right) / 2\right\}^{2}+\Delta^{2}\right]^{\frac{1}{2}} \text {. }
$$

This has been reduced to a relative uncertainty in the last column.

A second test was made, and this was applied also to 2-methylpropane. In this test, the uncertainties listed by Domalski were summed quadratically with the uncertainties listed by Pittam and Pilcher for their combustion experiments and the values of $\Delta$. This value is 


$$
s_{C}=\left(s_{D}^{2}+s_{P P}^{2}+\Delta^{2}\right)^{\frac{1}{2}}
$$

The data, the values of the square root of the sum of squares and the relative uncertainties are given in Table A7j.

Table A7i. Estimated total uncertainties - second test

\begin{tabular}{|c|c|c|c|c|c|c|c|}
\hline \multirow[t]{2}{*}{ substance } & $-\Delta_{c} H^{\circ}$ & ${ }^{s}{ }_{c}$ & $\begin{array}{r}-\Delta_{c} \cdot H^{\circ} \\
k J\end{array}$ & $-1{ }^{s} c$ & $\Delta$ & $\left(\Sigma^{2}\right)^{\frac{1}{2}}$ & $\begin{array}{l}\frac{10^{4}\left(\Sigma^{2}\right)^{\frac{1}{2}}}{\Delta_{c} H^{\circ}} \\
\text { relative }\end{array}$ \\
\hline & \multicolumn{2}{|c|}{ Domalski } & \multicolumn{3}{|c|}{ Pittam and Pilcher } & & \\
\hline $\mathrm{CH}_{4}$ & 890.31 & 0.29 & 890.71 & 0.38 & 0.4 & 0.62 & 7.0 \\
\hline $\mathrm{C}_{2} \mathrm{H}_{6}$ & 1559.84 & 0.46 & 1560.69 & 0.25 & 0.86 & 1.01 & 6.5 \\
\hline $\mathrm{C}_{3} \mathrm{H}_{8}$ & 2219.90 & 0.54 & 2219.17 & 0.46 & -0.73 & 1.02 & 4.6 \\
\hline$n-C_{4} H_{10}$ & 2877.25 & 1.26 & 2877.54 & 0.63 & 0.29 & 1.44 & 5.0 \\
\hline $\mathrm{i}-\mathrm{C}_{4} \mathrm{H}_{10}$ & 2868.72 & $\begin{array}{c}1.26 \\
(2.09)\end{array}$ & 2869.00 & 0.59 & 0.28 & 1.42 & 5.0 \\
\hline
\end{tabular}

This calculation gives a reasonably uniform set of absolute and relative uncertainties and is adopted for the data presented for these compounds in this document as shown in the right hand columns of Table A7g. Here again an adjustment was made to Domalski's estimate of $s_{C}$ for 2-methlypropane. He had given a large estimate based on disagreement between two sets of combustion measurements made by Rossini [57] and Prosen, Maron and Rossini [50]. The later results of Pittam and Pilcher eliminate the earlier measurements by Rossini from further consideration. On this basis the uncertainty for Domalski's average value for 2-methlypropane was reduced to the same uncertainty for n-butane for this calculation.

For the pentanes, the uncertainties estimated by Good [32] were considered to be appropriate and were adopted without change.

For the hexanes, the estimates of uncertainty made by Domalski [18b] are used. For the cyclic and unsaturated hydrocarbons the uncertainties given by Cox and Pilcher [28] are used. 
Uncertainties in heat capacities and enthalpies

For all of the alkane hydrocarbons, Scott, [7], presents values of $C_{p}$ for which he gives the first uncertain figure to be at the hundredths cal $\mathrm{mcl}^{-1} \mathrm{~K}^{-1}$. On this basis, we infer $s\left(C_{\mathrm{p}}\right)<0.05 \mathrm{cal} \mathrm{mol} \mathrm{l}^{-1} \mathrm{~K}^{-1}$ which would be $s\left(C_{p}\right)<0.21 \mathrm{~J} \mathrm{~mol}^{1} \mathrm{~K}^{-1}$. Over the range $273.15 \mathrm{~K}$ to $298.15 \mathrm{~K}$ this amounts to an error of $H(T)-H(298.15 \mathrm{~K})<25 \times 0.21 \mathrm{~J} \mathrm{~mol}^{-1} \mathrm{~K}^{-1}$ $\left(5.2 \mathrm{~J} \mathrm{~mol}^{-1} \mathrm{~K}^{-1}\right)$. We adopt the conservative position that $\mathrm{s}\{H(T)-$ $H(298.15)\}=5.2 \mathrm{~J} \mathrm{~mol}^{-1} \mathrm{~K}^{-1}$ for all the hydrocarbons.

In scott [7] individual uncertainties in the heat capacities of the hydrocarbons are given four ways: as $s\left(C_{p}\right.$, observed $), s\left(C_{p}\right.$, calculated $)$, $\Delta\left(C_{p}\right.$ obs $-C_{p}$ calc $)$, and statistical uncertainty at $298.15 \mathrm{~K}$ calculated from the appropriate variance-covariance matrix.

Table $A 7 j$. Estimated uncertainties in $C_{p}^{\circ}$ of hydrocarbons from Scott's [7] correlation of thermodynamic functions

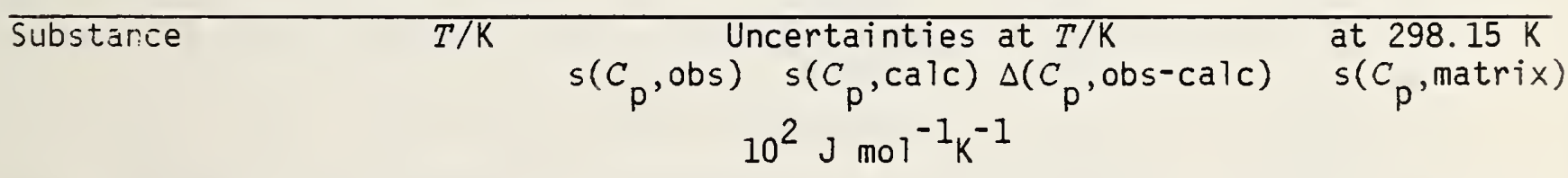

\begin{tabular}{llllrr} 
propane & 293.15 & 17 & 8 & 71 & 8 \\
n-butane & & & & & 4 \\
2-methylpropane & 273.15 & 17 & 8 & 21 & 13 \\
n-pentane & 298.15 & 25 & 8 & 4 & 8 \\
2-methylbutane & 317.2 & 25 & 21 & 4 & 37 \\
2,2-dimethylpropane & 298.15 & 25 & 25 & 8 & 25 \\
n-hexane & 333.85 & 29 & 13 & 13 & 17 \\
2-methyipentane & 325.10 & 29 & 17 & 46 & 17 \\
3-methy?pentane & 332.10 & 29 & 25 & 21 & 42 \\
2,2-dimethylbutane & 341.55 & 33 & 17 & 8 & 29 \\
2,3-dimethylbutane & 341.60 & 33 & 21 & 4 & 71 \\
\hline
\end{tabular}

Scott recommends that the uncertainties in the heat capacities be taken as twice the values listed. We have taken twice the values listed as the entries in the column headed $s\left(C_{p}^{\circ}\right.$,obs $)$, and these are listed in Table 15. 
Table A7k. Comparative calculations of $C_{p}^{\circ}$ Withoit [1] Scott[7] Gurvich[82] JANAF[81] Wagman[16] Angus[9,10]

\begin{tabular}{|c|c|c|c|c|c|c|c|}
\hline & & & \multicolumn{5}{|c|}{$C_{p}^{0} / \mathrm{J} \mathrm{mol} l^{-1} \mathrm{~K}^{-1}$} \\
\hline & $\mathrm{CH}_{4}$ & 35.71 & $(35.68)^{\star}$ & 35.695 & $(35.64)$ & $(35.31)$ & 35.71 \\
\hline & $\mathrm{C}_{2} \mathrm{H}_{2}$ & 44.06 & & 44.036 & $(44.095)$ & $(43.93)$ & \\
\hline & $\mathrm{C}_{2} \mathrm{H}_{4}$ & 42.88 & & 42.882 & $(42.89)$ & $(43.56)$ & 42.88 \\
\hline & $\mathrm{C}_{2} \mathrm{H}_{6}$ & 52.47 & $(52.59)$ & 52.486 & $(52.63)$ & & \\
\hline & $\mathrm{C}_{3} \mathrm{H}_{8}$ & 73.55 & $(72.96)$ & & & & \\
\hline cyclo & $\mathrm{C}_{4} \mathrm{H}_{8}$ & 70.86 & & & & & \\
\hline n & $\mathrm{C}_{4} \mathrm{H}_{10}$ & 98.44 & $(97.49)$ & & & & \\
\hline i & $\mathrm{C}_{4} \mathrm{H}_{10}$ & 96.59 & $(96.77)$ & & & & \\
\hline cyclo & $\mathrm{C}_{5} \mathrm{H}_{10}$ & 83.11 & & & & & \\
\hline$n$ & $\mathrm{C}_{5} \mathrm{H}_{12}$ & 119.96 & $(120.04)$ & & & & \\
\hline 1-me & $\mathrm{C}_{5} \mathrm{H}_{12}$ & 118.95 & $(118.85)$ & & & & \\
\hline 2,2 & $\mathrm{C}_{5} \mathrm{H}_{12}$ & 120.96 & $(120.83)$ & & & & \\
\hline cyclo & $\mathrm{C}_{6} \mathrm{H}_{12}$ & 105.25 & & & & & \\
\hline$n$ & $\mathrm{C}_{6} \mathrm{H}_{14}$ & 142.62 & $(142.59)$ & & & & \\
\hline 2-me & $\mathrm{C}_{6} \mathrm{H}_{14}$ & 142.25 & $(142.21)$ & & & & \\
\hline 3-me & $\mathrm{C}_{6} \mathrm{H}_{14}$ & 140.20 & $(140.12)$ & & & & \\
\hline 2,2 & $\mathrm{C}_{6} \mathrm{H}_{14}$ & 141.55 & $(141.46)$ & & & & \\
\hline \multirow[t]{6}{*}{2,3} & $\mathrm{C}_{6} \mathrm{H}_{14}$ & 139.56 & $(139.41)$ & & & & \\
\hline & $c_{6} H_{6}$ & 85.58 & & & & & \\
\hline & $\mathrm{O}_{2}$ & 29.37 & & 29.378 & $(29.37)$ & $(29.35)$ & \\
\hline & $\mathrm{CO}_{2}$ & 37.12 & & 37.135 & $(37.13)$ & $(37.11)$ & 37.13 \\
\hline & $\mathrm{H}_{2}$ & 28.83 & & 28.836 & $(28.836)$ & $(28.824)$ & \\
\hline & $c$ & & & 8.536 & $(8.527)$ & $(8.527)$ & \\
\hline
\end{tabular}


There are slightly different calculated values of $C_{p}$ in various compendia. They are compared in Table A7k. The differences are due largely to choices of molecular parameters, choices of energy differences between conformers and the calculational models. The differences are small and ignored here.

\section{Uncertainty in the vapor pressure of water}

The uncertainty of the vapor pressure of water has several aspects:

(1) the uncertainty with which the vapor pressure has been experimentally determined, which is taken by us as the uncertainty in the partial pressure of water vapor in the water saturated ideal-gas fuels; (2) the deviation of the vapor pressure of water from its standard value when in the presence of hydrocarbons; (3) the degree to which true saturation is achieved in real-gas mixtures measured under "saturated" conditions. The third aspect above is a measurement problem encountered in the field that must be treated as a separate issue. For the purposes of this document we assume uncertainty (1) to be $s\left(p, \mathrm{H}_{2} 0\right)=1 \mathrm{~Pa}$. While Wexler [84] does not specifically state estimates of uncertainty, he compares his formulation with measurements by Dous 1 in [85] and Besley and Bottomly [86] and finds differences not exceeding $1.3 \mathrm{~Pa}$ in the range 273.15 to $298.15 \mathrm{~K}$. At $T=273.15 \mathrm{~K}$ the triple point pressure is not uncertain by more than $0.01 \mathrm{~Pa}$. Uncertainty in the relative partial pressure of fuel

Using criterion (1) for the uncertainty in the partial pressure of water, we calculate the relative uncertainty $s(p$, fuel $) /(p$, fuel) in the partial pressure of fuel at the reference states to be $1 \times 10^{-5}$, as follows.

Taking $s\left(p, \mathrm{H}_{2} \mathrm{O}\right)=1 \mathrm{~Pa}$ and values of $s(p$, fue 1$)$ ranging from a maximum of $101.550 \mathrm{kPa}-0.611 \mathrm{kPa}=100.95 \mathrm{kPa}$ at $273.15 \mathrm{~K}$ to a minimum of $100 \mathrm{kPa}$ $3.168 \mathrm{kPa}=96.83 \mathrm{kPa}, \mathrm{s}(p$, fue 1$) /(p$, fuel $)$ ranges from $9.9 \times 10^{-6}$ to 10.3 
$\times 10^{-6}$. Since this range is much smaller than our knowledge of the uncertainty of $p\left(\mathrm{H}_{2} \mathrm{O}\right)$, we assign a value of $10 \times 10^{-6}$ for $s(p$, fuel $) /(p$, fuel) for water saturated gas at all pressures and temperatures. 


\section{References}

1. Wilhoit, R.C.; Letter to G.T.Armstrong (October 1981).

2. Rossini, F.D.; Pitzer, K.S.; Arnett, R.L.; Brown, R.M. ; Pi!nentei, G.C.; "Selected values of the properties of hydrocarbons and related compounds"; Carnegie Press, Pittsburgh (1953). API project 44 tabiles.

3. Stul1, D.R.; Westrum, E.F., Jr.; Sinke, G.C.; "Chemical thermodynamic properties of organic compounds"; John Wiley and Sons, inc., New York. (1969).

4. Angus, S.; Armstrong, B.; de Reuck, K.M.; "International thermodynamiic tables of the fluid state - 5. Methane"; Pergamon Press (1.978).

(Tables based on McDowe11, R.S.; Kruse, F.H.; J. Chem. Eng. Data (1963), $\underline{8}, 547-548$.

5. Chao, J.; Wilhoit, R.C.; Zwolinski, B.J.; J. Phys. Chem. Ref. Data (1973), 2, 427-437.

6. Chen, S.S.; Wilhoit, R.C.; Zwolinski, B.J.; J. Phys. Chem. Ref. Data (1975), $\underline{4}, 859-869$.

7. Scott, D.W.; J. Chem. Phys. (1974), 60, 3144-3165.

8. McCullough, J.P.; Pennington, R.E.; Smith, J.C.; Hossenlopp, I. A.; Waddington, G.; J. Am. Chem. Soc. (1959), 81, 5880-5883.

9. Angus, S.; Armstrong, B.; de Reuck, K.M.; Featherstone, W. ; Gibson, M.R.; "International thermodynamic tables of the fluid state. - 7. Ethylene, 1972" ; Butterworths, London (1974).

10. Angus, S.; Armstrong, B.; de Reuck, K.M.; "International tables of the fluid state. - 7. Propylene (propene)"; Pergamon Press, New York (1980). (Tables from Chao, J.; Zwolinski, B.J.; J. Phys. Chem. Ref. Data (1975), $\underline{4}, 251-261$. 
References (cont'd)

11. "Coal conversion systems technical data book"; U.S. Department of Energy, (US Government Printing Office, Order number HCP/T2286-01/2) (1980). (Table IB.21.1 May 1979 based on data in semiannual report no.

3 of Am. Petroleum Institute project 62, U.S. Bureau of Mines, Bartlesvilie, OK. July 1, 1977-Jan 1, 1978).

12. "Selected values of properties of chemical compounds"; Thermodynamics Research Center, Texas A\&M University, College Station, Texas (June 30, 1968), Table 1-v, (Dec. 31, 1968), Table 2-v, (June 30, 1980), Tables 14-1-v and 14-2-v, (Dec. 31, 1966), Table 23-1-v.

13. Angus, S.; de Reuck, K.M.; Armstrong, B.; Jacobson, R.T.; Stewart, R.B.; "International thermodynamic tables of the fluid state. - 6 . Nitrogen"; Pergamon Press, New York (1979).

14. Angus, S.; Armstrong, B.; de Reuck, K.M.; Altunin, V.; Godetskii, 0. G.; Chapela, G.A., Rowlinson, J.S.; "International thermodynamic tables of the fluid state - Carbon dioxide"; Pergamon Press (1976).

15. CODATA Task Group on Key Values for Thermodynamics, "CODATA recommended key values for thermodynamics"; CODATA Bulletin (1978), no. 28. Idem, "Tentative set of key values for thermodynamics. Part VIII"; CODATA Special Report (1980), no. 8 .

16. Wagman, D.D.; Evans, W.H.; Parker, V.B.; Halow, I. ; Bailey, S.M.; Schumm, R.H.; "Selected values of chemical thermodynamic properties"; Nat. Bur. Stand. (U.S.) Tech. Note (1968), 270-3.

17. Domalski, E.S.; J. Phys. Chem. Reference Data (1972), 1, 221-277. 
References (cont'd)

18. a. Armstrong, G.T.; Domalski, E.S.; Minor, J.I., Jr.; "Standard combustion data for the fuel gas industry"; American Gas Association 1972 Operating Section Proceedings, Arington, Va. (1972), pp D-74 to D-88; b. Domalski, E.S.; unpublished evaluations upon which the results reported in 18a are based (ca. 1972).

19. Andrews, T.; Phil. Mag. (1848), [3], 32, 321-339; 32, 426-434.

20. Berthelot, M. ; Ann. chim. et phys. (1878), [5], 13, 5-20.

21. Berthelot, M. ; Ann. chim. et phys. (1881), [5], 23, 176-181.

22. Berthelot, M. ; Matignon, C. ; Ann. chim. et phys. (1893), [6], 28, $139-144$.

23. Berthelot, M.; Matignon, C. ; Arn. chim. et phys. (1893), [6], 30, 547-565.

24. Berthelot, M. ; Matignon, C. ; Compt. Rend. (1893), 116, 1333-1339.

25. Conn., J.B.; Kistiakowsky, G.B.; Smith, E.A.; J. Am. Chem. Soc. (1939), 61, 1868-1876.

26. Coops, J.; Kaarsemaker, S.; Rec. trav. chim. pays bas (1950), 69, 1364 .

27. Coops, J.; Mulder, D.; Dienske, J. W. ; Smittenberg, J.; Rec. trav. chim. pays bas (1947), 65,$128 ; \underline{66}, 153-160$.

28. Cox, J.D.; Pilcher, G.; "Thermochemistry of organic and organometallic compounds"; Academic Press, London (1970).

29. Dulong, P.L.; Compte. Rend. (1838), I, 872-877.

30. Favre, P.A.; Silberman, J.T.; Ann. chim. et phys. (1852), [3], 34, $357-450$.

31. Good, W.D.; Smith, N.K.; J. Chem. Eng. Data (1969), 14., 102-106.

32. Good, W.D.; J. Chem. Thermodynamics (1970), 2, 237-244. 
References (cont'd)

33. Johnson, W.H.; Prosen, E.J.; Rossini, F.D.; J. Res. Nat. Bur. Stand. (U.S.) (1946), $\underline{36}, 463-468$.

34. Jessup, R.S.; J. Res. Nat. Bur. Stand. (U.S.) (1937), 18, 115-128.

35. Kaarsemaker, S.; Coops, J.; Rec. trav. chim. pays bas (1952), 71, $261-276$.

36. Kistiakowsky, G.B.; Romeyn, H., Jr.; Ruhoff, J.R.; Smith, H.A.; Vaughan, W. E.; J. Am. Chem. Soc. (1935), 57, 65-75.

37. Kistiakowsky, G.B.; Ruhoff, J. R.; Smith, H.A.; Vaughan, W.E.; J. Am. Chem. Soc. (1935), 57, 867-882.

38. Kilpatrick, J.E.; Pitzer, K.S.; J. Am. Chem. Soc. (1946), 68, 1066.

39. Knowlton, J.W.; Rossini, F.D.; J. Res. Nat. Bur. Stand. (U.S.) (1939), 22, $415-424$.

40. Knowlton, J.W.; Rossini, F.D.; J. Res. Nat. Bur. Stand. (U.S.) (1949), 43, 113-115.

41. Mixter, W.G.; Am. J. Sci. (1901), [4], 12, 345-357.

42. Mixter, W.G.; Am. I. Sci. (1906), [4], 22, 13-18.

43. Moore, G.E.; Renquist, M.L.; Parks, G.S.; J. Am. Chem. Soc. (1940), 62, $1505-1507$.

44. Osborne, N.S.; Ginnings, D.C.; J. Res. Nat. Bur. Stand. (U.S.) (1947), 39, $453-457$.

45. Pedley, J.B.; Rylance, J.; "Sussex - N.P.L. computer analyzed thermochemical data: Organic and organometallic compounds"; University of Sussex (1977).

46. Pines, H.; Kvetinskas, B.; Kasse1, L.S.; Ipatieff, V.N.; J. Am. Chem. Soc. (1945), 67, 631-637.

47. Pilcher, G.; Chadwick, J.D.M.; Trans. Faraday Soc. (1967), 63, 2357-2361. 
References (cont'd)

48. Pittam, D.A.; Pilcher, G.; J. Chem. Soc., Faraday Trans. I (1972), 68, 2225-2229.

49. Prosen, E.J.; Gilmont, R.; Rossini, F.D.; J. Res. Nat. Bur. Stand. (U.S.) (1945), $34,65-71$

50. Prosen, E.J.; Maron, F.W.; Rossini, F.D.; J. Res. Nat. Bur. Stand. (U.S.); (1951), $46,106-112$.

51. Prosen, E.J.; Rossini, F.D.; J. Res. Nat. Bur. Stand. (U.S.) (1941), 27, $289-310$.

52. Prosen, E.J.; Rossini, F.D.; J. Res. Nat. Bur. Stand. (U.S.) (1944), $33,255-272$.

53. Prosen, E.J.; Rossini, F.D.; J. Res. Nat. Bur. Stand. (U.S.) (1946), 36, 269-275.

54. Rathjens, G.W.; Gwinn, W.D.; J. Am. Chem. Soc. (1953), 75, 5629-5633.

55. Rossini, F.D.; J. Res. Nat. Bur. Stand. (U.S.) (1931), 6, 37-49; $\underline{7}$, $329-330$.

56. Rossini, F.D.; J. Res. Nat. Eur. Stand. (U.S.) (1934), 12, 735-750.

57. Rossini, F.D.; J. Res. Nat. Bur. Stand. (U.S.) (1935), 15, 357-361.

58. Rossini, F.D.; Knowiton, J.W.; J. Res. Nat. Bur. Stand. (U.S.) (1937), 19, 249-262.

59. Roth, W.A.; von Auwers, K. ; Ann. (1915), 407, 145-175.

60. Roth, W.A.; Macheleidt, R.; data quoted in Landolt-Bornstein Physikalisch-Chemische Tabellen, Dritt. Ergb., Springer, Berlin (1923), p. 1588.

61. Roth, W.A.; Banse, H. ; Arch. Eisenhuttenw. (1932/1933), ㅁ, 43-46.

62. Roth, W.A.; Pahike, H.; Z. angew. Chem. (1936), 49, 618-619.

63. Scott, D.W.; McCullough, J.P.; Williamson, K.D.; Waddington, G.; J. Am. Chem. Soc. (1951), 프, 1707. 
References (cont'd)

64. Spitzer, R.; Huffman, H.M. ; J. Am. Chem. Soc. (1947), 69, 211-213.

65. Stohmann, F.; Kleber, C. ; J. prakt. Chem. (1891), [2], 43, 1-21.

66. Stohmann, F.; Langbein, H.; J. prakt. Chem. (1892), [2], 45, 305-356.

67. Stohmann, F.; Langbein, H.; J. prakt. Chem. (1893), [2], 48, 447-453.

68. Swietoslawski, W.; J. Am. Chem. Soc. (1920), 42, 1092-1110.

69. Thomsen, J.; Ber. (1880), 13, 1321-1334.

70. Thomsen, J.; "Thermochemische Untersuchungen"; J.A. Barth, Leipzig (1886).

71. Waddington, G.; Smith, J.C.; Scott, D.W.; Huffman, H.M.; J. Am. Chem. Soc. (1949), 71, 3902-3906.

72. Wagman, D.D.; Kilpatrick, J.E.; Pitzer, K.S.; Rossini, F.D.; J. Res. Nat. Bur. Stand. (U.S.) (1945), 35, 467-496.

73. Wiberg, K.B.; Fenog7io, R.A.; J. Am. Chem. Soc. (1968), 90, 3395-3397.

74. Zubov, P.; Zhur. Russ. Fiz. Khim. Obshchestva, Chast Khim. (1901), 33, $708-722$.

75. Zubov, P.; Zhur. Russ. Fiz. Khim. Obshchestva, Chast Khim. (1913), $\underline{45}$, 240-251.

76. Zwolinski, B.J.; Wilhoit, R.C.; "Heats of formation and heats of combustion"; in "American Institute of Physics Handbook", Am. Inst. Phys., New York (1972), ch. 4, sect. 41, pp. 4-316 to 4-342. Data in this reference are drawn from API project 44 and Thermodynamic Research Center (Texas A\&M Univ.) Toose leaf tables, (ca. 1967). 
References (cont'd)

77. Thermodynamic Research Center Hydrocarbon Project; "Selected values of physical and thermodynamic properties of hydrocarbons and related compounds"; Thermodynamic Research Center, Texas A\&M Univ., College Station, Texas. These tables are the successor to those of API project 44. Current (1981) loose leaf tables for compounds of interest are: C1 - C5 hydrocarbons, Table 1n, (1955); C6 hydrocarbons, Tabie 23-2-(1.201)n, (1975); cycloalkanes, Table 23-2-(3.100)n, (1968); alkenes, Table 23-2-(5.1101)n, (1981); alkynes, Table 25n, (1952); normal aikyi benzenes, Table 23-2-(33.1100)n, (1962).

78. Kistiakowsky, G.B.; Nickle, A.G.; Disc. Faraday Soc. (1951), 10, $175-187$.

79. von Wartenberg, H.; Krause, G.; Z. physik. Chem. (1930), 151A, 105-108. .

80. Chao, J.; private communication (1981).

81. Stull, D.R.; Prophet, H.; editors, "JANAF thermochemical tables"; 2d ed., Nat. Stand. Ref. Data ser., Nat. Bur. Stand. (U.S.) (1971), 37.

82. Gurvich, L.V.; Veits, I.V.; Medvedev, V.A.; Khachkuruzov, G.A.; Yungman, V.S.; Bergman, G.A.; editors, "Termodinamicheskie svoistva individual'nykh veshchestv"; [Thermodynamic properties of individual substances], Glushko, V.P.; general editor "Nauka", Moscow (1978), 1; (1979), ㄱ; (1981), $\underline{3}$.

83. Armstrong, G.T.; "Calculation of the heating value of a sample of high purity methane for use as a reference material", Nat. Bur. Stand. (U.S.) Tech. Note 299 (1966).

84. Wexler, A.; J. Res. Nat. Bur. Stand. (U.S.) (1976), 80A, 775-785.

85. Douslin, D.R.; J. Chem. Thermodynamics (1971), $\underline{3}$, 187-193.

86. Besley, L.; Bottomley, G.A.; J. Chem. Thermodynamics (1973), $\underline{5}$, 397-410. 
References (cont'd)

87. Washburn, E.W.; editor, "International critical tables of numerical data, physics, chemistry and technology" ; McGraw Hill Book Co., Inc., New York (1926).

88. Rossini, F.D.; Pitzer, K.S.; Taylor, W.J.; Kilpatrick, J.E.; Ebert, J.P.; Beckett, C.W.; Williams, M.G.; Werner, H.G.; "Tables of selected values of properties of hydrocarbons"; Nat. Bur. Stand. (U.S.) Circ. (1947), C461.

89. Rossini, F.D.; Wagman, D.D.; Evans, W.H.; Levine, S.; Jaffe, I. ; "Selected values of chemical thermodynamic properties"; Nat. Bur. Stand. (U.S.) Circ. (1952), C500.

90. Auer, W.; "Organische Substanzen" ; in "Landolt-Bornstein Zahlenwerte und Funktionen aus Physik, Chemie, Astronomie, Geophysik, und Technik" (Sechste Auflage), Springer-Verlag, Berlin (1961), II. Band, 4. Teil table 24132 , p. 261. See also p. XI (atomic weights) and pp. 1,15 (energy conversion factors).

91. Goodwin, R.D.; "The thermophysical properties of methane, from 90 to $500 \mathrm{~K}$ at pressures to 700 bar"; Nat. Bur. Stand. (U.S.) Tech. Note (1974), 653 .

92. Goodwin, R.D.; Roder, H.M.; Straty, G.C.; "Thermophysical properties of ethane from 90 to $600 \mathrm{~K}$ at pressures to 700 bar" $^{\prime \prime}$ Nat. Bur. Stand. (U.S.) Tech. Note (1976), 684.

93. Mason, D.M. ; "Research report on standard method of calculating calorific value and specific gravity of gaseous fuels" ; ASTM Research Report, Am. Soc. for Testing and Materials, Philadelphia (1977), no. D03-1000, (Documentation for ASTM D3588). 
References (cont'd)

94. (a). "Standard table of physical constants of paraffin hydrocarbons and other components of natural gas"; Gas Processors Association, Tulsa (1977), publication 2145-77. (b). ----, (1980), publication 2145-80. (c). ----, (1981), publication 2145-81.

95. Robie, R.A.; Hemingway, B.S.; Fisher, J.R.; "Thermodynamic properties of minerals and related substances at $298.15 \mathrm{~K}$ and 1 bar (105 pascals) pressure and at higher temperatures"; Geological Survey (U.S.) Bulletin (1978), 1452 .

96. "Engineering data book"; Gas Processers Suppliers Association, Tulsa (1981).

97. "Physical Constants of hydrocarbons $C_{1}$ to $C_{10}$ "; ASTM Data Series, American Society for Testing and Materials, Philadelphia (1971), Publication DS 4A.

98. Somayajulu, G. R.; Wilhoit, R. C.; Ha11, K. R.; "Enthalpies of formation of the lower alkenes"; manuscript, received May 1982. 
Appendix 8. Relationships between thermodynamic quantities in Tables 3 and 4.

\section{Standard Enthalpy of formation from the elements}

The enthalpy of formation of a compound in Tables $3 a$ and $3 b$ from its elements is the enthalpy change of a process such as is illustrated below for $\mathrm{H}_{2} \mathrm{O}(1)$ and $\mathrm{CO}_{2}(\mathrm{~g})$.

$$
\begin{aligned}
& \mathrm{H}_{2}(\mathrm{~g})+\frac{\mathrm{I}}{2} \mathrm{O}_{2}(\mathrm{~g})=\mathrm{H}_{2} \mathrm{O}(\mathrm{l}) ; \\
& \mathrm{C}(\mathrm{c}, \text { graphite })+\mathrm{O}_{2}(\mathrm{~g})=\mathrm{CO}_{2}(\mathrm{~g}) ;
\end{aligned}
$$

Similar reactions can be written for the other substances. The enthalpy change, $\Delta_{f} H^{\circ}$, is for the process with the substances in their standard states. For example, the first reaction at $298.15 \mathrm{~K}$ is represented as follows

$$
\begin{gathered}
\Delta_{\hat{\mathrm{f}}} H^{\circ}\left(\mathrm{H}_{2} \mathrm{O}, 2,298.15 \mathrm{~K}\right)=H^{\circ}\left(\mathrm{H}_{2} \mathrm{O}, 2,298.15 \mathrm{~K}\right) \\
-H^{\circ}\left(\mathrm{H}_{2}, \mathrm{~g}, 298.15 \mathrm{~K}\right)-\frac{1}{2} H^{\circ}\left(\mathrm{O}_{2}, \mathrm{~g}, 298.15 \mathrm{~K}\right), p=101.325 \mathrm{~Pa} \text { (A.8.3) }
\end{gathered}
$$

Information in parentheses specifies the conditions, and if the conditions are clearly stated elsewhere some of this information may be omitted as being understood. The individual $H^{\circ}$ terms are not measurable, only changes in them are, e.g. $\Delta_{f} H^{\circ}, \Delta_{c} H^{\circ}$ or $\left[H\left(T_{1}\right)-H\left(T_{2}\right)\right]$.

The enthalpy of reaction (including formation) at another temperature can be calculated from that at $298.15 \mathrm{~K}$ using a cycle of reactions

$$
\begin{aligned}
& A+B \rightarrow C+D \quad T_{1}(298.15 \mathrm{~K}) \\
& \uparrow_{1} \uparrow_{2}{ }^{\downarrow_{3}}{ }^{\downarrow_{4}} \\
& A+B \rightarrow C+D \quad T_{2}
\end{aligned}
$$




$$
\begin{aligned}
\Delta_{r} H\left(T_{2}\right) & =\Delta H(1)+\Delta H(2)+\Delta_{r} H(298.15 K) \\
& +\Delta H(3)+\Delta H(4) .
\end{aligned}
$$

For reaction $A 8.1$, the formation of water in its standard state, this becomes:

$$
\begin{gathered}
\Delta_{f} H^{\circ}\left(H_{2} 0,1, T_{2}\right)=\left[H^{\circ}(298.15 \mathrm{~K})-H^{\circ}\left(T_{2}\right)\right]\left(H_{2}, g\right) \\
+0.5\left[H^{\circ}(298.15 \mathrm{~K})-H^{\circ}\left(T_{2}\right)\right]\left(0_{2}, g\right) \\
+\Delta_{f} H^{\circ}\left(H_{2} 0,1,298.15 \mathrm{~K}\right)-\left[H(298.15 \mathrm{~K})-H^{\circ}\left(T_{2}\right)\right]\left(H_{2} 0,1\right) .
\end{gathered}
$$

Note that all enthalpy differences have been written with $T=298.15 \mathrm{~K}$ first. The degree sign indicates standard state conditions. When $T=288.15 \mathrm{~K}$ equation A8.5 gives one of the conversions among reference conditions needed to calculate Table 3 .

Inserting values from Table $3 a$ and $3 b$ into equation $A 8.5$ we find:

$$
\begin{gathered}
\Delta H_{f}^{\circ}\left(\mathrm{H}_{2} 0,1,288.15 \mathrm{~K}\right)=-285.830 \mathrm{~kJ} \mathrm{~mol}^{-1} \\
-0.753 \mathrm{~kJ} \mathrm{~mol}^{-1}+0.288 \mathrm{~kJ} \mathrm{~mol}^{-1}+\frac{1}{2} \times 0.293 \mathrm{~kJ} \mathrm{~mol}^{-1} . \\
-\Delta_{\mathrm{f}} H^{\circ}\left(\mathrm{H}_{2} \mathrm{O}, 1,288.15 \mathrm{~K}\right)=286.1485 \mathrm{~kJ} \mathrm{~mol}^{-1} .
\end{gathered}
$$

This reproduces the value found in Table 3 .

By an analogous process the enthalpy of combustion of a hydrocarbon can be determined at a different temperature. The combustion of a gasecus hydrocarbon is represented by the following equation:

$$
\mathrm{C}_{\mathrm{a}} \mathrm{H}_{\mathrm{b}}(\mathrm{g})+\left(\mathrm{a}+\frac{\mathrm{b}}{4}\right) \mathrm{O}_{2}(\mathrm{~g})=\mathrm{aCO} \mathrm{CO}_{2}(\mathrm{~g})+\frac{b}{2} \mathrm{H}_{2} \mathrm{O}(\mathrm{l})
$$

where the stoichometric coefficients depend upon the composition of the hydrocarbon. The standard enthalpy of combustion at temperature $T=$ 298. $15 \mathrm{~K}$ represents the enthalpy of combustion with each reactant and each product of combustion in its standard state at the stated temperature.

The standard enthalpy of combustion depends on the temperature. The conversion of the standard enthalpy of combustion from one temperature to another will be illustrated for the combustion of methane. 


$$
\mathrm{CH}_{4}(\mathrm{~g})+2 \mathrm{O}_{2}(\mathrm{~g})=\mathrm{CO}_{2}(\mathrm{~g})+2 \mathrm{H}_{2} \mathrm{O}(\mathrm{l}) .
$$

In this case $a=1 ; b=4 ; b / 2=2 ;$ and $a+b / 4=2 ;$ giving the stoichiometric coefficients for carbon dioxide, water, and oxygen, for the combustion of one mole of methane. The standard enthalpy of combustion at $T=288.15 \mathrm{~K}$ can be calculated from the following relationship (which is a rearrangement of equation A8.4):

$$
\begin{aligned}
& \Delta_{c} H^{\circ}(298.15 \mathrm{~K})-\Delta_{c} H^{\circ}(288.15 \mathrm{~K})= \\
& \mathrm{a}\left[H^{\circ}\left(\mathrm{CO}_{2}, \mathrm{~g}, 298.15 \mathrm{~K}\right)-H^{\circ}\left(\mathrm{CO}_{2}, \mathrm{~g}, 288.15 \mathrm{~K}\right)\right] \\
& +\mathrm{b} / 2\left[H^{\circ}\left(\mathrm{H}_{2} \mathrm{O}, \ell, 298.15 \mathrm{~K}\right)-H^{\circ}\left(\mathrm{H}_{2} \mathrm{O}, \ell, 288.15 \mathrm{~K}\right)\right] \\
& -(\mathrm{a}+\mathrm{b} / 4)\left[H^{\circ}\left(\mathrm{O}_{2}, \mathrm{~g}, 298.15 \mathrm{~K}\right)-H^{\circ}\left(\mathrm{O}_{2}, \mathrm{~g}, 288.15 \mathrm{~K}\right)\right] \\
& -\left[H^{\circ}\left(\mathrm{C}_{\mathrm{a}} \mathrm{H}_{\mathrm{b}}, \mathrm{g}, 298.15 \mathrm{~K}\right)-\mathrm{H}^{\circ}\left(\mathrm{C}_{\mathrm{a}} \mathrm{H}_{\mathrm{b}}, \mathrm{g}, 288.15 \mathrm{~K}\right] .\right.
\end{aligned}
$$

for which the required data are found in Tables 3 and 4 . Using methane to illustrate the calculation we have:

$$
\begin{gathered}
{\left[\Delta_{\mathrm{C}} \mathrm{H}^{\circ}\left(\mathrm{CH}_{4}, \mathrm{~g}, 298.15 \mathrm{~K}\right)-\Delta_{\mathrm{C}} \mathrm{H}^{\circ}\left(\mathrm{CH}_{4}, \mathrm{~g}, 288.15 \mathrm{~K}\right)\right] / \mathrm{kJ} \mathrm{mol}^{-1}} \\
=0.369+2 \times 0.753-2 \times 0.293-0.355=0.934 .
\end{gathered}
$$

Taking $\Delta_{\mathrm{C}} \mathrm{H}^{\circ}\left(\mathrm{CH}_{4}, \mathrm{~g}, 298.15 \mathrm{~K}\right) / \mathrm{kJ} \mathrm{mol}^{-1}=-890.31$ from Table 4 we find $\Delta_{\mathrm{c}} H^{\circ}\left(\mathrm{CH}_{4}, \mathrm{~g}, 288.15 \mathrm{~K}\right) / \mathrm{kJ} \mathrm{mol}^{-1}=-890.31-0.934=891.244$ which rounds to -891.24 .

This process is illustrated in Figure 1.

Relationship between standard enthalpy of formation, $\Delta_{f} H^{\circ}$ and $\Delta_{c} H^{\circ}$ for

a hydrocarbon

The general reaction $A 8.7$ can be used as the basis for calculating the standard enthalpy of formation from the elements of a hydrocarbon compound $\Delta_{f} H^{\circ}\left(C_{a} H_{b}\right)$, if the enthalpy of combustion of the hydrocarbon is known. The relationship is:

$$
\begin{aligned}
\Delta_{c} H^{\circ}\left(\mathrm{C}_{\mathrm{a}} \mathrm{H}_{\mathrm{b}}\right) & =a \Delta_{f} H^{\circ}\left(\mathrm{CO}_{2}, \mathrm{~g}\right)+(\mathrm{b} / 2) \Delta_{\mathrm{f}} H^{\circ}\left(\mathrm{H}_{2} \mathrm{O}, \mathrm{l}\right) \\
& -\Delta_{\mathrm{f}} H^{\circ}\left(\mathrm{C}_{\mathrm{a}} \mathrm{H}_{\mathrm{b}}\right)-(\mathrm{a}+\mathrm{b} / 4) \Delta_{\mathrm{f}} H^{\circ}\left(\mathrm{O}_{2}, \mathrm{~g}\right) .
\end{aligned}
$$


By the use of information in Tables $3 b$ and $4 b$ this equation may be used to calculate the enthalpy of formation of methane as an example. The temperature to which the values taken from the tables correspond must be the same for all substances involved in the equation. We use $T=298.15 \mathrm{~K}$ for the example.

$$
\begin{aligned}
\Delta_{\mathrm{c}} \mathrm{H}^{\circ}\left(\mathrm{CH}_{4}, \mathrm{~g}\right) & =\Delta_{\mathrm{f}} \mathrm{H}^{\circ}\left(\mathrm{CO}_{2}, \mathrm{~g}\right)+2 \Delta_{\mathrm{f}} H^{\circ}\left(\mathrm{H}_{2} \mathrm{O}, \mathrm{i}\right) \\
& -\Delta_{\mathrm{f}} \mathrm{H}^{\circ}\left(\mathrm{CH}_{4}, \mathrm{~g}\right)-2 \Delta_{\mathrm{f}} H^{\circ}\left(\mathrm{O}_{2}, \mathrm{~g}\right) .
\end{aligned}
$$

Taking values from Tables $3 b$ and $4 b$ at $T=298.15 \mathrm{~K}$, we substitute:

$$
\begin{aligned}
-890.31 \mathrm{~kJ} \mathrm{~mol}^{-1} & =-393.51 \mathrm{~kJ} \mathrm{~mol}^{-1}+2(-285.830) \mathrm{kJ} \mathrm{mol}^{-1} \\
& -\Delta_{f} H^{\circ}\left(\mathrm{CH}_{4}, \mathrm{~g}\right)-2(0.0) .
\end{aligned}
$$

By rearrangement and addition

$$
\begin{aligned}
\Delta_{\mathrm{f}} \mathrm{H}^{\circ}\left(\mathrm{CH}_{4}, \mathrm{~g}\right) & =(+890.31-393.51-2.285 .830) \mathrm{kJ} \mathrm{mol}^{-1} \\
& =-74.86 \mathrm{~kJ} \mathrm{~mol} .
\end{aligned}
$$

Note that all of the enthalpies of formation in this example have negative values, meaning that heat is evolved in the reaction of formation from the elements.

The converse process, the calculation of the standard enthalpy of combustion from known values of standard enthalpy of formation, uses equation A8.11 and data from Tables 3 and 4 in the same way.

Molar volume of the ideal gas

All gases, when treated as ideal gases, have the same volume per mole at the same temperature and pressure.

$$
V_{\mathrm{m}}^{\mathrm{id}}(T)=R T / p
$$

where $R$ is the gas constant, $p$ is the pressure and $T$ is the absciute temperature. With the temperature in kelvin, pressure in pascal and volume in cubic meters, this equation becomes

$$
V_{\mathrm{m}}^{\mathrm{id}}=8.31441 \mathrm{~T} / \mathrm{p} .
$$

The value for $R$ is taken from Table 1 . Numerically it is the same for cubic meter-pascal per mole-kelvin as for joule per mole-kelvin. 
The amount of substance (molar) density is the reciprocal of the molar volume. 
Appendix 9. Non-ideality effects and the virial equation of state Two topics are discussed in this appendix: the procedures used to correct ideal-gas properties to those of the real gas and the selection of the virial coefficients in Table 8 (footnotes and references). Propagation of errors is discussed in Appendix 10.

The virial equation of state

The equation of state of a real gas is well represented by the so called virial equation of state:

$$
p V_{\mathrm{m}} / R T=1+B(T) / V_{\mathrm{m}}+C(T) / V_{\mathrm{m}}^{2}+\ldots,
$$

in which the second virial coefficient is $B(T)$; the third virial coefficient is $C(T) ; V_{\mathrm{m}}$ is the real-gas molar volume. The second virial coefficient is generally considered to represent the effects of interactions involving two molecules; the third virial coefficient, interactions involving three molecules, and so on. At the low pressures represented by the reference conditions, the second virial coefficient is adequate to represent the interactions that occur and so for this document the virial equation is truncated at the $B(T)$ term:

$$
p V_{\mathrm{m}} / R T=1+B(T) / V_{\mathrm{m}}
$$

$B$, as well as the other virial coefficients, is a function of temperature. The errors introduced by this procedure are considered to be less than those due to the uncertainties in the values of $B\left(T^{\prime}\right)$ for the various substances.

The virial coefficient is used for two purposes in this document: (a) to calculate the effect of non-ideality on enthalpy of the real gas as compared to the ideal gas; and (b) to calculate the molar volume of the real gas as opposed to the molar volume of the ideal gas. This is 
used both in the calcuiation of volumetric enthalpies of combustion and in correcting enthaipies.

(a) Enthalpic effect.

The difference $H-H^{\circ}$ in the enthalpy of the real gas and the ideal gas is given by:

$$
\left(H_{\mathrm{m}}-H_{\mathrm{m}}^{\circ}\right) / R T=\{B-T(\mathrm{~d} B / \mathrm{d} T)\} / V_{\mathrm{m}}
$$

For the purpose of determining $T(\mathrm{~d} B / \mathrm{d} T)$ it is convenient to have equations representing $B(T)$ as a polynomial in $T$. Equations of the form

$$
B(T)=c+d T+e T^{2}
$$

have been derived and the constants $c, d$, and $e$, are given in Table A9a.

(b) Volumetric effect.

Rearrangement of equation (A9.2) gives:

$$
V_{\mathrm{m}}=(R T / p)\left\{1+B(T) / V_{\mathrm{m}}\right\},
$$

a quadratic equation which has the solution:

$$
V_{\mathrm{m}}=V_{\mathrm{m}}^{\circ}\left[\frac{1}{2}+\frac{1}{2}\left\{1-4 B(T) / V_{\mathrm{m}}^{\mathrm{id}}\right\}^{\frac{1}{2}}\right]
$$

The negative solution is ignored as being physically meaningless. $V_{\mathrm{m}}^{\text {id }}$ is a constant for a given value of $p$ and $T$, and so the equation can be solved exactly if $B(T)$ is also known.

Virial coefficients of mixtures

Any gas has a second virial coefficient. For pure substances $B(T)$ is a characteristic physical property of the substance. For a mixture, $B(T)$ is a function of the composition as well as the pressure and temperature. Reflecting the probabilities of binary interactions between molecules, the virial coefficient of a binary mixture is given as a linear combination of terms:

$$
B \text { (mixture) }=x_{1}^{2} B_{11}+2 x_{1} x_{2} B_{12}+x_{2}^{2} B_{22}
$$


in which $x_{1}$ and $x_{2}$ are the mole fractions, respectively, of components 1 and 2, for which the virial coefficients of the pure substance are $B_{11}$ and $B_{22}$ respectively. $B_{12}$ represents the effect of interaction between unlike molecules.

For more complex mixtures equation (A9.7) can be generalized by taking pairwise interactions of all combinations of molecules.

$$
\begin{aligned}
B \text { (mixture }) & =x_{1}^{2} B_{11}+x_{2}^{2} B_{22}+x_{3}^{2} B_{33}+ \\
& +2 x_{1} x_{2} B_{12}+2 x_{1} x_{3} B_{13}+ \\
& +2 x_{2} x_{3} B_{23}+\ldots
\end{aligned}
$$

For calculation of enthalpic effects and volumetric effects $B$ (mixture) obtained in this way is used to calculate the properties of any particular mixture for which the composition $\left(x_{1}, x_{2} \ldots x_{n}\right)$ is known.

Most of the virial coefficients for individual substances and for binary interactions for substances and mixtures with which this document is concerned have been measured and have been compiled by Dymond and Smith $[2]^{*}$.

The virial coefficients $B(T)$ for the substances in this document are listed in Table 8a. For binary mixtures involving methane as one gas, the interaction coefficients $B_{12}$ are given in Table $8 \mathrm{~b}$. Because the importance of terms involving minor constituents is proportional to the products of their mole fractions, the interaction terms not involving methane have been omitted from the tables. Many of them can be found in Dymond and Smith, if necessary.

\footnotetext{
References are given at the end of this appendix.
} 
Selection of virial coefficients: footnotes to Table 8.

a The uncertainties assigned to the virial coefficients from references [1] and [2] in Table 8 are those suggested by the respective authors unless otherwise stated.

b Methane virial coefficients at the required temperatures were obtained from a smooth curve through the values tabulated in reference [1].

c The values given by Dymond and Smith [2] bracket those given by Levelt Sengers et al. [1].

d Ethene values given by Dymond and Smith [2] bracket those given by Douslin and Harrison [5] which were plotted. The values of Douslin and Harrison were used at $273.15 \mathrm{~K}, 288.15 \mathrm{~K}$ and $298.15 \mathrm{~K}$. The value at $288.71 \mathrm{~K}$ was interpolated from the graph.

e Ethane values given by Dymond and Smith [2] bracket those given by Douslin and Harrison [6]. The values given by Douslin and Harrison were plotted as well as those by Dymond and Smith. The values of Douslin and Harrison were used at $273.15 \mathrm{~K}$ and $298.15 \mathrm{~K}$ and values interpolated from the curve were used for other values.

f Propane values given by Dymond and Smith [2] were plotted and interpolated to give all values.

g n-Butane has been studied frequently. The selected values are interpolated on a curve drawn by eye through the points given by Dymond and Smith [2]. 
h The data for isobutane are scattered. Two points at $273.15 \mathrm{~K}$ by Jessen and Lightfoot [10] and by Das, Reed, and Eubank [11] were averaged; although they do not convert well to higher temperature data. A rough curve was drawn by eye through points from $288 \mathrm{~K}$ to $333 \mathrm{~K}$ by Kretschmer and Wiebe [12], Mason and Eakin [9]; Strein, Lichtenthaler, Schramm, and Schäfer [13], and Das, et al. [11]. This curve was used for interpolation at the other temperatures.

The data for n-pentane are not plentiful in the temperature region below $300 \mathrm{~K}$. Dymond and Smith [2] recommend values down to $300 \mathrm{~K}$, and a smooth curve was drawn through them and extended to $273.4 \mathrm{~K}$ where a point is given by Kapello, et a1. [14] whose data unfortunately drops $~ 100$ $\mathrm{cm}^{3} \mathrm{~mol}^{-1}$ below the line at higher temperatures. The line passes near a point presented by Mason and Eakin [9], and somewhat above two points given by Rätzsch and Bittrich [15] and the lower limit of the smoothed data evaluated by Das, et al. [11] and below data given by McGlashan and Potter [16] and by Hajjar, et al. [17]. For 2-methylbutane, Dymond and Smith [2] recommended values from Das et al. [8] and a curve was drawn and values interpolated.

For 2,2-dimethylpropane a smooth curve was drawn through the data recommended by Dymond and Smith [2] and the values were interpolated.

Benzene values were interpolated from a curve drawn from data recommended by Dymond and Smith [2].

m For 2-methylpentane the data of Waddington, et al. [7] were plotted and the curve was extrapolated below $298.15 \mathrm{~K}$. One other point was given by 0sborne and Ginnings [19] at $298.15 \mathrm{~K}$ but it was more negative by $40 \mathrm{~cm}^{3}$ $\mathrm{mol}^{-1}$. 
For 3-methylpentane the data of Waddington et al. [7] were plotted from 303 to $336 \mathrm{~K}$ and a curve below $300 \mathrm{~K}$ was extrapolated. One point at $298.15 \mathrm{~K}$ was given by Osborne and Ginnings [19] but it appeared to be negative by about $40 \mathrm{~cm}^{3} \mathrm{~mol}^{-1}$.

0

For 2,3-dimethylbutane the data of Waddington et al. [7] were plotted from 295 to $331 \mathrm{~K}$ and a curve was drawn and extrapolated. One point was determined from Osborne and Ginnings [19] but it appeared to be negative by about $40 \mathrm{~cm}^{3} \mathrm{~mol}^{-1}$.

For argon the uncertainties and values were recommended by Leveit Sengers, et al. [1]. A smooth curve was drawn through their recommended values and the points at temperatures other than $273.15 \mathrm{~K}$ were taken from the curve. The value at $273.15 \mathrm{~K}$ also is from [1]. Argon plus methane, $B_{12}$ was fitted from data listed in [2] over the range 250 to $323 \mathrm{~K}$. The data of Thomas, et al. [23] and of Byrne, et al. [22] and of Belim et al. [20] fall about 6 to $8 \mathrm{~cm}^{3} \mathrm{~mol}^{-1}$ below the rest of the data. A smooth curve was drawn through the upper data and the tabulated values were found by interpolation on the smooth curve. The value of $B_{12}$ may be as much as $8 \mathrm{~cm}^{3} \mathrm{~mol}^{-1}$ more negative than the tabulated values that are based on the work by Schäfer and colleagues $[13,18,21]$.

The only data given in [2] are by Mason and Eakin [9]. [36] and the values used were obtained by interpolation.

A line was drawn through the point from $[38,39]$ listed in [2] at $248.53 \mathrm{~K}$ and midway between points of $[38,39]$ at $291.4 \mathrm{~K}$ and [9] at $288.7 \mathrm{~K}$. The values listed were obtained from the curve by interpolation. 
u Ref. [2] lists only ref. [37] as a source. A slightly curved line was drawn through the two points in the range 250 to $325 \mathrm{~K}$ and was extrapolated to obtain the values listed.

$\checkmark$ For ethene plus methane, $B_{12}$ is given in [2] by Mason [9], McMath and Edmister [24], Lee and Edmister [25] which form a fairly consistent set, plus unpublished work by Lee (with Saville) $[26,27]$ which fall about $6 \mathrm{~cm}^{3} \mathrm{~mol}^{-1}$ lower. The values cited are from a smooth curve through the upper data.

W A smooth curve was drawn by eye through all points found in [2] in the range 250 to $325 \mathrm{~K}$. The points were found by interpolation on the curve.

$x$ All values 1 isted for $B_{12}$ in [2] in the range 250 to $325 \mathrm{~K}$ were plotied and a smooth curve drawn by eye through the points. The data listed were obtained by interpolation on the curve.

y A curve was drawn through all values for $B_{12}$ listed in [2] in the range 250 to $325 \mathrm{~K}$. The data scatter badly. The curve was drawn with slightly greater slope than for propane and methane, but otherwise of a similar shape. The values listed were interpolated on the curve.

Only one point is given for iso-butane plus methane. A curve was drawn through it and equally proportioned between the curves for methane plus propane and methane plus $n$-butane.

aa For n-pentane plus methane values of $B_{12}$ scatter badly and the slopes from different sources are not consistent. A curve with minimum slope was drawn. The value at $273.15 \mathrm{~K}$ had to be extrapolated; otherwise points were interpolated.

bb Very bad scatter; a curve was drawn parallel to n-pentane, and a little less negative. 
cc For 2,2-dimethylpropane plus methane the data of Strein [13], Hamann [34], and Belim [20] were plotted, a curve drawn through [13] and [20] fell about $25 \mathrm{~cm}^{3} \mathrm{~mol}^{-1}$ more negative than for [34]. Other data by Baughman [35] from 199 to $257 \mathrm{~K}$ was plotted and values were less negative. Values were extrapolated from the curve drawn through data of [34].

dd For n-hexane plus methane the data of Pecsok [32] and Dantzler [29] were plotted and a smooth curve was drawn by eye and values extrapolated.

ee

For 2,2-dimethylbutane plus methane a smooth curve was drawn by eye through the only two points given by Pecsok [32] and values were extrapolated.

ff A uniform uncertainty of $\pm 100 \mathrm{~cm}^{3} \mathrm{~mol}^{-1}$ is used for the hexanes on the basis of [2] and cyclohexane at $300 \mathrm{~K}$. The uncertainty is probably larger at $273.15 \mathrm{~K}$ because of lack of data.

gg

Ref. [2] does not list smoothed data below $300 \mathrm{~K}$. The data point given at $298.15 \mathrm{~K}$ is from [4].

hh Uncertainty taken equal to that for $\mathrm{CO}_{2}$-free dry air. Uncertainty taken as twice that of helium. 
References for Virial Coefficient Data

1. Levelt Sengers, J.M.H.; Klein, M.; Gallagher, J.S.; "Pressure Volume-Temperature Relationships of Gases; Virial Coefficients"; D. E. Gray; editor, American Institute of Physics Handbook, 3rd Edition, 1972, pp. 4-204 to 4-221.

2. Dymond, J.H.; Smith, E.G.; "The Virial Coefficients of Pure Gases and Mixtures: A Critical Compilation"; Oxford University Press, 1980.

3. Schäfer, K.; Z. Phys. Chem. (1937), B36, 85.

4. Bottomley, G.A.; Reeves, C.G.; Seiflow, G.H.F.; Nature. (London) (1958), 182, 596 .

5. Douslin, D.R.; Harrison, R.H.; J. Chem. Thermodynamics (1976), $\underline{8}, 301$.

6. Douslin, D.R.; Harrison, R.H.; J. Chem. Thermodynamics (1978), 5 , 491.

7. Waddington, G.; Smith, J.C.; Scott, D.W.; Huffman, H.M.; J. Am. Chem. Soc. (1949), 71, 3902.

8. Das, T.R.; Reed, C.0., Jr.; Eubank, P.T.; J. Chem. Eng. Data (1977). 22, 9.

9. Mason, D.M.; Eakin, B.E.; J. Chem. Eng. Data (1961), ㅁ, 499.

10. Jesson, F.W.; Lightfoot, J.H.; Ind. Eng. Chem. Ind. Ed. (1938), 30, 312.

11. Das, T.R.; Reed, C.0., Jr.; Eubank, P.T.; J. Chem. Eng. Cata (1973), 18, 253.

12. Kretschmer, C.B.; Wiebe, R.; J. Am. Chem. Soc. (1951), 73 , 3778.

13. Strein, K.; Lichtenthaler, R.N.; Schramm, B.; Schäfer, K.; Ber. Bunsenges Phys. Chem. (1971), 75, 1308. 


\section{References (continued)}

14. Kape110, W.; Lund, N.; Schäfer, K.; Z. Phys. Chem. N. F (Frankfurt). $(1963), 37,196$.

15. Rätzsch, M.; Bittrich, H.J.; Z. Phys. Chem. (1965), 228, 81.

16. McGlashan, M.L. ; Potter, D.J.B. ; Proc. Roy Soc. (1978), A267, 478.

17. Hajjar, R.F.; Kay, W.B.; Leverett, G.F.; J. Chem. Eng. Data (1969), 14, 377

18. Lichtenthaler, R.N., Schäfer, K.; Ber. Bunsenges. Phys. Chem. (1969), 73, 42.

19. Osborne, N.S.; Ginnings, D.C.; J. Res. National Bur. Stand. (1947), 39, 453

20. Belim, J.; Renche, W. ; Schäfer, K.; Schramm, B.; Ber. Bunsenges.

Phys. Chem. (1974), 78, 282.

21. Hahn, R.; Schäfer, K.; Schramm, B.; Ber. Bunsenges. Phys. Chem. $(1974), 78,287$.

22. Byrne, M.A. ; Jones, M.R. ; Staveley, L.A.K. ; Trans Faraday Soc. (1968), 64, 1747.

23. Thomas, G.; Steenwinke1, R. Van.; Stone, W.; Mol. Phys. (1962), $5,301$.

24. McMath, H.G. ; Edmister, W.C. ; A.I.CH.E.J. (1969), 15, 370.

25. Lee, R.C.; Edmister, W.C.; A.I.CH.E.J (1970), 16, 1047.

26. Lee, J.'W.; Saville, G.; unpub. [2] See also Lee, [27].

27. Lee, J.W.; PhD - Thesis, University of London (1976).

28. Gunn, R.D.; M.S. Thesis, University California Berkeley (1958).

29. Dantzler, E.M. ; Knobler, C.M. ; Windsor, M. L. ; J. Phys. Chem. Ithaca (1968), 72, 676 .

30. Hoover, A.E.; Nagata, I.; Leland, T.W., Jr.; Kobayashi, R., J. ; Chem. Phys. (1968), 48, 2633. 


\section{References (continued)}

31. Wormald, C.J.; Lewis, E.J.; Hutchings, D.J.; J. Chem. Thermodynamics (1979), $\underline{11}, 1$.

32. Pecsok, R.L.; Windsor, M. L. ; Anal. Chem. (1968), 40, 1238.

33. Massondi, R.; King, A.D., Jr.; J. Phys. Chem. (1973), 77, 2016.

34. Hamann, S.D.; Lambert, J.A.; Thomas, R. B. ; Australian J. Chem. (1955), 8 , 149.

35. Baughman, G.L.; Westhoff, S.P.; Dincer, S.; Duston, D.D.; Kidnay, A.J.; J. Chem. Thermodynainics (1975), 7, 875.

36. Mueller, W.H.; Leland, T.W.; Kobayashi, R. ; A.I.C.H.E.J. (1961), I, 267.

37. Rigby, M.; Prausznitz, J.M. ; J. Phy's. Chem. (1968), 72, 330.

38. Roe, D.R.; Saville, G.; Unpubiished (see [2]).

39. Roe, D.R.; PhD Thesis, University of London (1972). 
Table A9a. Constants for quadratic equations for the virial coefficients as functions of $T$ in the range 273 to $300 \mathrm{~K}^{\mathrm{a}}$

$$
B=c+d T+e T^{2}
$$

Substance
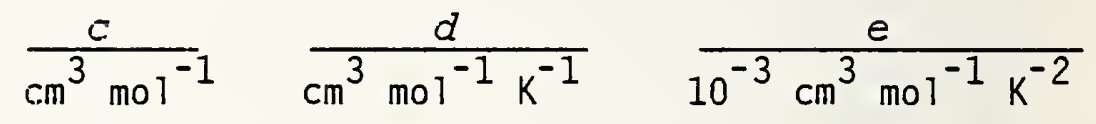

methane

$$
-264.3
$$

$-1.0899$

$-1.166$

ethane

$-1333.6$

$-6.4626$

$-8.763$

propane

$-1618.0$

$-5.1270$

$-3.303$

n-butane

$-7937.1$

$+42.5325$

$-61.636$

2-methylpropane

$-18754.8$

$+117.552$

$n$-pentane

$-25054.4$

$+148.949$

2-methylbutane

$-10077.8$

$+52.7664$

$-11735.3$

$+63.9039$

n-hexane

2-methlypentane

3-methlypentane

2,2-dimethy 1 butane

2,3-dimethylbutane

ethyne

ethene

propene

benzene

carbon monoxide

carbon dioxide

oxygen

nitrogen

helium

argon

hydrogen

air $\left(\mathrm{CO}_{2}\right.$-free, dry)

$-3577.8$

$-16491.6$

$-15607.0$

$-912.2$

$-1577.5$

$-17679.2$

$-1280.8$

$-110.8$

$-151.7$

$+2.0$

$-185.3$

$+62.7$

$-154.7$
$-1.8440$

$+87.5927$

$-85.6304$

$+4.2046$

$+5.5834$

$+97.4720$

$+6.9745$

$+0.4066$

$+0.7923$

$+0.0773$

$+0.9461$

$-0.3694$

$+0.7924$
$-190.852$

$-232.017$

$-75.838$

$-92.816$

$+27.174$

$-127.131$

$-128.881$

$-5.413$

$-4.873$

$-144.782$

$-10.374$

$+0.299$

$-1.009$

$-0.149$

$-1.271$

$+0.696$

$-1.009$

water vapor

Data in Table 8 were fitted to the quadratic form. The main use is to obtain $\mathrm{d} B / \mathrm{d} T$ near $288 \mathrm{~K}$. Because some points are extrapolated, these expressions must be considered to be approximate. 
Table A9b. Constants for quadratic equations for the second virial coefficierits of interaction, $B(1, i)$, as functions of temperature for the range 273 to $300 \mathrm{~K}^{\mathrm{a}}$

\begin{tabular}{|c|c|c|c|}
\hline \multicolumn{3}{|c|}{$B(1, i)=\Xi+d T+e T^{2}(1=$ methane $)$} & $e$ \\
\hline Substance pair & $\mathrm{cm}^{3} \mathrm{~mol}^{-1}$ & $\mathrm{~cm}^{3} \mathrm{~mol}^{-1} \mathrm{k}^{-1}$ & $10^{-3} \mathrm{~cm}^{3} \mathrm{~mol}^{-1} \mathrm{~K}^{-2}$ \\
\hline methane + ethane & -561.6 & +3.2100 & -4.358 \\
\hline$(1)^{b}+$ propane & -560.8 & +2.0478 & -2.044 \\
\hline (1) $+n$-butane & -899.5 & +3.7585 & -4.478 \\
\hline (1) + 2-methy !propane & -941.2 & +4.3346 & -5.627 \\
\hline (1) + n-pentane & -1276.3 & +5.6426 & -7.076 \\
\hline (1) + 2-methlybutane & -1449.9 & +7.0162 & -9.551 \\
\hline (1) + 2,2-dime thylpropane & -3123.8 & +18.7127 & -29.534 \\
\hline (1) $+n$-hexane & -3201.1 & +18.7225 & -29.901 \\
\hline (1) + 2-methylpentane & --- & --- & --- \\
\hline (1) + 3-methylpentane & -- & --- & --- \\
\hline (1) + 2,2-dimethlybutane & -4491.4 & +26.2291 & -39.888 \\
\hline (1) $+2,3$-dimethlybutane & -- & --- & --- \\
\hline$(1)+$ cyclopropane & --- & --- & --- \\
\hline (1) + cyclobutane & -- & -- & --- \\
\hline (1) + cyclopentane & --- & --- & --- \\
\hline (1) + cyclohexane & --- & --- & --- \\
\hline$(1)+$ ethyne & --- & --- & --- \\
\hline (1) + ethene & -496.1 & +2.2641 & -2.738 \\
\hline (1) + propene & --- & --- & --- \\
\hline$(1)+$ benzerie & --- & --- & --- \\
\hline (1) + carton monoxide & --- & --- & --- \\
\hline (1) + carbon dioxide & -- & --- & --- \\
\hline$(1)+$ oxygen & --- & --- & --- \\
\hline (1) + nitrogen & -333.8 & +2.0150 & -3.198 \\
\hline$(1)+$ helium & --- & --- & --- \\
\hline (1) + argon & -368.1 & +2.0854 & -3.090 \\
\hline (1) + hydrogen & +89.9 & -0.7904 & +1.769 \\
\hline$(1)+\operatorname{air}\left(\mathrm{CO}_{2}-\right.$ free, dry $)$ & --- & --- & --- \\
\hline $\begin{array}{l}(1)+\text { water vapor } \\
\text { a See footnote to Table } A 9 a\end{array}$ & -545.3 & +2.4226 & -2.700 \\
\hline
\end{tabular}


Table A9c. Enthalpy differences, $H-H^{\circ}$, between the real and ideal gases for pure substances $p=101.325 \mathrm{kPa}$ at various reference temperatures

\begin{tabular}{|c|c|c|c|c|}
\hline \multirow{2}{*}{$\begin{array}{l}\text { Substance } \\
\frac{T / K}{}\end{array}$} & \multicolumn{3}{|c|}{$\frac{H-H^{\circ}}{\mathrm{J} \cdot \mathrm{m} 0 \mathrm{I}^{-1}}$} & \multirow[b]{2}{*}{298.15} \\
\hline & 273.15 & 288.15 & 288.71 & \\
\hline methane & -18.0 & -17.0 & -17.0 & -16.3 \\
\hline ethyne & --- & --- & --- & --- \\
\hline ethene & -51.9 & -47.2 & -47.0 & -43.9 \\
\hline ethane & -69.5 & -61.9 & -61.6 & -56.6 \\
\hline propene & -125 & -121 & -121 & -118 \\
\hline propane & -142 & -139 & -139. & -136 \\
\hline cyclobutane & --- & --- & --- & --- \\
\hline n-butane & -353 & -296 & -294 & -257 \\
\hline 2-meth lypropane & -478 & -306 & -299 & -188 \\
\hline cyclopentane & --- & --- & --- & --- \\
\hline n-pentane & -854 & -626 & -618 & -475 \\
\hline 2-methylbutane & -478 & -404 & -401 & -355 \\
\hline 2,2-dimethylpropane & -517 & -428 & -424 & -368 \\
\hline benzene & -767 & -619. & -613 & -521 \\
\hline cyclohexane & --- & --- & --- & --- \\
\hline n-hexane & --- & --- & --- & --- \\
\hline 2-methylpentane & -633 & -547 & -647 & -657 \\
\hline 3-methylpentane & -790 & -656 & -651 & -568 \\
\hline 2,2-dimethylbutane & --- & --- & --- & --- \\
\hline 2,3-dimethylbutane & -667 & -537 & -532 & -451 \\
\hline carbon monoxide & --- & --- & --- & --- \\
\hline carbon dioxide & -51.7 & -42.7 & -42.4 & -36.5 \\
\hline oxygen & -8.98 & -8.72 & -8.71 & -8.54 \\
\hline nitrogen & -7.74 & -6.88 & -6.85 & -6.28 \\
\hline helium & 1.33 & 1.46 & 1.47 & 1.55 \\
\hline argon & -9.18 & -8.09 & -8.05 & -7.33 \\
\hline hydrogen & 1.09 & 0.50 & 0.48 & 0.09 \\
\hline air $\left(\mathrm{CO}_{2}\right.$ free dry $)$ & -8.05 & -7.19 & -7.15 & -6.59 \\
\hline water vapor & --- & --- & --- & --- \\
\hline
\end{tabular}


Appendix 10. Propagation of uncertainties

\section{Propagation of uncertainties}

In calculating the propagation of uncertainties, we use the relationship, below, recommended by the IUPAC Commission on Thermodynamics [17]*. Where a quantity $F$ is a function of variables $x, y, z$ :

$$
F=F(x, y, z)
$$

then the uncertainty $s_{F}$ in $F$ is related to the uncertainties in $x, y$, and $z$ by the equation:

$$
\left(s_{F}\right)^{2}=(\partial F / \partial x)^{2} s_{x}^{2}+(\partial F / \partial y)^{2} s_{y}^{2}+(\partial F / \partial z)^{2} s_{z}^{2}
$$

strictly speaking, $x, y$ and $z$ must be independent, non-correlated variables for this equation to hold. Usually, when there is some correlation this equation gives an upper limit. It is adopted here as an ad hoc expression to define the method of calculations.

In this document we use several functions of the type:

$$
\begin{gathered}
F=a x \\
F=a x+b y-c z
\end{gathered}
$$

where $a, b$, and $c$, are constants.

For equation (A10.3), by application of (A10.2) we obtain:

$$
\left.s_{F}^{2}=\{\partial a x) / \partial x\right\}^{2} s_{x}^{2}+\{\partial(a x) / \partial a\}^{2} s_{a}^{2}
$$

Since $a$ is a constant $s_{a}=0$ and the last term of (A10.5) is zero. As a result:

$$
s_{F}^{2}=a^{2} s_{x}^{2}=\left(a s_{x}\right)^{2}
$$

or

$$
s_{F}=s_{x}
$$

* See general list of references. 
For equation (A10.4), by application of (A10.2) we have, dropping the zero terms as above:

$$
s_{F}^{2}=\{\partial(a x) / \partial x\}^{2} s_{x}^{2}+\{\partial(b y) / \partial y\}^{2} s_{y}^{2}+\{\partial(-c z) / \partial z\}^{2} s_{z}^{2} .
$$

This reduces to:

$$
\begin{gathered}
s_{F}^{2}=a^{2} s_{x}^{2}+b^{2} s_{y}^{2}+(-c)^{2} s_{z}^{2} \\
s_{F}^{2}=\left(a s_{x}\right)^{2}+\left(b s_{y}\right)^{2}+\left(c x_{z}\right)^{2}
\end{gathered}
$$

or:

$$
s_{F}=\left\{\left(a_{x}\right)^{2}+\left(b_{y}\right)^{2}+\left(c s_{z}\right)^{2}\right\}^{\frac{1}{2}}
$$

Uncertainties in enthalpies of combustion and enthalpies of formation under different conditions

(a) Enthalpies of combustion and formation

The chemical equation for the combustion reaction:

$$
\mathrm{C}_{a} \mathrm{H}_{b}+(\mathrm{a}+\mathrm{b} / 4) \mathrm{O}_{2}=\mathrm{aCO}_{2}+(\mathrm{b} / 2) \mathrm{H}_{2} \mathrm{O}
$$

leads to relationships between the enthalpies of formation $\Delta_{\mathrm{f}} H^{\circ}$ and the enthalpy of combustion $\Delta_{C} H^{\circ}$ :

$$
\begin{aligned}
\Delta_{c} H^{\circ}\left(C_{a} H_{b}\right)=a \Delta_{f} H^{\circ}\left(C O_{2}\right) & +(b / 2) \Delta_{f} H^{\circ}\left(H_{2} \mathrm{O}\right)-(a+b / 4) \Delta_{f} H^{\circ}\left(O_{2}\right) \\
& -\Delta_{f} H^{\circ}\left(C_{a} H_{b}\right)
\end{aligned}
$$

which is a function of the type of equation (A10.4). By application of equation (A10.2) as illustrated in equations (A10.3 - 11) we obtain:

$$
\begin{aligned}
s_{c}\left(C_{a} H_{b}\right) & =\left[\left\{a_{f}\left(C O_{2}\right)\right\}^{2}+\left\{(b / 2) s_{f}\left(H_{2} O\right)\right\}^{2}+\right. \\
& \left.+\left\{(a+b / 4) s_{f}\left(O_{2}\right)\right\}^{2}+\left\{s_{f}\left(C_{a} H_{b}\right)\right\}^{2}\right]^{\frac{1}{2}},
\end{aligned}
$$

or alternatively:

$$
\begin{aligned}
s_{f}\left(\mathrm{C}_{a} H_{b}\right) & =\left[\left\{\operatorname{as}_{f}\left(\mathrm{CO}_{2}\right)\right\}^{2}+\left\{(b / 2) s_{f}\left(\mathrm{H}_{2} \mathrm{O}\right)\right\}^{2}\right. \\
& \left.+\left\{(\mathrm{a}+\mathrm{b} / 4) s_{f}\left(\mathrm{O}_{2}\right)\right\}^{2}+\left\{\mathrm{s}_{\mathrm{c}}\left(\mathrm{C}_{\mathrm{a}} \mathrm{H}_{b}\right)\right\}^{2}\right]^{\frac{1}{2}}
\end{aligned}
$$

depending on whether $\Delta_{c} H^{\circ}\left(\mathrm{C}_{a} H_{b}\right)$ or $\Delta_{f} H^{\circ}\left(\mathrm{C}_{a} H_{b}\right)$ is taken as the dependent quantity. In the above equation $\Delta_{f} H^{\circ}\left(0_{2}\right) \equiv 0$ and $s_{f}\left(0_{2}\right)=0$. 
(b) Adjustment from one temperature to another

For the adjustment of heating values from one temperature to another, the following relationships are derived from equation (A10.12).

$$
\begin{aligned}
\Delta_{c} H_{T}^{\circ}\left(\mathrm{C}_{\mathrm{a}} \mathrm{H}_{b}\right) & =\Delta_{c} H_{298.15 \mathrm{~K}}^{\circ}\left(\mathrm{C}_{\mathrm{a}} \mathrm{H}_{\mathrm{b}}\right) \\
& +\mathrm{a}\left\{\left(H_{T}^{\circ}-H_{298.15 \mathrm{~K}}^{\circ}\right)\left(\mathrm{CO}_{2}\right)\right\}+(\mathrm{b} / 2)\left\{\left(H_{T}^{\circ}-H_{298.15 \mathrm{~K}}^{\circ}\right)\left(\mathrm{H}_{2} \mathrm{O}, 1\right)\right\} \\
& -(\mathrm{a}+\mathrm{b} / 4)\left\{\left(H_{T}^{\circ}-H_{298.15 \mathrm{~K}}^{\circ}\right)\left(0_{2}\right)\right\}-\left\{\left(H_{T}^{\circ}-H_{298.15 \mathrm{~K}}^{\circ}\right)\left(\mathrm{C}_{\mathrm{a}} \mathrm{H}_{\mathrm{b}}\right)\right\}
\end{aligned}
$$

Equation (A10.16) is also a function of the type of equation (A10.4). From equation (16) we derive:

$$
\begin{aligned}
\left\{s_{c}(T)\right\}^{2} & =\left\{s_{c}(298.15 K)\right\}^{2}+\left\{\mathrm{as}_{H(T)}\left(\mathrm{CO}_{2}\right)\right\}^{2}+\left\{(\mathrm{b} / 2) s_{H(T)}\left(\mathrm{H}_{2} \mathrm{O}, 1\right)\right\}^{2} \\
& +\left\{(\mathrm{a}+\mathrm{b} / 4) s_{H(T)}\left(\mathrm{O}_{2}\right)\right\}^{2}+\left\{\mathrm{s}_{H(T)}\left(\mathrm{C}_{\mathrm{a}} \mathrm{H}_{\mathrm{b}}\right)\right\}^{2},
\end{aligned}
$$

in which $s_{C}(T)$ is the estimated uncertainty in enthalpy of combustion at $T,{ }_{C}(298.15 \mathrm{~K})$ is the estimated uncertainty in enthalpy of combustion at $T=298.15 \mathrm{~K}$ (Table $\mathrm{A} 7 \mathrm{~g}$ ) and $\mathrm{s}_{H(T)}$ is the estimated uncertainty in the quantity $\left(H_{T}^{\circ}-H_{298.15}^{\circ} \mathrm{K}\right.$ ) for the subtance identified parenthetically beside it.

\section{Conversion of enthalpy from molar to mass basis}

In calculating $\Delta_{\mathrm{C}} H_{\mathrm{W}}^{\circ}$ we use the relationship:

$$
\Delta_{\mathrm{c}} H_{\mathrm{w}}^{\circ}=\Delta_{\mathrm{c}} H_{\mathrm{m}}^{\circ} / M
$$

where $M$ is the molar mass. From equation (A10.2) we have:

$$
\begin{gathered}
s_{\mathrm{cW}}^{2}=\left\{\partial\left(\Delta_{\mathrm{c}} H_{\mathrm{w}}^{\circ}\right) / \partial\left(\Delta_{\mathrm{c}} H_{\mathrm{m}}^{\circ}\right)\right\}^{2}\left(\mathrm{~s}_{\mathrm{cm}}\right)^{2}+\left\{\partial\left(\Delta_{\mathrm{c}} H_{\mathrm{W}}^{\circ}\right) / \partial M\right\}^{2}\left(s_{\mathrm{m}}\right)^{2} \\
\partial\left(\Delta_{\mathrm{c}} H_{\mathrm{W}}^{\circ}\right) / \partial\left(\Delta_{\mathrm{c}} H_{\mathrm{m}}^{\circ}\right)=1 / M \\
\partial\left(\Delta_{\mathrm{c}} H_{\mathrm{w}}^{\circ}\right) / \partial M=-\Delta_{\mathrm{c}} H_{\mathrm{m}}^{\circ} / M^{2}
\end{gathered}
$$

${ }^{5} \mathrm{~cm}$ for this purpose is ${ }_{{ }_{C}}$ from Table $\mathrm{A7g} ; \mathrm{s}_{M}$ is found in the discussion on atomic weights in Section 13 and Appendix $5 \mathrm{a}$.

$$
s_{\mathrm{CW}}^{2}=(1 / M)^{2}\left(\mathrm{~s}_{\mathrm{cm}}\right)^{2}+\left\{\left(\Delta_{\mathrm{C}}{ }_{\mathrm{m}}\right) / M^{2}\right\}^{2}\left(\mathrm{~s}_{M}\right)^{2}
$$

In equations ( $\mathrm{A} 10.20$ and $\mathrm{A} 10.20 \mathrm{a}), \mathrm{S}_{\mathrm{CW}}$ and $\mathrm{s}_{\mathrm{Cm}}$ are the estimated uncertainties of $\Delta_{\mathrm{C}} H_{\mathrm{W}}^{\circ}$ and $\Delta_{\mathrm{C}} H_{\mathrm{m}}^{\circ}$ respectively. $s_{M}$ is the estimated uncertainty in the 
molar mass. We can obtain the estimated relative uncertainty $\left(\mathrm{s}_{\mathrm{CW}} / \Delta_{\mathrm{C}} H_{\mathrm{W}}^{\circ}\right)$ by dividing equation (A10.20) by $\left(\Delta_{\mathrm{C}} H_{\mathrm{W}}^{\circ}\right)^{2}=\left(\Delta_{\mathrm{c}} H_{\mathrm{m}}^{\circ} / M\right)^{2}$. We thus obtain:

$$
\left(\mathrm{s}_{\mathrm{cw}} / \Delta_{\mathrm{c}} H_{\mathrm{w}}^{\circ}\right)^{2}=\left(\mathrm{s}_{\mathrm{cm}} / \Delta_{\mathrm{c}} H_{\mathrm{m}}^{\circ}\right)^{2}+\left(\mathrm{s}_{M} / M\right)^{2}
$$

Conversion of enthalpies from molar to volumetric basis

(a) Uncertainty in ideal gas molar volume

In calculating $V_{\mathrm{m}}^{i d}$ we use the relationship:

$$
V_{\mathrm{m}}^{\mathrm{id}}=R T / p
$$

In a manner similar to that used in earlier examples, we obtain:

$$
\left\{\mathrm{s}_{V(T, p)}^{\mathrm{id} \cdot}{ }^{/ V_{T}, p^{\mathrm{d}^{2}}}\right\}^{2}=\left(\mathrm{s}_{R} / R\right)^{2}+\left(\mathrm{s}_{T} / T\right)^{2}+\left(\mathrm{s}_{p} / p\right)^{2}
$$

(b) Conversion of enthalpy

In calculating $\Delta_{\mathrm{c}} H_{\mathrm{v}}^{\circ}$ from $\Delta_{\mathrm{c}} H_{\mathrm{m}}^{\circ}$ we use the relationships:

$$
\begin{gathered}
\Delta_{c} H_{v}^{o}=\Delta_{c} H_{m}^{\circ} / V_{m}^{i d} \\
\left(s_{c v}^{i d} / \Delta_{c} H_{v}^{o}\right)^{2}=\left(s_{c m}^{i d} / \Delta_{c} H_{m}^{\circ}\right)^{2}+\left(s_{V(T, p)}^{i d} / V_{m}^{i d}\right)^{2}
\end{gathered}
$$

\section{(c) Uncertainty in the ideal gas volume of water saturated gas}

For the dry gas, the partial pressure of the fuel gas $p$ for equation (A10.21) is equal to the defined reference pressure $p^{\circ}$. However for the water saturated gas, $V_{m}$ requires that $p($ fuel $)=p^{\circ}-p\left(\mathrm{H}_{2} \mathrm{O}\right)$ at that temperature. The uncertainty $s(p, f$ fuel $)$ in the partial pressure of fuel is obtained from:

$$
\{s(p, \text { fue } 1)\}^{2}=\left\{s\left(p^{\circ}\right)\right\}^{2}+\left\{s\left(p, H_{2} 0\right)\right\}^{2}
$$

Because $p^{\circ}$ is a defined constant $s\left(p^{\circ}\right)=0$ and:

$$
\{s(p, \text { fuel })\}^{2}=\left\{s\left(p, H_{2} 0\right)\right\}^{2}
$$

for the water saturated gas.

Uncertainties of Virial Coefficients

The estimated uncertainties $s(B)$ in the virial coefficients $B$ are given in Table $8 a$ for pure substances and in Table $8 b$ for binary interactions between substances. The uncertainty of the virial coefficient of a mixture is dependent on the composition of the mixture as is discussed below. 
We start with the general function:

$$
B(\operatorname{mix})=B\left(B_{i j}, x_{i}\right)
$$

in which $B(\operatorname{mix})$ is the virial coefficient of the mixture having $n$ individual components $i$ or $j, x_{i}$ is the mole fraction of component $i$ and $B_{i j}$ is the virial coefficient corresponding to binary interactions between molectiles of $i$ and of $j$. If $j=i$ the virial coefficient is that of pure substance i.

If $B$ (mix) has the functional form given in equation (A10.28) it can be shown by simple algebraic manipulation based on equation (A10.2) that the un:certainty $\mathrm{s}(B, \mathrm{mix})$ can be separated into two independent sets of contributing terms, equation (A10.29) below, one of which depends on the uncertainties $s\left(B_{i j}\right)$ in the virial coefficients and the other depends on the uncertainties $s\left(x_{j}\right)$ in the composition.

$$
\begin{aligned}
B(\text { mix }) & =B_{11} x_{1}^{2}+B_{22} x_{2}^{2}+B_{33} x_{3}^{2}+B_{44} x_{4}^{2}+\ldots \\
& +2 B_{12} x_{1} x_{2}+2 B_{13} x_{1} x_{3}+2 B_{14} x_{1} x_{4}+\ldots \\
& +2 B_{23} x_{2} x_{3}+2 B_{24} x_{2} x_{4}+\ldots \\
& +2 B_{34} x_{3} x_{4}+\ldots \\
\{s(B, \text { mix })\}^{2}=\sum_{i j}\{\partial B(\text { mix }) / \partial B & \left.B_{i j}\right\}^{2}\left\{s\left(B_{i j}\right)\right\}^{2}+\sum_{i}\left\{\partial B(\text { mix }) / \partial x_{i}\right\}^{2}\left\{s\left(x_{i}\right)\right\}^{2}
\end{aligned}
$$

Because the $x_{i}$ are variables that are particular to a gas mixture and are measured parameters, except for illustrative purposes of defined gas mixtures, the assignment of $s\left(x_{i}\right)$ is dependent on the measurement process used, and is beyond the scope of this chapter. However the relationship of $s(B, m i x)$ to $s\left(x_{i}\right)$ can be shown.

The coefficients in the first set of terms on the right hand side of equation (A10.29) all have the form:

$$
\left(\partial B(\operatorname{mix}) / \partial B_{i j}\right)=x_{i} x_{j}
$$

The coefficients in the second set of terms in equation (A10.29) are more 
complex because the $x_{j}{ }^{\prime} s$ are not all independent but must sum to unity:

$$
\Sigma x_{i}=1
$$

If this condition is ignored the coefficient of each $\left(s\left(x_{j}\right)\right)^{2}{ }_{i}$ is:

$$
\left(\partial B(\operatorname{mix}) / \partial x_{i}\right)^{2}=\left(2 \Sigma_{j} B_{i j} x_{j}\right)^{2} \quad j=1,2, \ldots n
$$

When the condition A10.31 is introduced in equation A10.28 in the form:

$$
x_{1}=1-x_{2}-x_{3}-x_{4}-\ldots
$$

the coefficients of the $\left(s\left(x_{j}\right)\right)^{2}$ are replaced by terms of the form shown in equations (A10.34) below.

$$
\begin{aligned}
& s\left(x_{j}\right) \quad \text { coefficient: }\left(\partial B(\operatorname{mix}) / \partial x_{j}\right)^{2} \\
& s\left(x_{1}\right) \\
& s\left(x_{2}\right) \\
& {\left[2\left(B_{12}-B_{11}\right)+2\left(B_{22}{ }^{-2 B_{12}}+B_{11}\right) x_{2}+2\left(B_{11}{ }^{-B_{12}}{ }^{-B_{13}}+B_{23}\right) x_{3}\right.} \\
& +2\left(B_{11}-B_{12}-B_{14}+B_{24}\right) x_{4} \\
& \left.+2\left(B_{11}-B_{12}-B_{15}+B_{25}\right) x_{5} \cdots\right]^{2} \\
& \mathrm{~s}\left(\mathrm{x}_{3}\right) \quad\left[2\left(B_{13}{ }^{-B_{11}}\right)+2\left(B_{11}{ }^{-B_{12}}{ }^{-B_{13}}+B_{23}\right) x_{2}\right. \\
& +2\left(B_{11}-2 B_{13}+B_{33}\right) x_{3}+2\left(B_{11}-B_{13}-B_{14}+B_{34}\right) x_{4} \\
& \left.+2\left(B_{11}-B_{13}-B_{15}+B_{35}\right) x_{5}+\ldots\right]^{2} \\
& \mathrm{~s}\left(\mathrm{x}_{4}\right) \quad\left[2\left(B_{14}{ }^{-B_{11}}\right)+2\left(B_{11}{ }^{-B_{12}}{ }^{-B_{14}}+B_{24}\right) x_{2}\right. \\
& +2\left(B_{11}{ }^{-B_{13}}{ }^{-B_{14}}+B_{34}\right) x_{3}+2\left(B_{11}-2 B_{14}+B_{44}\right) x_{4} \\
& \left.+2\left(B_{11}-B_{14}{ }^{-B_{15}}+B_{45}\right) x_{5}+\ldots\right]^{2}
\end{aligned}
$$

$s\left(x_{5}\right)$

The final result, for the real gas mixture in which the errors in composition are constrained by the fact that $\Sigma x_{i}=1$, is given by equation (A10.35). 


$$
\begin{aligned}
& \{s(B, \mathrm{mix})\}^{2}=\left(x_{1}^{2}\right)^{2}\left\{s\left(B_{11}\right)\right\}^{2}+\left(2 x_{1} x_{2}\right)^{2}\left\{s\left(B_{12}\right)\right\}^{2} \\
& +\left(2 x_{1} x_{3}\right)^{2}\left\{s\left(B_{13}\right)\right\}^{2}+\left(2 x_{1} x_{4}\right)^{2}\left\{s\left(B_{14}\right)\right\}^{2}+\ldots \\
& +\left(x_{2}^{2}\right)^{2}\left\{s\left(B_{22}\right)\right\}^{2}+\left(2 x_{2} x_{3}\right)^{2}\left\{s\left(B_{23}\right)\right\}^{2}+\ldots \\
& +\left(x_{3}^{2}\right)^{2}\left\{s\left(B_{33}\right)\right\}^{2}+\left(2 x_{3} x_{4}\right)^{2}\left\{s\left(B_{34}\right)\right\}^{2}+\ldots \\
& +\left(x_{4}^{2}\right)^{2}\left\{s\left(B_{44}\right)\right\}^{2}+\ldots \\
& +\ldots \\
& +\left\{2\left(B_{12}-B_{11}\right)+2\left(B_{22}-2 B_{12}+B_{11}\right) x_{2}+2\left(B_{11}-B_{12}-B_{13}+B_{23}\right) x_{3}\right. \\
& \left.+2\left(B_{11}-B_{12}-B_{14}-B_{22}\right) x_{4}+\ldots\right]^{2}\left\{s\left(x_{2}\right)\right\}^{2} \\
& +\left\{2\left(B_{13}-B_{11}\right)+2\left(B_{11}-B_{12}-B_{13}+B_{23}\right) x_{2}+2\left(B_{11}-2 B_{13}+B_{33}\right) x_{3}\right. \\
& \left.+2\left(B_{11}-B_{13}-B_{14}+B_{34}\right) x_{4}+\ldots\right]^{2}\left\{s\left(x_{3}\right)\right\}^{2} \\
& +\left\{2\left(B_{14}{ }^{-B_{11}}\right)+2\left(B_{11}{ }^{-B_{12}}{ }^{-B_{14}}+B_{24}\right) x_{2}+2\left(B_{11}{ }^{-B_{13}}{ }^{-B_{14}}+B_{34}\right) x_{3}\right. \\
& \left.+2\left(B_{11}-2 B_{14}+B_{44}\right) x_{4}+\ldots\right]^{2}\left\{s\left(x_{4}\right)\right\}^{2}
\end{aligned}
$$

In practice, drastic simplification of the general result is required (by the lack of data) and is warranted (by the small size of many terms). Usualiy, for the coefficients of $s\left(B_{i j}\right)$ oniy terms involvirig $x_{1}$ will be large enough to matter. The situation is less clear for the coefficients of $s\left(x_{j}\right)$ unless that quantity itself is very small, because (1), only mole fractions of the impurities appear, and, (2), some $B_{i j}$ are likely to be unknown. In some cases the entire set of terms in $s\left(x_{j}\right)$ will be small, but each case must be tested.

Uncertainties in $\mathrm{d} B / \mathrm{d} T$

$B(T)$ is fitted by equation of type (A10.36) for which constants and their uncertainties are listed in Tables A9a and A9b.

$$
\begin{gathered}
B(T)=c+d T+e T^{2} \\
\mathrm{~d} B / \mathrm{d} T=d+2 e T
\end{gathered}
$$


Using equation ( $A 10.2)$ we calculated $\mathrm{s}(\mathrm{d} B / \mathrm{d} T)$ as follows:

$$
\begin{aligned}
\{\mathrm{s}(\mathrm{d} B / \mathrm{d} T)\}^{2} & =\{\partial[\mathrm{d} B / \mathrm{d} T) \partial b]^{2}\{\mathrm{~s}(b)\}^{2}+\{\partial(\mathrm{d} B / \mathrm{d} T) / \partial\}^{2}\{\mathrm{~s}(c)\}^{2} \\
& +\{\partial(\mathrm{d} B / \mathrm{d} T) / \partial T\}^{2}\{\mathrm{~s}(T)\}^{2} .
\end{aligned}
$$

Because $T$ is the independent variable, $s(T)$ will be taken as zero. We obtain:

$$
\{\mathrm{s}(\mathrm{d} B / \mathrm{d} T)\}^{2}=\{2 T \mathrm{~s}(\mathrm{C})\}^{2}
$$


4. TITLE AND SUBTITLE

Heating Values of Natural Gas and its Components

Conversion of values to measuremerit bases and calculation of mixtures

5. $A \cup T H O R(S)$

George T. Armstrong and Thomas L. Jobe, Jr.

6. PERFORMING ORGANIZATION (If joint or other thon NBS, see instructions)

NATIONAL BUREAU OF STANDARDS

DEPARTMENT OF COMMERCE

WASHINGTON, D.C. 20234

9. SPONSORING ORGANIZATION NAME AND COMPLETE ADDRESS (Street, City, State, ZIP)

7. Contracu Grant No.

Groupe Internationale des Importateurs de Gaz Natural Liquefie (GIIGNL)

10. SUPPLEMENTARY NOTES

Document describes a computer program; SF-185, FIFS Software Summary, is attached.

11. ABSTRACT (A 200-word or less foctual summary of most significant information. If rocument inciudes a significant bibliogrophy or literoture survey. mention it heire)

The standard enthalpies of combustion of the pure hydrocarbons $C$, to $C_{6}$ at $298.15 \mathrm{~K}$ and $101325 \mathrm{~Pa}$ selected from the literature, with reference t8 a more detailed document, are used to derive heating values for the ideal gas and the real gas on molar, mass, and volumetric bases at five reference conditions involving other temperatures and pressures. Values can be obtained at both dry and water saturated conditions. The second virial coefficients and their first derivatives are used to calculate the effects of non-ideality. Procedures are given and illustrated for calculating the heating vaiues of mixtures from the composition and the data given for the pure compounds. The relationships between the quantities presented in the tables are illustrated by charts. A procedure is given for estimating the uncertainties of the calculated results.

12. KEY WORDS (Six to iwelve entries; olphobeticol order: copitolize only proper nomes; ono seporote key worcs ey semicolons) Heating value; calorific value; enthaipy of combustion; hydrocarbon gases; gaseous fuel mixtures; real gas; ideal gas; estimation from composition; reference measurement conditions

13. AVAILABILITY

X Unlimited

For Official Distribution. Do Not Release to NTIS

Order From Superintendent of Documents, U.S. Government Printing Office, Washington, D.C. 20402.

Order From National Technical Information Service (NTIS), Springfield, VA. 22161

14. NO. OF

PRINTED PAGES

164

15. Price 


